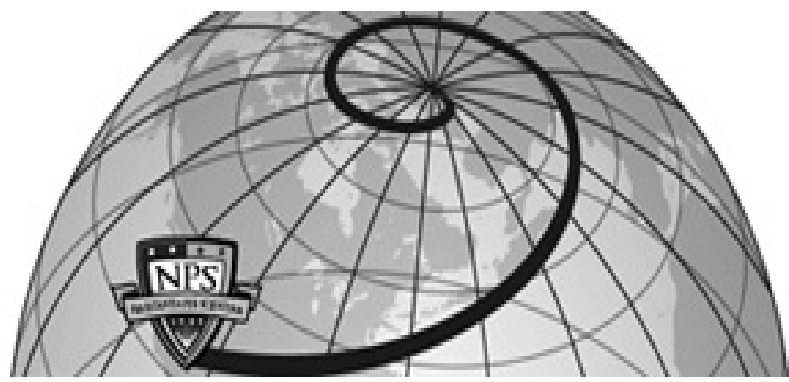

Calhoun: The NPS Institutional Archive DSpace Repository

Mission and Installation Contracting Command

Services Acquisition: Empirical Analysis of Army Service Contract Management Practices

Ramos, Michelle; Nabors, Joshua

Monterey, California. Naval Postgraduate School

https://hdl.handle.net/10945/33764

This publication is a work of the U.S. Government as defined in Title 17, United States Code, Section 101. Copyright protection is not available for this work in the United States.

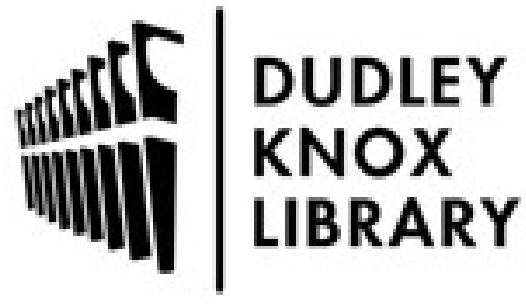

http://www.nps.edu/library
Calhoun is the Naval Postgraduate School's public access digital repository for research materials and institutional publications created by the NPS community. Calhoun is named for Professor of Mathematics Guy K. Calhoun, NPS's first appointed -- and published -- scholarly author.

Dudley Knox Library / Naval Postgraduate School 411 Dyer Road / 1 University Circle Monterey, California USA 93943 
NPS-CM-11-167

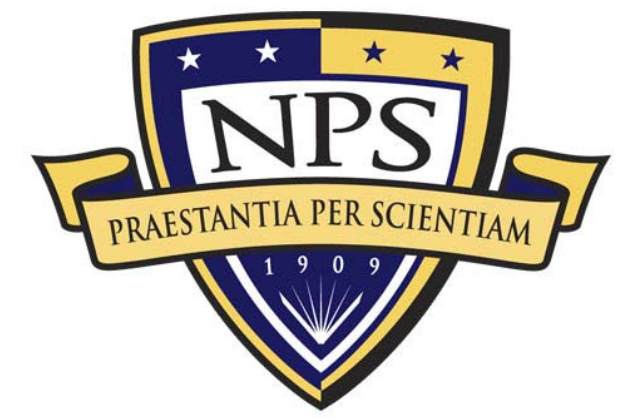

\section{ACQUISITION RESEARCH \\ SPONSORED REPORT SERIES}

\section{Mission and Installation Contracting Command Services Acquisition: Empirical Analysis of Army Service Contract Management Practices}

10 November 2011

by

MAJ Michelle Ramos, USA, and Capt Joshua Nabors, USAF

Advisors: Dr. Rene G. Rendon, Associate Professor, and Dr. Uday M. Apte, Professor

Graduate School of Business \& Public Policy

Naval Postgraduate School

Approved for public release, distribution is unlimited.

Prepared for: Naval Postgraduate School, Monterey, California 93943 
The research presented in this report was supported by the Acquisition Chair of the Graduate School of Business \& Public Policy at the Naval Postgraduate School.

\section{To request Defense Acquisition Research or to become a research sponsor, please contact:}

NPS Acquisition Research Program

Attn: James B. Greene, RADM, USN, (Ret.)

Acquisition Chair

Graduate School of Business and Public Policy

Naval Postgraduate School

555 Dyer Road, Room 332

Monterey, CA 93943-5103

Tel: (831) 656-2092

Fax: (831) 656-2253

E-mail: jbgreene@nps.edu

Copies of the Acquisition Sponsored Research Reports may be printed from our website www.acquisitionresearch.net 


\title{
MISSION AND INSTALLATION CONTRACTING COMMAND SERVICES ACQUISTION: EMPIRICAL ANALYSIS OF ARMY SERVICE CONTRACT MANAGEMENT PRACTICES
}

\begin{abstract}
The overall purpose of this research is to develop a comprehensive understanding of how the Army Mission and Installation Contracting Command (MICC) manages the acquisition of services. The specific objective of the project is to build on the understanding developed in prior research projects and to identify the factors that promote or obstruct the use of best practices in acquisition management and influence the efficiency and effectiveness of service contracts performance. In this study, data was collected from eight Army installation contracting offices. The study is meant to serve as a follow-on project for research conducted at additional Mission and Installation Contracting Command offices. In prior research projects, researchers showed a relationship between service type and contract characteristics and management practices as well as a relationship between capacity and management practices. The current study confirms the findings of previous researchers and provides recommendations for improving performance of service contracts through enhanced capabilities and acquisition processes.
\end{abstract}


THIS PAGE INTENTIONALLY LEFT BLANK

ACQUISITION RESEARCH PROGRAM

GRADUATE SCHOOL OF BUSINESS \& PUBLIC POLICY

- ii NAVAL POSTGRADUATE SCHOOL 


\section{TABLE OF CONTENTS}

I. INTRODUCTION.

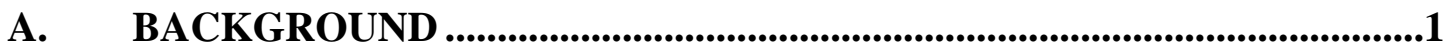

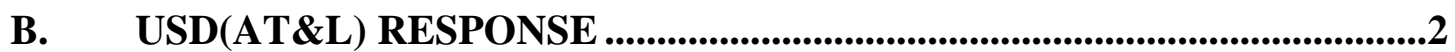

C. PURPOSE OF RESEARCH ..............................................................................4

D. RESEARCH QUESTIONS ...................................................................6

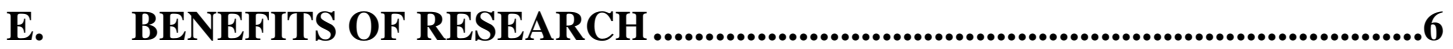

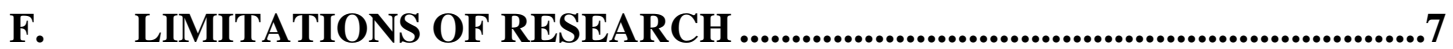

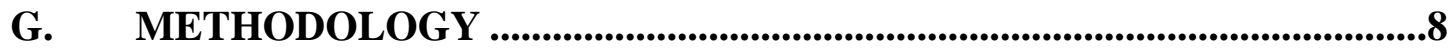

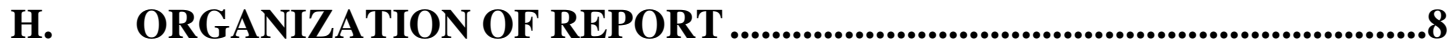

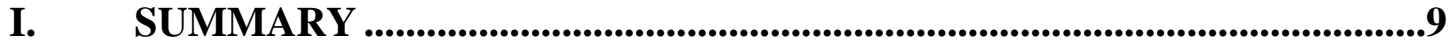

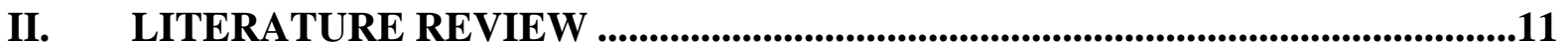

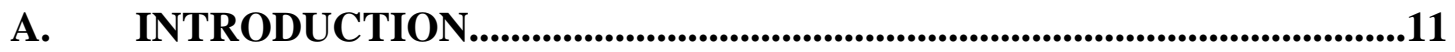

B. PUBLIC MANAGEMENT REFORM .......................................................11

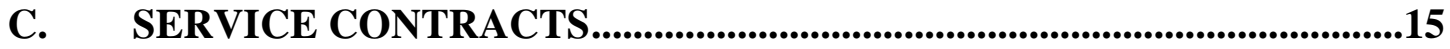

D. SERVICE CONTRACT MANAGEMENT ...................................................20

E. PREVIOUSLY COMPLETED RESEARCH .............................................23

F. SUMMARY ............................................................................................23

III. MISSION AND INSTALLATION CONTRACTING COMMAND ..................25

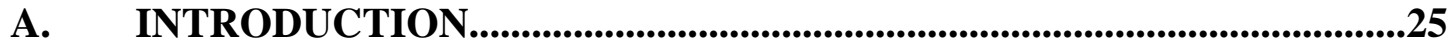

B. ARMY CONTRACTING CONCERNS ...................................................25

C. ARMY CONTRACTING COMMAND MISSION AND ORGANIZATION .......................................................................................27

D. MICC MISSION, VISION, GOALS, AND SCOPE OF SERVICES .......28

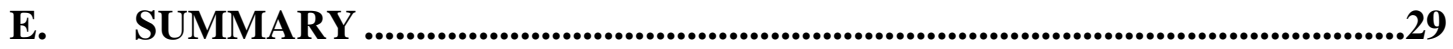

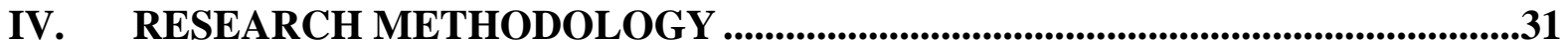

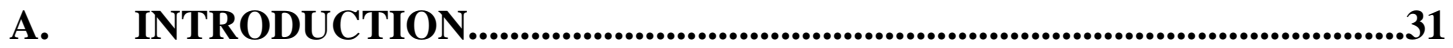

B. METHODS USED IN SELECTION AND DATA COLLECTION ..........31

C. DATA COLLECTION QUESTIONS..........................................................32

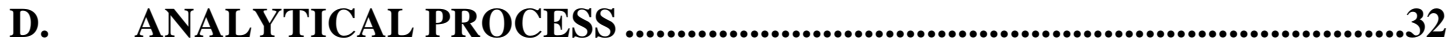

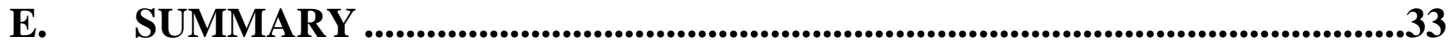

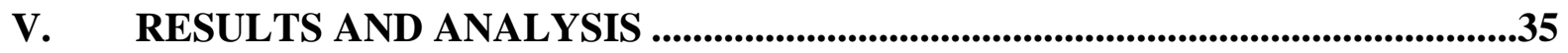

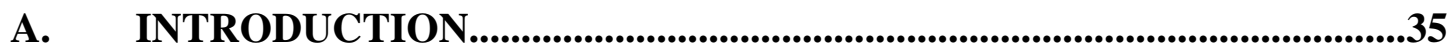

B. SERVICE TYPE AND CONTRACT CHARACTERISTICS...................36

1. Level of Competition Used ..........................................................39

2. Contract Type and Incentive or Award Fees .................................41

3. Contract Value ........................................................................................43

4. Number of Modifications ....................................................................44

5. Award Basis or Contractor Selection Process.................................45

C. SERVICE TYPE AND MANAGEMENT PRACTICES ..........................47 
1. Use of Independent Government Estimates by Service Type and Use of Independent Government Estimates for Contracts Over $\$ 100,000$. 49

2. The Number of Personnel Assigned to a Contract and the Number of Personnel Generating or Changing Requirements.

3. The Number of Personnel Assigned to Contract Management Oversight..........................................................................................................52

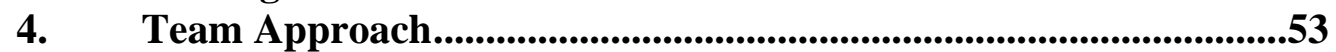

5. Acquisition Lead ......................................................................53

6. Contract Award Time.......................................................................54

7. Documentation .....................................................................................55

D. CAPACITY AND MANAGEMENT PRACTICES ......................................56

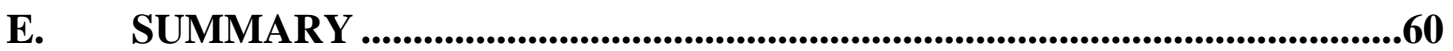

VI. SUMMARY, CONCLUSION, AND AREAS FOR FURTHER RESEARCH.....61

A. SUMMARY .....................................................................................61

B. CONCLUSION .........................................................................................62

1. Research Findings....................................................................................62

2. Recommendations .................................................................................66

C. AREAS FOR FURTHER RESEARCH...................................................65

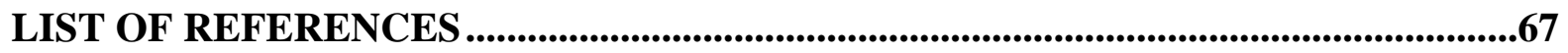

APPENDIX A. SAMPLE DATA COLLECTION FORMS .................................................71

APPENDIX B. CHI-SQUARED CALCULATIONS................................................................77 


\section{LIST OF FIGURES}

Figure 1. DoD Contract Spending on Services by Component, 1990-2010...................3

Figure 2. $\quad$ Army Contract Spending by Category, 1990-2010.....................................4

Figure 3. Conceptual Model: Drivers of Acquisition Practices and Performance ...........6

Figure 4. Department of Defense Top Line ...................................................... 12

Figure 5. Department of Defense Acquisition Trends .............................................13

Figure 6. Top-Line DoD Contract Spending, 1990-2010 ...........................................14

Figure 7. DoD Contract Spending for Services, 1990-2010 ......................................16

Figure 8. DoD Total Contract Spending for Fiscal Year 2010 ...................................17

Figure 9. Army Contract Spending by Category, 1990-2010...................................18

Figure 10. Key ASA(ALT) Strategic Objectives (Ends) ..........................................22

Figure 11. The Army Materiel Command Contracting Statistics for 1995-2006 ............26

Figure 12. Recommended Army Contracting Organizations and Responsibilities...........27

Figure 13. U.S. Army Contracting Command Organizational Chart..............................28

Figure 14. Assessment of Relationship Between Service Type and Contract

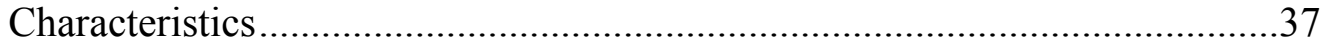

Figure 15. Analysis of Level of Competition Used by Service Types...........................40

Figure 16. Justification for Sole-Source Solicitation .................................................41

Figure 17. Average Annual Base Value of Contracts by Service Type ..........................43

Figure 18. Percentage of Modifications for Contracts by Service Type ..........................44

Figure 19. Composition of Award Basis by Service Type ...........................................46

Figure 20. Evidence of Price Fair and Reasonableness of All Sole-Source Contracts ....47

Figure 21. Assessment of Relationship Between Service Type and Management Practices ...........................................................................................48

Figure 22. Percentage of IGEs Provided by Service Type.........................................50

Figure 23. IGEs Provided for Contracts Over or Under \$100,000.................................51

Figure 24. Contracts Meeting PALT by Service Type.................................................55

Figure 25. Percentage of Contract File Documentation Found in Contract Files ............56

Figure 26. Diagram of Findings From Data Analysis ...............................................62 
THIS PAGE INTENTIONALLY LEFT BLANK 


\section{LIST OF TABLES}

Table 1. Breakdown of Service Contracts in the Army for FY 2009 ........................19

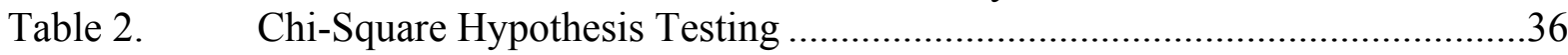

Table 3. Chi-Square Hypothesis Testing Results Between Service Type and Contract

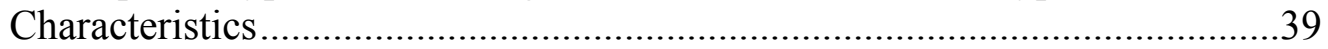

Table 4. Chi-Square Hypothesis Testing Results Between Service Type and Management Practices ..............................................................................49

Table 5. FY 2010 Service Contracts Awarded ...........................................................58

Table 6. Office Capacity of MICC Offices Observed …..........................................59 
THIS PAGE INTENTIONALLY LEFT BLANK 


\section{LIST OF ACRONYMS}

ACC

$\mathrm{ACOM}$

AMC

AR

ARFORGEN

ARP

ASA(ALT)

AT\&L

CI

CONUS

COR

CSIS

DAW

DAWIA

DOC

DoD

DoDIG

DRU

DSB

ECC

FAR

FASA

FFP

FPDS

FY

GAO

IDIQ

IGE

$\mathrm{JCC}-\mathrm{I} / \mathrm{A}$
Army Contracting Command

Army Commands

Army Materiel Command

Army Regulation

Army Force Generation

Acquisition Research Program

Assistant Secretary of the Army (Acquisition, Logistics, and Technology)

Acquisition, Technology, and Logistics

Confidence Interval

Continental United States

Contracting Officer Representatives

Center for Strategic and International Studies

Defense Acquisition Workforce

Defense Acquisition Workforce Improvement Act

Directorate of Contracting

Department of Defense

Department of Defense Inspector General

Direct Reporting Units

Defense Science Board

Expeditionary Contracting Command

Federal Acquisition Regulation

Federal Acquisition Streamlining Act

Firm-Fixed-Price

Federal Procurement Data System

Fiscal Year

General Accounting Office (before July 7, 2004);

Government Accountability Office (after July 7, 2004)

Indefinite Delivery Indefinite Quantity

Independent Government Estimate

Joint Contracting Command-Iraq/Afghanistan 


$\begin{array}{ll}\text { LPTA } & \text { Lowest Priced Technically Acceptable } \\ \text { MICC } & \text { Mission and Installation Contracting Command } \\ \text { NISH } & \text { National Industries for the Severely Handicapped } \\ \text { NPS } & \text { Naval Postgraduate School } \\ \text { OCONUS } & \text { Outside the Continental United States } \\ \text { OMB } & \text { Office of Management and Budget } \\ \text { PALT } & \text { Procurement Acquisition Lead-Time } \\ \text { PCO } & \text { Procurement Contracting Officer } \\ \text { PNM } & \text { Price Negotiation Memorandum } \\ \text { POTUS } & \text { President of the United States } \\ \text { PSC } & \text { Product Service Code } \\ \text { PWS } & \text { Performance Work Statement } \\ \text { QAE } & \text { Quality Assurance Evaluators } \\ \text { QASP } & \text { Quality Assurance Surveillance Plan } \\ \text { QDR } & \text { Quadrennial Defense Review } \\ \text { SBA } & \text { Small Business Administration } \\ \text { SECDEF } & \text { Secretary of Defense } \\ \text { SOW } & \text { Statement of Work } \\ \text { USARNORTH } & \text { United States Army, North } \\ \text { USD } & \text { Under Secretary of Defense } \\ \text { USD(AT\&L) } & \text { Under Secretary of Defense for Acquisition, Technology, and Logistics }\end{array}$




\section{ABOUT THE AUTHORS}

Major Michelle Ramos, U.S. Army, Student, Graduate School of Business and Public Policy at the Naval Postgraduate School. MAJ Ramos earned a BS in 2001 from the United States Military Academy. MAJ Ramos is an Army Acquisition Officer with previous service in the Signal Corps. MAJ Ramos has served in a wide range of operational and staff assignments, including Platoon leader, Battalion S4 (Logistics) Officer, Battalion S6 (Communications) Officer, and Company Commander. During her most recent tour, she served as a Blue Team Lead and Operations Officer for the Vulnerability Assessment Detachment, $1^{\text {st }}$ Information Operations (IO) Battalion, 1st Information Operations Command (Land). Upon graduation from the MBA program with a concentration in acquisition contract management, MAJ Ramos will report to Army Contracting CommandWarren (ACC-WRN).

Captain Joshua Nabors, U.S. Air Force, Student, Graduate School of Business and Public Policy at the Naval Postgraduate School. Capt Nabors earned a BSBA in 2006 at East Carolina University and is a graduate from the Squadron Officer School in correspondence. Capt Nabors is a Contracting Officer who served at Kadena Air Base, Japan, for three years. He has managed a 10-member flight and handled \$125 million dollars in contracts. Purchases he has managed have varied and include multiple appliance and furniture contracts, a bulk fuel service contract, multiple Army requirements, 47 passenger buses for NAF, a stevedoring contract, vehicles for OSI and DECA, a port fuel hose system used to offload JP8 , and many more. Upon graduation from the MBA program with a concentration in strategic purchasing at the Naval Postgraduate School in December 2011, Capt Nabors will report to Air Force Enterprise Sourcing Group Office at Wright Patterson AFB, OH. 
THIS PAGE INTENTIONALLY LEFT BLANK 


\section{ACKNOWLEDGMENTS}

First, we would like to thank our spouses, MAJ Daniel Ramos and Mandy Nabors, as well as Michelle's son, Daniel, for their tremendous love, support, and encouragement in our writing of this MBA project. We cannot express our appreciation and thanks for their understanding and sacrifice as we dedicated ourselves to this research.

We would also like to thank major contributors at Army Contracting Command and at the Mission Installation Contracting Command who generously provided us with information, insights, and answers to our numerous questions. The support we received from their staff was critical in the timely collection of data for this research. Their professionalism should be commended.

Additionally, we would like to thank the Acquisition Research Program, especially RADM James Greene, USN (Ret.), Ms. Karey Shaffer, and Ms. Tera Yoder, for providing funding and resources to ensure the success of this MBA project.

Finally, we would like to thank our advisors, Dr. Rendon and Dr. Apte, for their support, guidance, and encouragement throughout the duration of this project. 
THIS PAGE INTENTIONALLY LEFT BLANK 


\section{INTRODUCTION}

\section{A. BACKGROUND}

Services acquisitions in the Department of Defense (DoD) have received a lot of attention over the past decade due to the significant increase in scope and dollars. DoD service contracting in 2010 added up to more than $\$ 200$ billion (in constant dollars), which is almost over 50\% of the total DoD acquisition budget (Defense Science Board [DSB], 2011). A 2002 report by the General Accounting Office (GAO) stated that the DoD spent $\$ 53$ billion in services during fiscal year (FY) 2000. Therefore, from 2000 to 2010, there was an increase of over $\$ 147$ billion (current-year dollars) in DoD services acquisitions. Additionally, the Acquisition Advisory Panel stated in its January 2007 report that the DoD's acquisition workforce had declined by nearly $50 \%$ since the $1990 \mathrm{~s}$. Despite efforts to hire personnel, there remains an acute shortage of federal procurement professionals with between five and 15 years of experience (Government Accountability Office [GAO], 2008). An increase in requirements and a decrease in qualified personnel indicates that the DoD may struggle to ensure that contracted services are delivered according to the cost, quality, and quantity specified in the contract (GAO, 2008).

Since 2001 government and non-government agencies have conducted numerous assessments of improvements in the procurement and oversight of services by the DoD. Most assessments have revealed and continue to reveal many areas requiring improvement, calling for the need to reform procurement and oversight of services acquisition. Furthermore, another important motive for reform is the current budget crisis the United States is facing. Since 1960, Congress has acted 78 separate times to permanently raise, temporarily extend, or revise the definition or amount of the debt limit (Department of Treasury, 2011).

The president's 2012 budget recognizes that the United States cannot rebuild its economy and "win the future" if the American people pass on a mountain of debt to their children and grandchildren (Office of Management and Budget [OMB], n.d., para. 1). The President of the United States (POTUS) and Congress are making efforts to restore fiscal responsibility and reform the government to make it more effective, efficient, and open to the 
American people (OMB, n.d.). One action specific to this initiative in the 2010 National Security Strategy, issued by the POTUS, Barack Obama, called for the reform of acquisition and contracting processes, in which the DoD accounts for $70 \%$ of all federal procurement spending (Office of the POTUS, 2010). As a result, Secretary of Defense Robert Gates also addressed the need for reform in the 2010 Quadrennial Defense Review (QDR) Report, calling for a change in how the DoD does business and how it buys (DoD, 2010). In a speech given on January 6, 2011, Gates announced his plan to find at least $\$ 100$ billion in savings that the DoD could keep and shift to higher priority programs through an effort to get better value and results in the contracting arena for defense goods and services (Gates, 2011). His statements echoed the importance of the budgetary guidance and concerns from the White House and Congress. The "Department of Defense Efficiency Initiatives" is aimed at "generating efficiency savings by reducing overhead costs, improving business practices, or culling excess or trouble programs" (Gates, 2011, para. 2). In response to this initiative, USD(AT\&L) Ashton B. Carter has taken action to demand acquisition reform.

\section{B. USD(AT\&L) RESPONSE}

In an effort to answer Secretary Gates' call for reform, USD(AT\&L) Carter issued a memo dated June 28, 2010, mandating that the DoD "DO MORE WITHOUT MORE" (USD[AT\&L], 2010, p. 1). In the memo, USD(AT\&L) Carter established guidance for achieving greater efficiency and productivity in defense spending. His Better Buying Power memorandum revealed 23 actions to improve efficiency in five target areas. The five major areas include the following: (1) target affordability and control cost growth, (2) incentivize productivity and innovation in industry, (3) promote real competition, (4) improve tradecraft in services acquisition, and (5) reduce non-productive processes and bureaucracy (USD[AT\&L], 2010).

In this research, we focus on the fourth target area, improving tradecraft in services acquisition. The goal for improvement in this area centers around the following four tenets: (1) create a senior manager for acquisition of services in each component, (2) adopt uniform taxonomy for different types of services, (3) address causes of poor tradecraft in services acquisition, and (4) increase small business participation in providing services (USD[AT\&L], 2010). USD(AT\&L) Carter's vision is critical to acquire proper, reliable services that meet 
mission needs and strongly encourage fiscal responsibility. Congress and the DoD are emphasizing how critical it is to deliver better value to the taxpayers and to improve the way the DoD conducts business.

The DoD is the largest buyer of services in the federal government (McFall \& La, 2011). The Defense Science Board (DSB) stated that "today, almost every defense task that is not an inherently governmental function is carried out in some part through contracted services" (DSB, 2011, p. vii). In a Center for Strategic and International Studies (CSIS) report, researchers revealed that out of three categories in defense spending, services grew the fastest at $6.1 \%$ per year over the course of 21 years (CSIS, 2011). Specifically, the Army's spending on contracts for services grew at an amazing 13\% per year between 2002 and 2010, as seen in Figure 1.

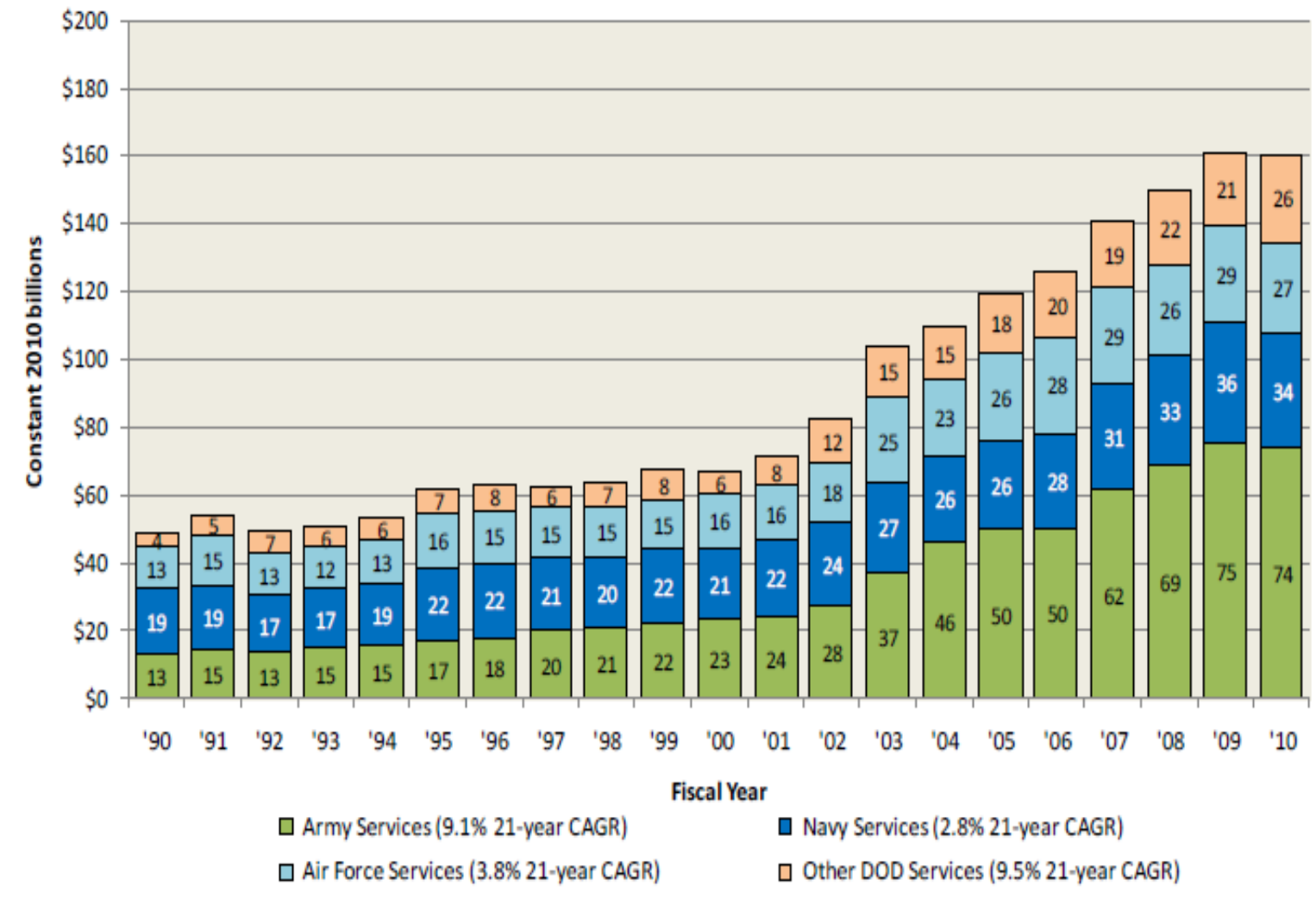

Figure 1. DoD Contract Spending on Services by Component, 1990-2010 (CSIS, 2011, p. 11)

Figure 2 illustrates Army contract spending by category from 1990 to 2010 and reveals that spending on contracts for services increased far more rapidly than spending for products (CSIS, 2011, p. 11). The wars in Iraq and Afghanistan appear to have had a huge 
effect on contract spending for the Army. Service contracting for the Army accounted for $45 \%$ to $53 \%$ of all Army contract spending every year after September 11, 2001.

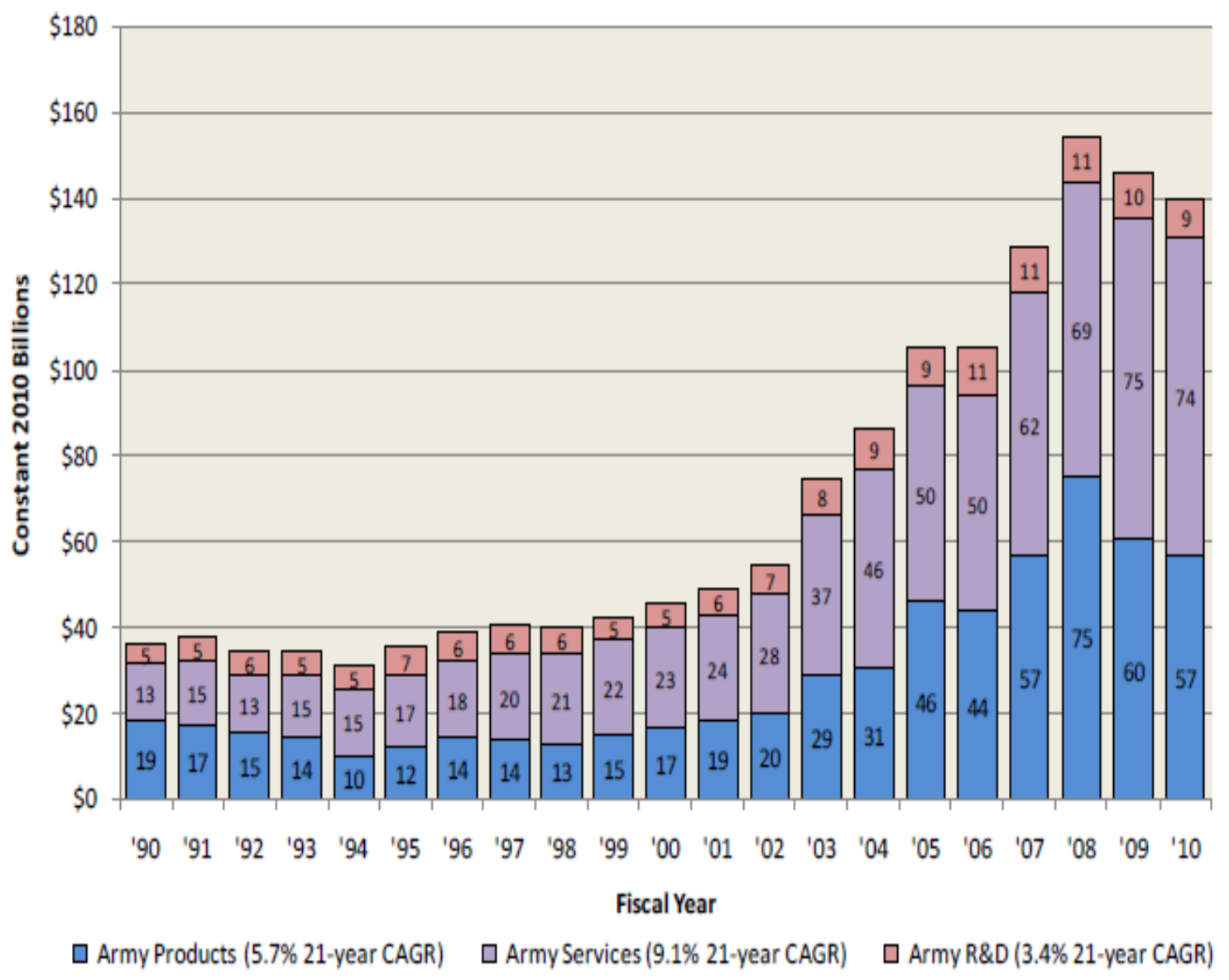

Figure 2. Army Contract Spending by Category, 1990-2010

(CSIS, 2011, p. 20)

Thus far, we have established the importance of improving DoD acquisition and have demonstrated senior leadership support within the DoD for acquisition reform. With this support, it is up to the individual military Services to take action and work together to implement contract efficiencies. This attempt to streamline contracting efficiencies within the DoD leads to the topic of this research report: specifically, an analysis of the management of service contracts in the Army.

\section{PURPOSE OF RESEARCH}

The overall purpose of this research is to develop a comprehensive understanding of how the Army Mission and Installation Contracting Command (MICC) manages the acquisition of services. Thomas McFall and Dennis La (2011) developed and used the data 
collection form (see Appendix A) in a pilot study to collect empirical data regarding the current state of services acquisition management at the installation level within the Army in order to conduct a follow-on analysis of collected data. Our study builds on prior research and specifically expands upon McFall and La's effort by increasing the database and applying the same model developed in their 2011 Master of Business Administration (MBA) report. In this study, we build upon identifying factors that influence the efficiency and effectiveness of service contracts performance. Moreover, our research is an in-depth study of the acquisition of services in the Army and the drivers of acquisition management practices. Our research revolves around four main objectives:

- $\quad$ Build on the understanding developed in prior research projects and develop a data collection instrument that will identify the factors that promote or obstruct the use of best practices in acquisition management.

- $\quad$ Provide recommendations to help improve efficiency and effectiveness in service contracts performance, geared toward savings in the tail end of military operations.

- Assess how the data collection form can be improved to apply this study across all Army MICC centers and Directorates of Contracting (DOCs) in future research.

- $\quad$ Create teaching materials for Naval Postgraduate School (NPS) instructors in acquisition and contracting courses.

Figure 3 illustrates the importance of understanding the drivers of acquisition management practices in order to improve the performance of service contracts. 


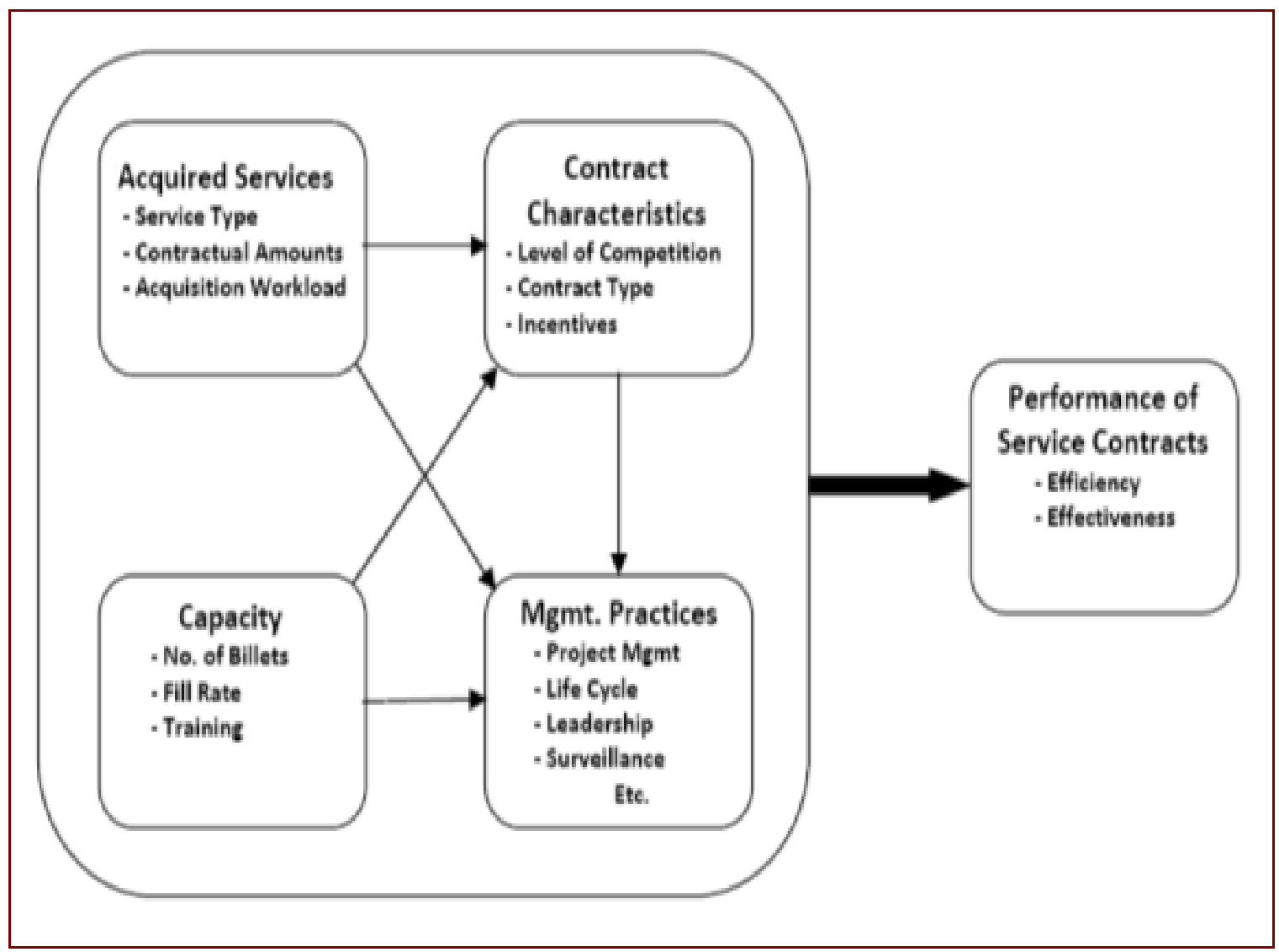

Figure 3. Conceptual Model: Drivers of Acquisition Practices and Performance (Apte, Apte, \& Rendon, 2010b, p. 4)

\section{RESEARCH QUESTIONS}

In an effort to build on prior research, we attempt to answer the same questions used in the McFall and La MBA project. The three major research questions that relate to services acquisition within the Army MICC are as follows:

- Do the contract characteristics differ for different types of services?

- $\quad$ Do the types of services being acquired affect the management practices being used?

- Does the capacity for carrying out acquisition-related work affect the management practices being used?

\section{E. BENEFITS OF RESEARCH}

Our research focus is to understand and analyze the drivers of service contracting practices and performance to help improve the acquisition of services in the Army MICC. 
Additionally, in this research we reveal a more in-depth understanding of contract characteristics for different types of services, and we demonstrate how management practices affect the type of service being acquired, as well as the capacity for carrying out the related work. Also, we build upon and corroborate the results found in previous studies of the acquisition of services. Our overall intent is to increase the efficiency and effectiveness of meeting service requirements through contracting.

\section{F. LIMITATIONS OF RESEARCH}

The broad scope of the acquisition of services is a limitation of this research. The sample size of data that we used in this research is minuscule compared to the number of services the Army MICC acquires in terms of type of services, number of contracting offices, and number of service contracts. For instance, the Army uses the Federal Procurement Data System (FPDS), which describes over 20 different product service codes (PSCs) that categorize the type of services being acquired; our research focuses on only four PSCs. Of the four PSCs we analyzed in this study, two are considered complex and two are considered simple, based on their respective requirements. Throughout our report the term PSC and service type will be used interchangeably.

Additionally, Army MICC contracting activities include six contracting centers and 36 DOCs; however, we used only two contracting centers and four DOCs to collect data for this study. Furthermore, of the six contracting offices we visited, we collected and combined data from 114 service contracts with the data of 40 service contracts from McFall and La's 2011 study, for a total of 154 service contracts for analysis. This is a small sample size considering that the command awards more than 260,000 contracts each year (Army Contracting Command [ACC], 2011b).

Finally, numerous players are involved in the acquisition process, and the contracting officer is just one part of the entire team; in our research, we do not capture all the other players involved in the process. As was the case in previous reports similar to ours, because

of the limited sample size of our study, we may have been unable to identify some drivers of management practices and performance in services acquisition, or we may have captured some that are not important. We discuss the drivers that may not be captured in Chapters IV 
and $\mathrm{V}$ of this report and recommend further studies to supplement the limitations of this research project.

\section{G. METHODOLOGY}

We conducted this research by collecting contract and management practice data from six MICC installations, focusing on collecting objective-based data. In collecting our data for this project, we used the data collection form (see Appendix A) developed in the McFall and La (2011) MBA report. The data collection form is geared toward achieving the objectives and answering the research questions that we presented in Sections $\mathrm{C}$ and $\mathrm{D}$ of this chapter. McFall and La conducted a pilot study that evaluated 40 service contracts at two MICC installations. In our research, we employed the lessons learned from the pilot in order to expand the data collection at six other MICC offices. We analyzed the collected data quantitatively and qualitatively to draw conclusions about management practices at a total of eight MICC centers. That analysis includes data from the two MICC installations McFall and La used in the pilot project and six others that we visited for this report.

\section{H. ORGANIZATION OF REPORT}

This report is made up of six chapters. Chapter I includes background information, the USD(AT\&L) response, the purpose of the research, research questions, the benefits of the research, the limitations of the research, and the research methodology. In Chapter II, a literature review, we examine documentation and research published with regard to the DoD's acquisition management process and reform initiatives. In the literature review, we also cover public management reform, history of service contracts, service contract management, acquisition workforce training, and previously completed research. In Chapter II, we explore prior research papers in order to determine how our study will help further those studies. In Chapter III, we present the mission and organization of the MICC. In Chapter IV, we describe the research methodology in more detail. We outline the procedures for collecting data and explain how it will be analyzed. In Chapter V, we examine the collected data and present the findings of the analysis to help answer our three research

questions. In Chapter VI, we summarize the research, which includes responses to the research questions, recommendations to the Army MICC on acquisition management 
practices, ways to improve the data collection and application of this research to other DoD contracting units, and areas to consider for further research in the field of services acquisition.

\section{SUMMARY}

Our purpose in this chapter was to provide background knowledge of the acquisition of services within the DoD and to highlight the effect of acquisition reform. Furthermore, we provided information on the importance of improving the management and practices used in services acquisition to achieve better value and results in the contracting arena for defense goods and services. Ultimately, we revealed how improving services acquisition can create efficiencies that will help support the United States' financial and national security. In Chapter II, we review prior literature relevant to the acquisition of services within the DoD. 
THIS PAGE INTENTIONALLY LEFT BLANK 


\section{LITERATURE REVIEW}

\section{A. INTRODUCTION}

In order to present a foundation for this research, we examined documentation and research published with respect to the DoD's acquisition management process and reform initiatives, with specific attention given to services acquisition. Our purpose was to continue McFall and La's (2011) efforts and to discuss current and relevant sources that contribute to the basis of this research. In this literature review, we first discuss public management reform and the present efforts to streamline the DoD's acquisition policies and processes. Second, we review the financial impact and the reliance of service contracts in the DoD. Third, we review service contract management, the relevant issues affecting acquisition processes, and the lack of specific training for the procurement of services and its effect on the acquisition workforce. Finally, we introduce a summary of previous NPS Acquisition Research Program (ARP) projects associated with service contracting as the basis for this project.

\section{B. PUBLIC MANAGEMENT REFORM}

The mission and structure of the DoD continually changes in order to meet the intent of the current national security strategy. In order to provide the products and services necessary to accomplish the objectives associated with this strategy, the DoD must also introduce acquisition reform to ensure compliance with corresponding budgets, as well as with current laws and acts passed by Congress.

The DoD contracts out certain functions and relies on contractors to perform services for numerous reasons. In the early 2000s, the DoD realized that it needed to modernize its forces in order to improve its capabilities and maintain a military advantage. With outdated equipment and a reduction in troop strength, the DoD's top budgetary concern was procurement funding for new systems, which included products and associated services to develop and sustain. According to a DoD news release detailing the budget for FY 2000, leadership in the DoD considered "higher modernization spending to be essential to the future readiness and battlefield superiority of U.S. forces" (DoD, 1999, para. 5). At the time, 
the DoD's push for modernization drove budgetary decision-making. Greve (2008) argued that the reason for contracting changes over time, and sometimes innovation is a priority over saving money. Since 2001 the vision for a future combat force has been a priority, and obtaining the necessary funds from Congress has been essential.

Over the past decade, the need for modernization, especially evident as a result of the Iraq and Afghanistan conflicts, has permitted the DoD to become accustomed to receiving ample budgets from Congress, with generous increases each year. The DoD's budget in FY 2011 was more than double the budget in FY 2001. Figure 4 represents the department's top-line trend for the past decade.

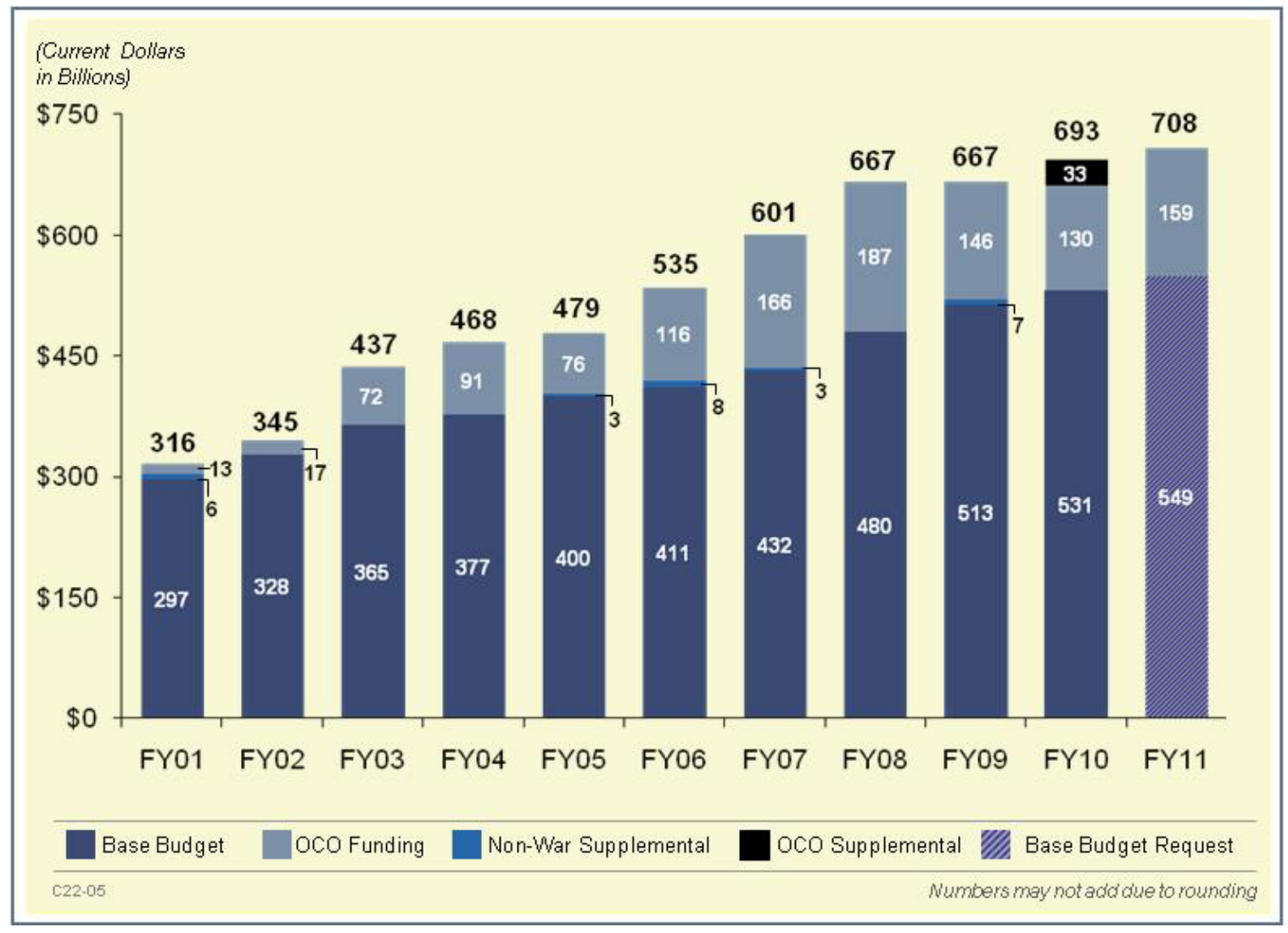

Figure 4. Department of Defense Top Line

(Office of the Under Secretary of Defense, Comptroller [OUSD(C)], 2010)

The introduction of the Federal Acquisition Streamlining Act (FASA) in 1994 encouraged a reduced acquisition workforce based on the expectation of the streamlining process, including foreseeing an increased reliance on credit cards (DoDIG, 2000). The huge cut in the workforce, as a result of the streamlining process, coupled with the continuous growth of the procurement budget, eventually led to an overworked and insufficiently trained 
workforce, which we discuss later in this chapter in Section C, and to the need for major reform. Figure 5 illustrates the decrease in the DoD acquisition workforce compared to the increase in the procurement budget.

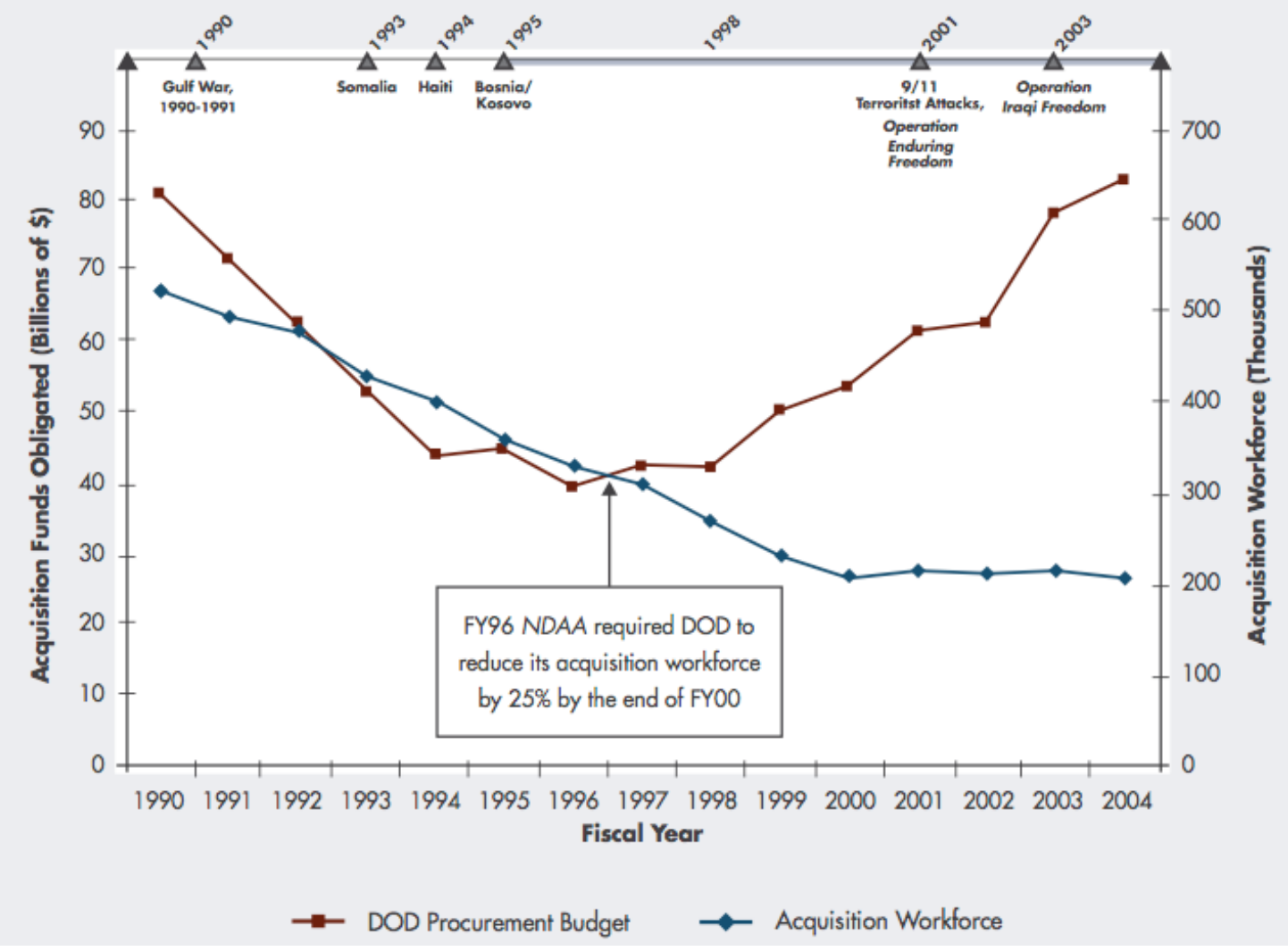

Figure 5. Department of Defense Acquisition Trends

(Spisak, 2011, p. 127)

Starting in the early 2000s, increased budgets provided the DoD with the opportunity to contract out more goods and services, at home and abroad, in order to support the overall mission. As of 2011, contracts awarded by the DoD have nearly doubled since 2001 . Consequently, the amount of dollars the DoD has obligated has outgrown other DoD outlays (CSIS, 2011). As a result, the DoD's reliance on contracted goods and services to conduct daily business increased considerably. The DoD's top-line contract spending for the past two decades is illustrated in Figure 6. 


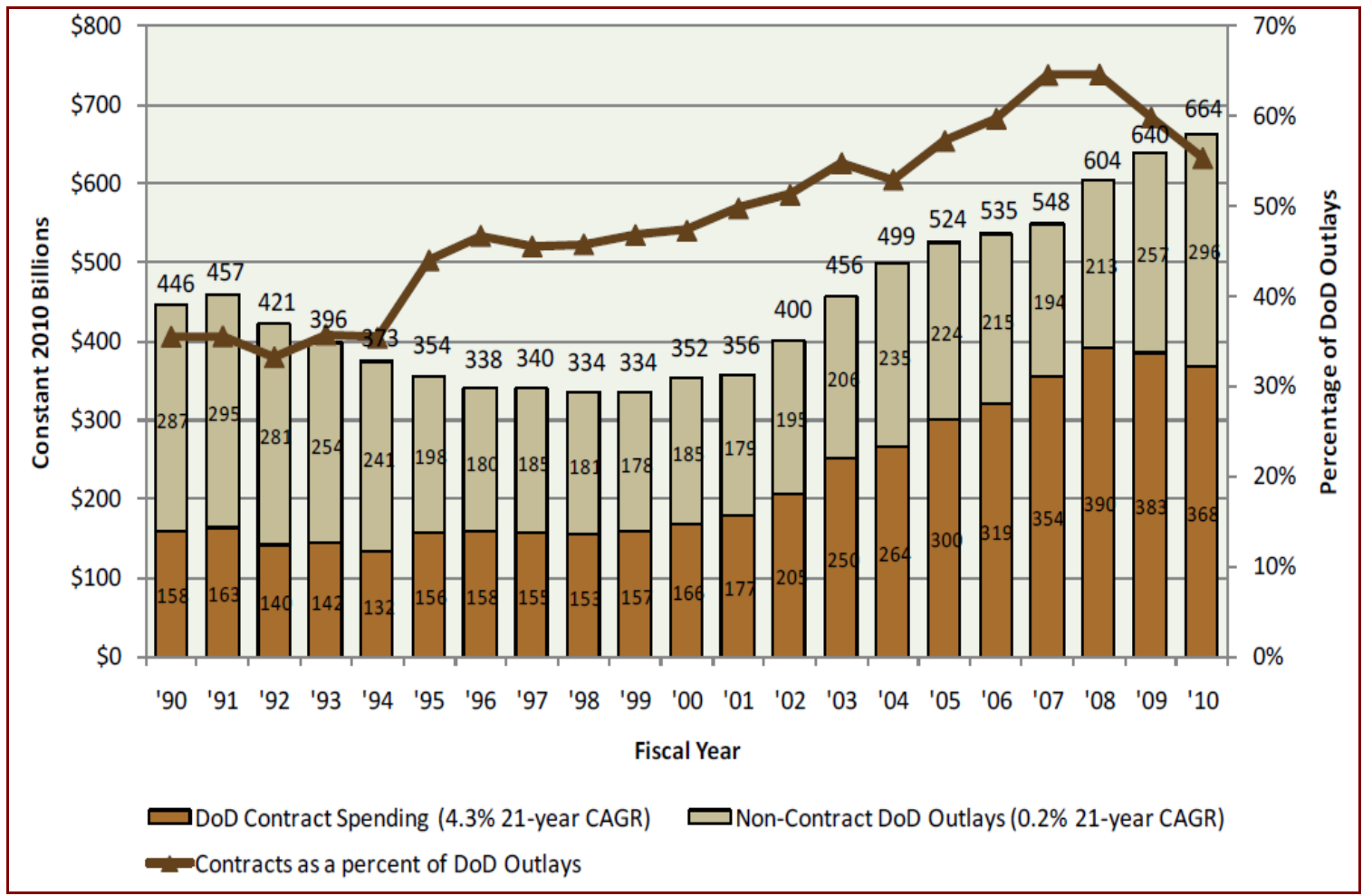

Figure 6. Top-Line DoD Contract Spending, 1990-2010

(CSIS, 2011)

In a statement delivered in January 2011, Secretary of Defense Robert Gates announced the necessity for altering the way the department conducts business, specifically its spending habits. His statement reflected the stance of the department in response to budgetary guidance and concerns from the White House and Congress. In an effort to streamline costs and reduce waste, Secretary Gates' reform agenda introduced the Efficiencies Initiative that scrutinizes spending without sacrificing readiness (Gates, 2011).

As we mentioned in Chapter I, USD(AT\&L) Carter published a memorandum establishing guidance for obtaining greater efficiency and productivity in defense spending in response to Secretary Gates' initiative. His September 2010 Better Buying Power memorandum highlighted 23 actions to improve efficiency in five target areas (USD[AT\&L], 2010).

Specific to our research is USD(AT\&L) Carter's fourth target area, improving tradecraft in services acquisition (USD[AT\&L], 2010). For each tenet, USD(AT\&L) Carter issued explicit directives in order to guide the acquisition workforce towards the improvement of procuring services. Particularly relevant to our research is the second tenet, 
adopting a uniform taxonomy for different types of services. Currently, there is limited regulatory guidance that addresses services in general or the approach necessary to handle service contracts. The Army, for instance, published Army Regulation (AR) 70-13 in July 2010, a short 13-page broad brushstroke of how to manage and oversee services acquisitions. While necessary, this is the only specific guidance the Army has for procuring services, which happens to be very similar to the process for procuring goods.

An article published by Vernon Edwards (2010) challenged some of the directives that USD(AT\&L) Carter issued, specifically with respect to the tradecraft in the services target area. In response to the new services taxonomy tenet, Edwards acknowledged that there is "no good theory, set of principles, or terminology for the specifications of services" (Edwards, 2010, p. 3). He argued that of all government agencies, the DoD spends the most on services and has the most experience with procuring services, but it has not consolidated and organized that knowledge in order to effectively manage it. Contracting offices have simply not properly captured the DoD's experience with procuring services, nor have they used the lessons learned to build a foundation for services acquisition regulation.

With most public agencies, reform is necessary as time progresses and events shape the way the government conducts business. However, certain initiatives may unknowingly create future problems. For example, Greve (2008) concluded that public agencies rely on contracting out services because of prior reform initiatives. The sheer complexity of the Iraq and Afghanistan conflicts has highlighted the need for acquisition reform, not only for contingency operations, but for home installation operations as well. Furthermore, Snider and Rendon (2008) have discussed how some procurement reform initiatives, such as the FASA, resulted in less-than-desirable procurement outputs, outcomes, or impacts. While the DoD as a whole has made positive efforts in finding solutions to services acquisition challenges, there is still an essential need for continued improvement.

\section{SERVICE CONTRACTS}

In this section we discuss the understated considerations of service contracting, given its substantial impact on the budget. The magnitude and effect of service contracting on the DoD's operations is immense, yet regulations and guidance for service contracting is weak. 
Across the DoD, the amount of dollars obligated for service contracts has considerably increased since 2000. As the DSB Task Force on Improvements to Services Contracting revealed, over $\$ 200$ billion (in real dollars) - more than $50 \%$ of the DoD budget - was allocated for service contracting in 2010 (DSB, 2011). As a result of the reduction of forces in the early 1990s and the unexpected scale of the global war on terrorism, the DoD's reliance on services became critical to the mission. As presented by the CSIS Defense Contract Trends report (CSIS, 2011), spending on services surpassed spending for products and research and development, at a rate of $6.1 \%$ per year over the past two decades. Figure 7 illustrates this trend.

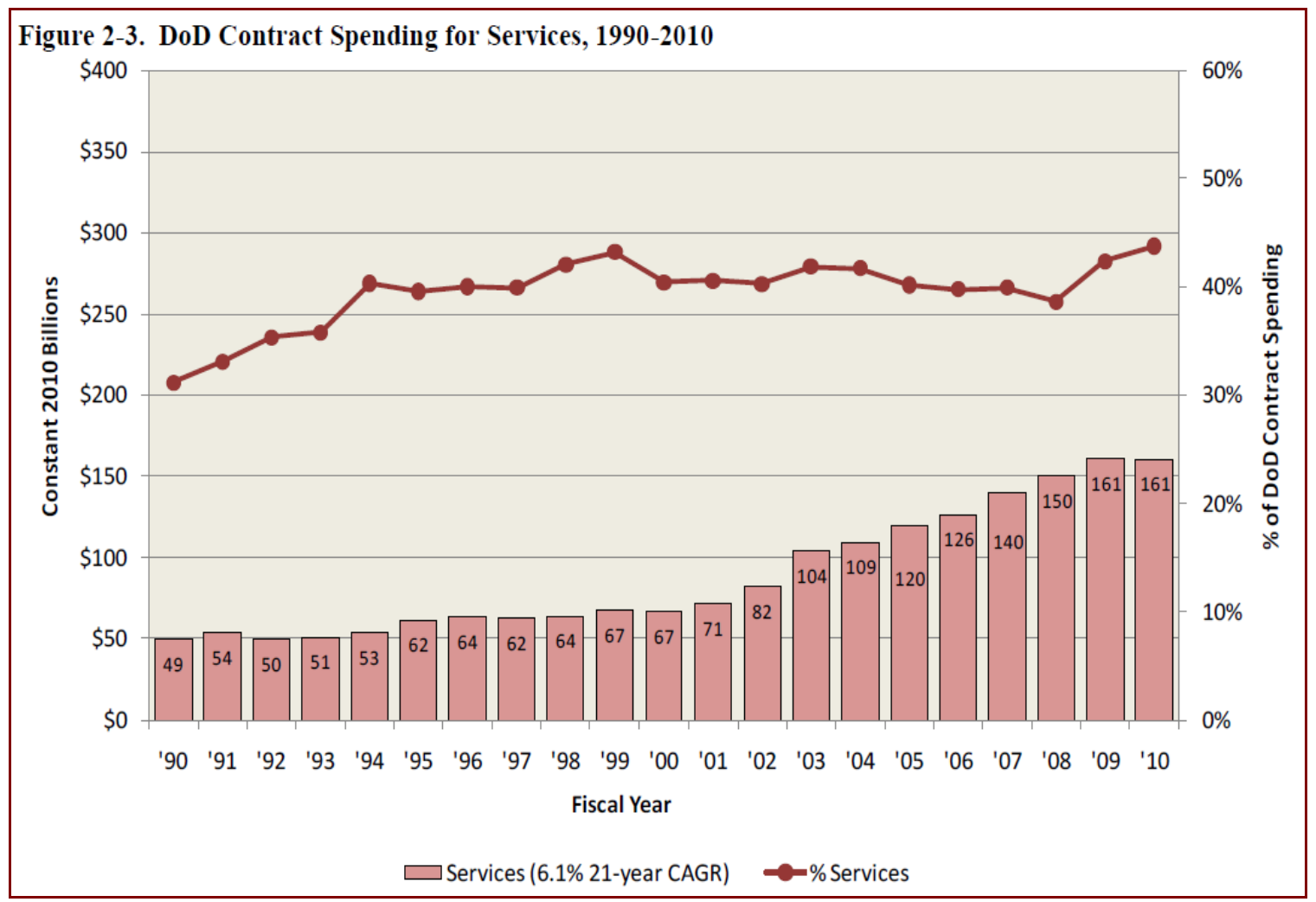

Figure 7. DoD Contract Spending for Services, 1990-2010 (CSIS, 2011)

Not surprisingly, the DoD annual procurement obligations far exceeded those of other government agencies. The department as a whole realized a significant increase in the amount of service dollars obligated. Specifically, the Army significantly increased its reliance on service contracting and experienced a far greater rate of growth for service contracting compared to the Navy and Air Force (see Figure 8). 


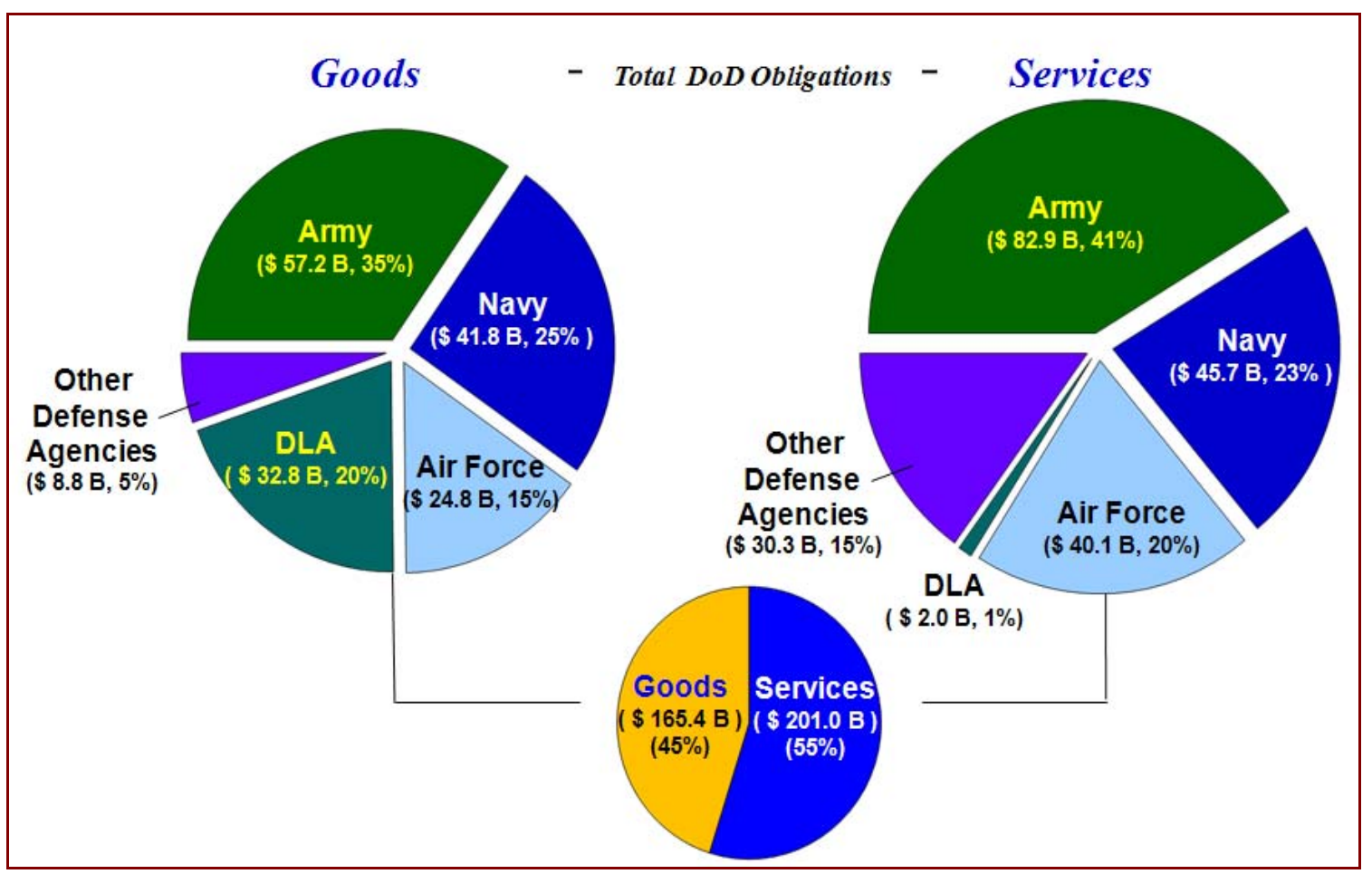

Figure 8. DoD Total Contract Spending for Fiscal Year 2010

(Spruill, 2011)

Accounting for between $45 \%$ and $53 \%$ of all spending since 2001, service contracts continue to be pivotal to the Army's mission (CSIS, 2011). More notably, the Army's increased reliance on service contracts is in large part a result of the Army's response to the Iraq and Afghanistan conflicts, for forward operations, as well as home station operations. Contractor support is as essential to supporting forward operations as it is to maintaining home station installation operations. Figure 9 shows the sizable increase in Army service contracting. 


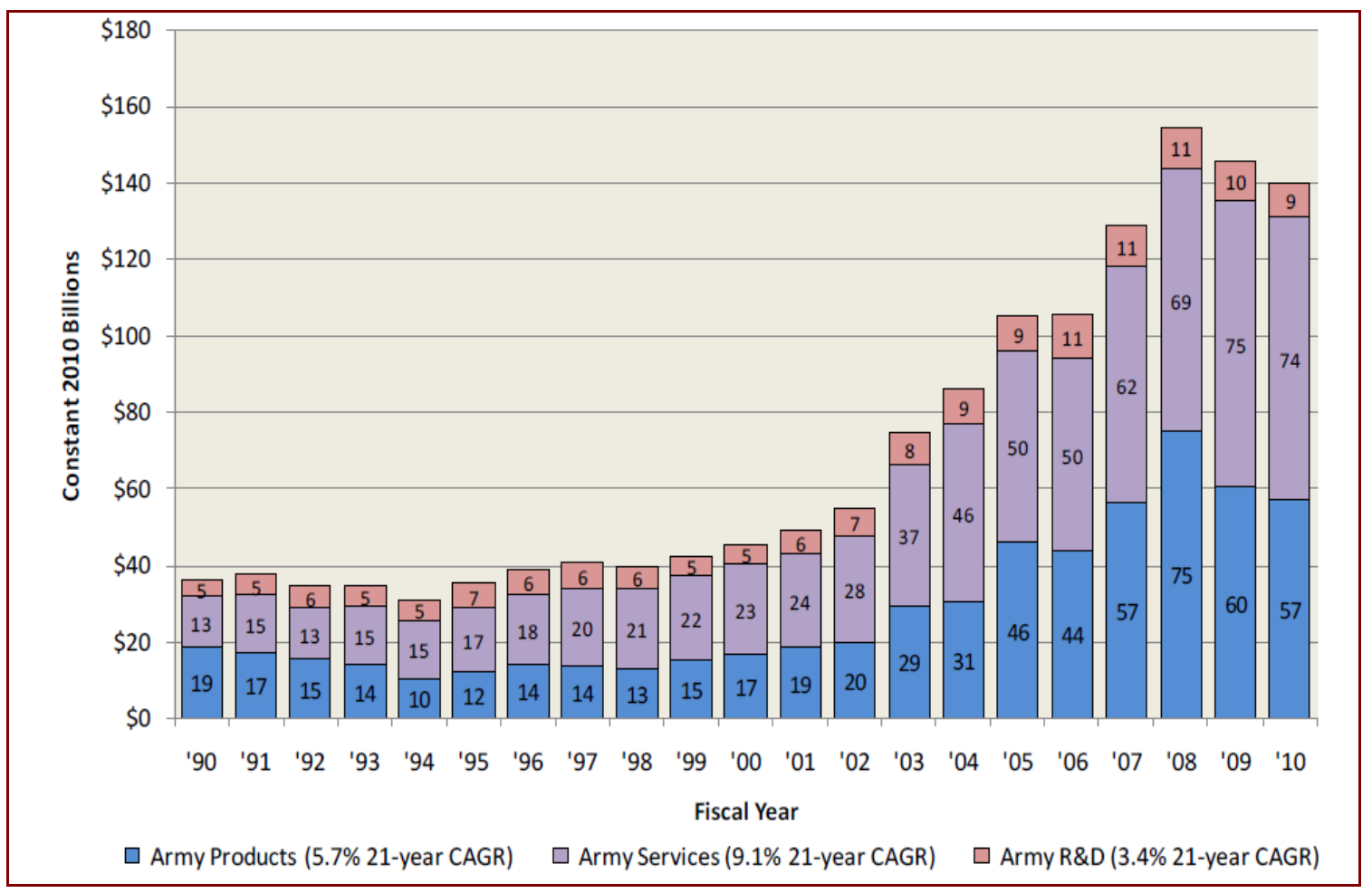

Figure 9. Army Contract Spending by Category, 1990-2010 (CSIS, 2011)

The type of services purchased greatly defines the impact of contracted services on the DoD and their significance. A vast majority of the DoD's services are grouped into 24 PSCs, which represent how service contracts are categorized and accounted for. We intended to continue the research initiated by McFall and La (2011) and to collect additional data in order to analyze the use of service contracts in the Army. In order to maintain data integrity, we focused our data collection on four of the 24 PSCs, which represent common services across Army installations and accounted for over $60 \%$ of the service contracts in terms of dollar value for FY 2009 (McFall \& La, 2011). Table 1 lists the 24 PSCs and their associated obligation for FY 2009, with the highlighted PSCs selected for data collection purposes. 
Table 1. Breakdown of Service Contracts in the Army for FY 2009

(McFall \& La, 2011)

\begin{tabular}{|c|c|c|l|}
\hline PSC & $\begin{array}{c}\text { FY 2009 } \\
\text { Obligation (\$) }\end{array}$ & $\begin{array}{c}\text { \% of } \\
\text { Total } \\
\text { Services }\end{array}$ & \multicolumn{1}{|c|}{ Service Category } \\
\hline R & $11,674,519,717$ & $27.4 \%$ & Professional, Administrative, and Management Support Services \\
\hline J & $7,645,271,950$ & $18.0 \%$ & Maintenance, Repair, and Rebuilding of Equipment \\
\hline A & $6,472,306,540$ & $15.2 \%$ & Research and Development \\
\hline S & $5,015,441,637$ & $11.8 \%$ & Utilities and Housekeeping Services \\
\hline U & $1,909,983,556$ & $4.5 \%$ & Education and Training Services \\
\hline D & $1,689,891,641$ & $4.0 \%$ & Automatic Data Processing and Telecommunication Services \\
\hline C & $1,557,067,711$ & $3.7 \%$ & Architect and Engineering Services-Construction \\
\hline B & $1,247,897,017$ & $2.9 \%$ & Special Studies and Analyses- Not R\&D \\
\hline M & $1,160,055,305$ & $2.7 \%$ & Operation of Government-Owned Facility \\
\hline Y & $897,151,344$ & $2.1 \%$ & Construction of Structures and Facilities \\
\hline Q & $489,328,909$ & $1.1 \%$ & Medical Services \\
\hline V & $455,413,266$ & $1.1 \%$ & Transportation, Travel, and Relocation Services \\
\hline Z & $454,447,794$ & $1.1 \%$ & Maintenance, Repair, or Alteration of Real Property \\
\hline F & $394,962,703$ & $0.9 \%$ & Natural Resources Management \\
\hline L & $353,565,935$ & $0.8 \%$ & Technical Representative Services \\
\hline K & $237,852,282$ & $0.6 \%$ & Modification of Equipment \\
\hline W & $208,523,670$ & $0.5 \%$ & Lease or Rental of Equipment \\
\hline O & $201,915,384$ & $0.5 \%$ & Other \\
\hline N & $183,192,192$ & $0.4 \%$ & Installation Equipment \\
\hline G & $155,301,816$ & $0.4 \%$ & Social Services \\
\hline P & $90,103,239$ & $0.2 \%$ & Salvage Services \\
\hline H & $45,398,154$ & $0.1 \%$ & Quality Control, Testing, and Inspection Services \\
\hline T & $25,816,540$ & $0.1 \%$ & Photographic, Mapping, Printing, and Publication Services \\
\hline E & $6,270,563$ & $<1.0 \%$ & Purchase of Structures and Facilities \\
\hline X & $1,680,844$ & $<1.0 \%$ & Lease or Rental of Facilities \\
\hline Total & $\mathbf{4 2 , 5 7 3 , 3 5 9 , 7 0 8}$ & $\mathbf{1 0 0 . 0 \%}$ & \\
\hline & & & \\
\hline
\end{tabular}

The selected service codes for data collection were the following:

- $\quad$ PSC R (Professional, Administrative, and Management Support Services),

- $\quad$ PSC J (Maintenance, Repair, and Rebuilding of Equipment Services),

- $\quad$ PSC S (Utilities and Housekeeping Services), and

- $\quad$ PSC D (Automatic Data Processing and Telecommunications Services).

In keeping with the model developed by McFall and La (2011), we sustained the following considerations:

- $\quad$ PSC A (Research and Development) and PSC U (Education and Training) would not be used because they are not common services across all military installations. 
- $\quad$ PSCs R and D represent complex-type services that require unique skills and are more difficult to define than simple-type services.

- $\quad$ PSCs J and S represent simple-type services.

Overall, service contracts in the DoD are unique and vary in scope and size. Detailed guidance for the procurement of services does not exist. Compared to the procurement of goods or systems, the GAO found that the reasons services differ from products can be attributed to the fact that services are less homogenous, more numerous, and harder to measure (GAO, 2009). Yet, current laws and regulations and training for the acquisition workforce are primarily directed at the procurement of goods, not services. In Section D of this chapter, we discuss the lack of management and oversight for service contracts, and the effect on the acquisition process and workforce.

\section{SERVICE CONTRACT MANAGEMENT}

With the realization that service contracting commands a huge portion of the defense budget, we can easily identify and magnify the inefficiencies and problems with defense service contract procedures. At the request of the Secretary of Defense, the DSB created a task force to conduct an independent assessment of procurement oversight and procedures for services in the DoD. In March 2011, the task force's report was published and provided insights and guidance for improving DoD policies, and procedures for procuring services. The task force identified five key findings in its assessment:

- Contracts for services supported major DoD programs and their major associated administrative, technological, and logistics services and were a strategic component of all military operations.

- Buying services was fundamentally different from buying weapons systems, yet most current acquisition regulations, laws, policies, processes, standards, training, education, and management structures were focused on optimizing the characteristics of products.

- The workforce was inadequately prepared to acquire and execute service contracts. 
- $\quad$ The DoD urgently needed to establish a meaningful taxonomy for services in order to develop useful definitions, performance standards, and outcome measures for each type of service.

- New and more detailed guidance was needed in the DoD that clarified the inherently governmental functions that government personnel should always perform. (DSB, 2011)

With these findings, the task force portrayed the complexity of service contracting due to the absence of structured rules and laws focused specifically on managing service contracts, combined with an acquisition workforce that was inadequately trained. Most relevant to our research are the second, third, and fourth findings. All offices and departments within the DoD must understand the differences between purchasing services versus products, and understand the efforts that must be taken to award and manage a service contract. In order to do so, the DoD must update and tailor policies and procedures for service contracting. The recommendation of the task force focused on "setting definitions and standards for services, making decisions to retain organic capacity or contract for services, and setting effective processes and policies to guide services contracting" (DSB, 2011). As portrayed in Figure 8, approximately 55\% of the DoD's annual contracts for FY 2010 were for services, yet the DoD has not defined policies to adequately manage them.

More important, the acquisition workforce must be knowledgeable in order to understand the requirements of and administer the process for a service contract. The DSB Task Force also highlighted the fact that acquisition training programs lacked any form of education on service contracting (DSB, 2011). Additionally, the Commission on Army Acquisition and Program Management in Expeditionary Operations pointed out that the Army acquisition workforce was already challenged with staying current with basic training and certifications, let alone any services-specific training (Gansler et al., 2007). However, in order to support the Army's Grow the Army initiative, the objective for Army acquisition was to provide an "agile, right-sized, right skilled acquisition workforce to support the Army's growth and transformation" (Defense Acquisition Workforce [DAW], 2010, p. A92). In order to align with the Army's strategy, the Assistant Secretary of the Army for Acquisition, Logistics, and Technology (ASA[ALT]) incorporated five key objectives to 
support its mission and vision for the reinforcement of its workforce. Figure 10 depicts the five strategic objectives.
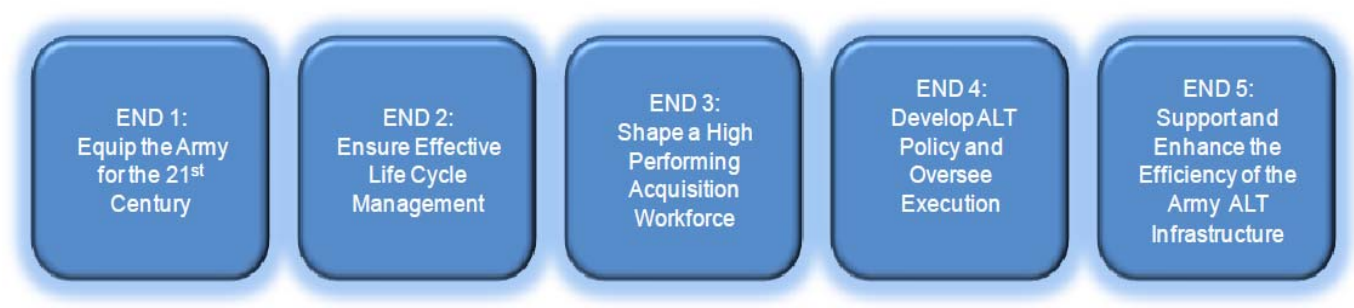

Figure 10. Key ASA(ALT) Strategic Objectives (Ends)

(DAW, 2010, p. A9-3)

In accordance with Secretary Gates' initiative and USD(AT\&L) Carter's Better Buying Power criteria, the Army still faces challenges with properly executing service contracts, but it has taken strong steps toward implementing a strategy to reconcile these issues.

Consistent with the findings of the DSB Task Force, several GAO reports have reported similar findings and recommendations. In 2007 a GAO report focusing on the improvement of management and oversight for services acquisitions argued that the DoD did not completely grasp whether its services acquisition processes were working, or whether these processes accurately supported its mission and protected taxpayer interests (GAO, 2007). The unique mission of the DoD requires varying types of services, which have varying durations and requirements, which have made it difficult to adequately capture whether current practices are functioning to meet the DoD's needs. A 2009 GAO report followed up with this concern, citing poorly defined or changing requirements as the reason services did not meet the DoD's needs, largely because of the absence of clear requirements (GAO, 2009).

In 2009 the GAO examined the DoD's reliance on contractors for services to the point where "DoD officials have acknowledged their inability to perform their mission without contract support" (GAO, 2009, p. 1). While the GAO did not argue that the DoD should not contract out services, it contended that the department needed to improve upon the oversight of service contracts, a key factor in the proper handling of service contracts. 


\section{E. PREVIOUSLY COMPLETED RESEARCH}

This research ultimately stems from a series of five ARP-sponsored research projects focusing on services acquisition in the DoD. McFall and La (2011) based their research on the conclusions and recommendations of the following series of research projects. In the first services research (Apte, Ferrer, Lewis, \& Rendon, 2006) and in the second services research (Apte \& Rendon, 2007), the authors examined the types of services the DoD acquired to understand the respective growth rate and possible opportunities and challenges faced in the service supply chain. The third phase of services research (Apte, Apte, \& Rendon, 2008) and the fourth phase (Apte, Apte, \& Rendon, 2009) were empirical studies and incorporated survey-based data collection in order to determine how services acquisitions were managed at Army, Navy, and Air Force installations. In the surveys, researchers focused on collecting information regarding contract characteristics, acquisition management methods, and other program management issues. These studies concluded that services acquisition management lacks a strong management approach, sufficient training of acquisition personnel, and necessary manning levels. In the fifth services research (Apte, Apte, \& Rendon, 2010a), the researchers focused on analyzing the data compiled from the third and fourth services research studies in order to understand how individual agencies within the DoD manage services acquisition. They concluded that most of the service contracts were competitive, fixed-price contracts, managed at the regional level in the Navy and by the project team in the Army and Air Force, and none of the services utilized project life cycles for services acquisition.

As we stated in our introduction, this research is a continuation of McFall and La's (2011) research in which they examined services acquisition within the Army. Their efforts focused on the development of a model that effectively assessed the services acquisition procedures of Army MICCs by collecting data from two Army MICC offices. Using the same model and data collection procedures, we focus on collecting data from an additional six Army MICCs in an effort to conduct a more detailed analysis of a larger sample.

\section{F. SUMMARY}

Our intent in this chapter was to present the basis for our current research. We introduced and discussed previous research and administrative directives for DoD services 
acquisition management. In our review, we depicted the complex nature of services acquisitions and the challenges they present to the DoD and to the Army MICC organizations. In the next chapter, we present the organization of the Army Contracting Command and its associated MICCs. 


\section{MISSION AND INSTALLATION CONTRACTING COMMAND}

\section{A. INTRODUCTION}

In this chapter, we focus on the history and current state of Army contracting. First, we explore acquisition failures that have been identified by an independent commission on Army acquisitions, the Commission on Army Acquisition and Program Management in Expeditionary Operations, also commonly referred to as the Gansler Commission, appointed by the Secretary of the Army. Second, we present readers with an explanation of why the Army Contracting Command (ACC) was established. Third, we explore the ACC's organizational structure and the relationship between the MICC and the ACC. Last, we provide an overview of the MICC's purpose, mission, and organizational structure.

\section{B. ARMY CONTRACTING CONCERNS}

In 2007 the Secretary of the Army formed the Gansler Commission to review lessons learned in recent operations and provide recommendations to ensure that future military operations will have greater effectiveness, efficiency, and transparency. The commission found that the Army lacked the leadership and personnel to provide adequate contracting support to either expeditionary or peacetime operations. Since 1995 Army contracting personnel have faced a more than $350 \%$ increase in contract actions, a $382 \%$ increase in dollars spent, and a stunning 53\% decrease in acquisition workforce, as illustrated in Figure 11. Meanwhile they are performing more complex actions than ever before (Gansler et al., 2007, p. 32). 
People $\square$ Actions $>\$ 100 \mathrm{~K} \square$ Total Dollars in Billions $\square$

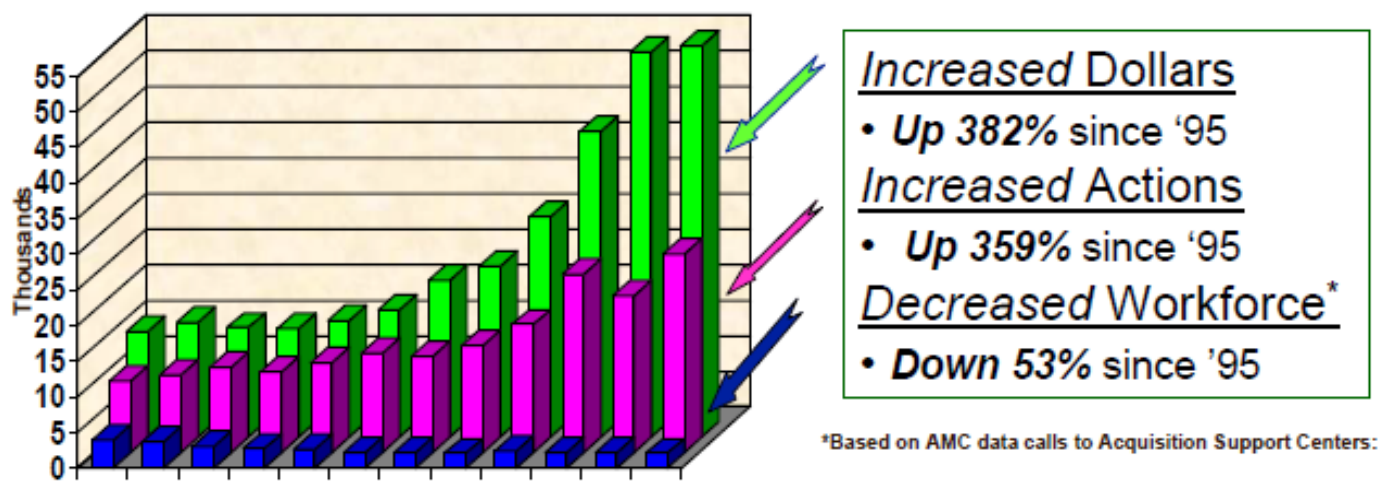

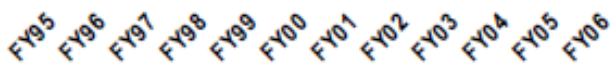

FY95 Workforce: 3,905

FY06 Workforce: 2,070

Figure 11. The Army Materiel Command Contracting Statistics for 1995-2006

(Gansler et al., 2007, p. 32)

Furthermore, in the report the commission revealed that only 3\% of Army contracting personnel were military. Due to the lack of military contracting professionals, the Army was unable to fill military or civilian contracting billets in Iraq and Afghanistan. As a result, the Air Force provided over $67 \%$ of the Joint Contracting Command-Iraq/Afghanistan (JCCI/A) contracting resources (Gansler et al., 2007, p. 93).

The Gansler Commission identified a significant number of proposed changes to improve Army acquisition and program management in expeditionary operations. Additionally, the commission proposed the following four overarching recommendations to achieve success in the future:

- $\quad$ Increase the stature, quantity, and career development of military and civilian contracting.

- $\quad$ Restructure the organization and restore responsibility to facilitate contracting and contract management in expeditionary and continental United States (CONUS) operations.

- $\quad$ Provide training and tools for overall contracting activities in expeditionary operations.

- $\quad$ Obtain legislative, regulatory, and policy assistance to enable contracting effectiveness in expeditionary operations. (Gansler et al., 2007, pp. 47-58) 
These four recommendations led to the establishment of the ACC. In order to restructure the organization and make possible effective and efficient contracting and contract management, the Gansler Commission proposed a reorganization of contracting responsibilities, as depicted in Figure 12.

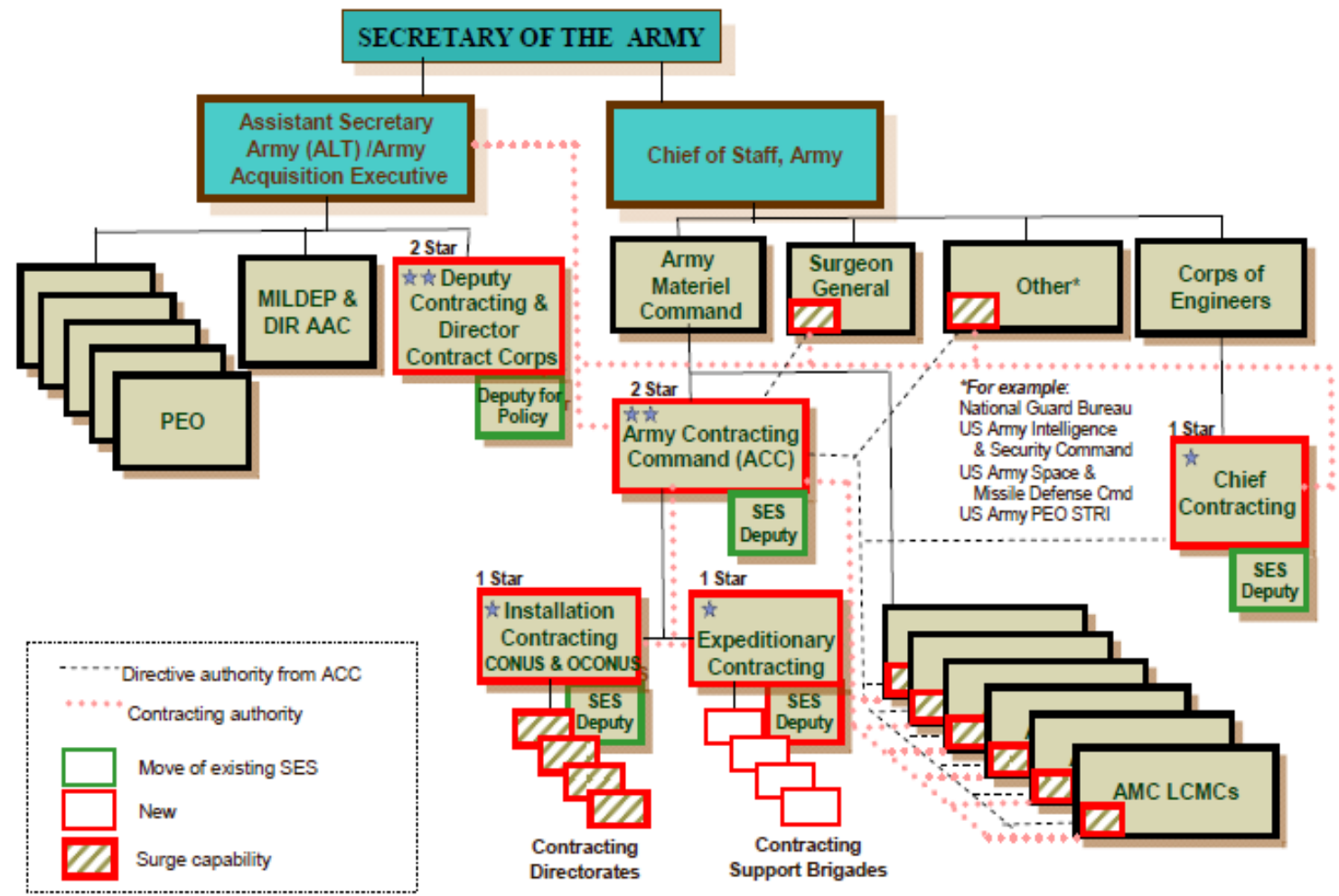

Figure 12. Recommended Army Contracting Organizations and Responsibilities

(Gansler et al., 2007, p. 51)

\section{ARMY CONTRACTING COMMAND MISSION AND ORGANIZATION}

In compliance with the Gansler Commission, on October 1, 2008, the Army recognized the formal establishment of the ACC as a major subordinate command of the Army Materiel Command (AMC; ACC, 2011a). The new command performs the majority of all contracting work for the Army and consists of two subordinate commands: the Expeditionary Contracting Command (ECC) and the MICC.

The mission of the ACC is to "provide global contracting support to warfighters through the full spectrum of military operations" (ACC, 2011a, para. 1). The ACC vision is "a professional workforce providing quality contracting solutions in support of our warfighters" (ACC, 2011a, para. 2). The ACC reports directly to the AMC. Figure 13 
reveals the current ACC organizational structure. In line with the recommendations from the Gansler Commission, the reorganization allows for better oversight and management of contingency contracting, program management, and installation contracting. As Figure 13 illustrates, a two-star general leads the ACC, and a one-star general leads the ECC and MICC, which suggests the importance of reform to the Army. The MICC specifically controls installation contracting in the CONUS with 36 DOCs and six regional contracting centers within its chain of command (ACC, 2011a). The ECC is in charge of all contingency contracting operations for the Army with seven Contract Support Brigades to support the warfighters (ACC, 2011a). Furthermore, there are nine program management offices that support the development of new systems for the Army.

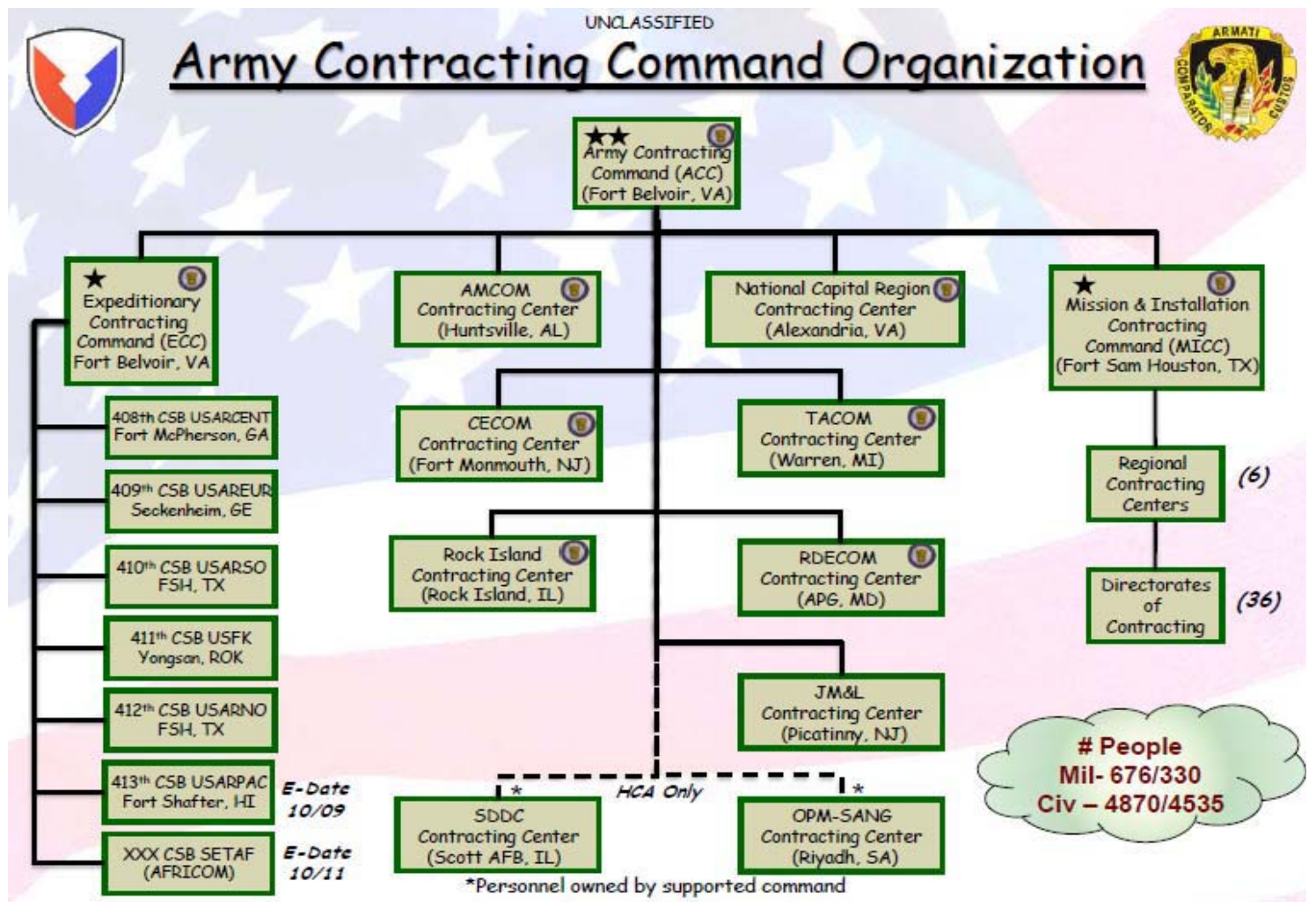

Figure 13. U.S. Army Contracting Command Organizational Chart

(Jones, Klaft, \& Pettygrue, 2010, p. 24)

\section{MICC MISSION, VISION, GOALS, AND SCOPE OF SERVICES}

As part of the Army's generating force, the MICC's mission is to plan, integrate, award, and administer contracts throughout the Army Force Generation (ARFORGEN) Cycle supporting the Army Commands (ACOMs); Direct Reporting Units (DRUs); U.S. 
Army, North (USARNORTH); and other organizations to provide the best value for the mission, soldiers, and their families (MICC, 2011). The MICC's vision is to function "as an integral and indispensable partner in accomplishing the Army's mission through contracted materiel and services solutions (MICC, 2011, para. 2). The establishment of the MICC has provided a framework for contracting personnel to improve coordination and responsiveness, which has resulted in better contract support (McFall \& La, 2011). The four goals that leadership established for the MICC are the following:

- $\quad$ To ensure that contracts meet customer requirements, reflect sound business judgment, and comply with laws and regulations.

- To select contractors that provide the best value to the government.

- To ensure that contractors deliver quality goods and services that meet the commander's requirements on time and at a reasonable cost.

- To ensure that contractors are paid fair and reasonable compensation for their services. (MICC, 2011)

As we stated in Chapter II, in this study we focus on four PSCs (R, D, S, and J) because they represent the largest part of the service contracts in terms of dollar value and are common services used throughout all Army installations. PSCs R and D represent complextype services and PSCs J and S represent simple-type services, based on contract requirements (McFall \& La, 2011). In order to expand the data collected in McFall and La's 2011 report, we chose two MICC centers and four DOCs as locations to visit for this study. Combined with the data collected from the two MICC centers that McFall and La (2011) analyzed, we analyze a total of four MICC centers and four DOCs in this study.

\section{E. SUMMARY}

The purpose of this chapter was to establish a basis for the empirical analysis of Army service contract management practices at the MICC. First, we presented issues and recommendations that the Gansler Commission identified. These recommendations laid the foundation for the establishment of the ACC and the MICC. We then provided detailed information about the mission, vision, and organization of the ACC and the MICC. Next, we discussed the different service contracts that the MICC offices administer and award. Last, we discussed the service contracts by PSC and highlighted the four PSCs that we evaluated 
for the purposes of this research. In the next chapter, we present the methodology behind data collection and analysis. 


\section{RESEARCH METHODOLOGY}

\section{A. INTRODUCTION}

In this chapter, we explain how we collected and evaluated data to meet our research objectives and answer the research questions proposed in Chapter I. Specifically, we reveal how we selected participants or MICCs offices for evaluation, the questions used on the data collection form, and the information we obtained from the collected data. Furthermore, we provide a brief description of the qualitative and quantitative methods we used in analyzing the data collected from the six Army MICC installations we visited.

\section{B. METHODS USED IN SELECTION AND DATA COLLECTION}

As we mentioned in Chapter III, the MICC is configured with six regional contracting centers and 36 Directorates of Contracting (DOCs; ACC, 2011a). The purpose for this research is to perform an evaluation of Army service contract management, including procurement and administrative methods, to help understand the drivers of service contracting practices, and to improve the acquisition process. We used a data collection form (see Appendix A), developed during a pilot study in McFall and La's 2011 MBA report, to collect data for this research. The form was geared towards collecting objective-based data. We chose the six locations used in this research because they had a wide variety of service contracts that we could analyze. We analyzed the data quantitatively and qualitatively to draw conclusions about management practices used at the MICC installations we visited, similar to McFall and La's 2011 MBA report. In addition, as we discussed in Chapter III, we focused our data collection on only four types of services. The service types examined were PSC R (Professional, Administrative, and Management Support Services), PSC J (Maintenance, Repair, and Rebuilding of Equipment), PSC S (Utilities and Housekeeping Services), and PSC D (Automatic Data Processing and Telecommunications Services). In their pilot project, McFall and La evaluated 40 contracts, and in this study we collected data on 114 contracts. Combining the two data sets, our total sample size consisted of 154 contracts. We did not use a specific method for selecting contracts for analysis. The selected MICC offices provided a random sampling of contracts for these specific service codes. 


\section{DATA COLLECTION QUESTIONS}

The data collection form used in our research is included in Appendix A. McFall and $\mathrm{La}$ (2011) developed the form to answer the following questions:

- $\quad$ Do the contract characteristics differ for different types of services?

- Do the types of services being acquired affect the management practices being used?

- Does the capacity for carrying out acquisition-related work affect the management practices being used?

Part I of the data collection form concentrates on important contract characteristics, such as type of service contract, use of competition, award type and basis, key acquisition dates, use of an independent government estimate (IGE), and contract value. Additionally, we gathered data on management practices, such as the use of a team approach, the number people assigned to the contract, the personnel generating requirements, the number of modifications, the contract surveillance used, and contract closeout (McFall \& La, 2011).

McFall and La developed Part II of the form to capture the capacity of MICC offices in relation to management practices. Part II of the data collection form (see Appendix B) focuses on administrative management issues. Answers to questions in Part II provide the number and dollar value of service contracts awarded in FY 2011, the annual budget for service contracts staff, the number of billets authorized and filled at each MICC office, and the current training level and certification of the acquisition workforce at each MICC office. Other questions concentrate on the level of experience of the workforce and the average workload at each MICC office.

\section{ANALYTICAL PROCESS}

We used descriptive and inferential statistics to analyze the data collected from six MICC offices, similar to McFall and La's 2011 MBA report, in order to maintain data integrity. Our goal was to expand their research and obtain a larger sample of contracts from different MICC offices. In Chapter V, we reveal nominal (qualitative) and interval (quantitative) data in graphical and tabular formats. We draw conclusions on relationships depicted in these graphs to answer the three research questions we identified in Chapter I. In 
order to support these relationships, we used information from the literature review to identify the drivers of acquisition management practices, as well as to analyze the similarities and differences among the six installations.

In this study, factor 1 refers to service type and factor 2 refers to one of the various contract characteristics or management practices we observed during our visits to the MICC offices. To test the relationship between these factors in service contracts, we applied a chisquared test of a contingency table using Equation 1. We started with a null hypothesis that factor 1 does not have a relationship with factor 2 .

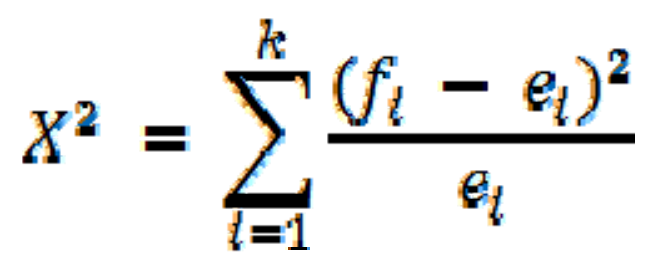

In Equation 1, $k$ is the number of cells in the cross-classification table, $f$ is the observed values, and $e$ represents the expected values. The chi-squared value $\left(\chi^{2}\right)$ corresponds to a $p$ value in a chi-squared distribution table. A lower $p$ value disproves that there is no relationship between the variables at that level of confidence. We evaluated all data in Chapter V using a 95\% confidence interval, or a 0.05 significance level. Among statisticians, a chi-square of 0.05 is typically considered an acceptable threshold of statistical significance (Rosenzweig \& Thelen, 1998). When the $p$ value is less than 0.05 , the null hypothesis is rejected and usually considered as "statistically significant" (Rosenzweig \& Thelen, 1998). On the contrary, when the $p$ value is greater than 0.05 , the probability that the recorded observation occurred by chance increases, and the null hypothesis cannot be rejected (Rosenzweig \& Thelen, 1998). In this study, when the $p$ value is less than 0.05 , we are confident in rejecting the possibility that no association exists between the independent and dependent variables (Rosenzweig \& Thelen, 1998).

\section{E. SUMMARY}

In Chapters I through IV, we provided a foundation for this research. We covered the magnitude of this research (Chapters I and II), from where we collected the data (Chapter III), and how we collected and analyzed the data (Chapter IV). In the next two chapters, we 
present our findings and the applications from the data we collected. In Chapter V, we present the results and analysis of the data we collected and discuss the data and what we believe affects its behavior. In Chapter VI, we summarize the entire research project, draw conclusions about the findings, and recommend areas for future studies. 


\section{RESULTS AND ANALYSIS}

\section{A. INTRODUCTION}

In Chapter V, we capture the analysis of the data we collected in order to answer the three questions we proposed for this research in Chapter I. We answer these questions individually using qualitative and quantitative methods. The three research questions are restated below:

- Do the contract characteristics differ for different types of services?

- Do the types of services being acquired affect the management practices being used?

- Does the capacity for carrying out acquisition-related work affect the management practices being used?

We used the statistical technique of chi-squared hypothesis testing in our analysis to determine whether or not we can disprove that there is not a relationship among service types, specific contract characteristics, and specific management practices in service contracting. The chi-squared test does not directly determine whether or not service type affects a specific contract characteristic or the strength of the relationship; however, it can suggest, with a certain degree of confidence, if a relationship exists between the service type and a specific contract characteristic. We conduct chi-squared tests for this analysis using a 95\% confidence interval. The null hypothesis states that there is no relationship between factor 1 and factor 2. Therefore, we reject the null hypothesis for all chi-squared tests in this report whenever the $p$ value is less than 0.05 . As a result, in those cases, we interpret the data with a $95 \%$ level of confidence that the test disproves that there is not a relationship between the two factors, as described in Table 2. The results for the chi-squared calculations presented in this chapter are found in Appendix B. 
Table 2. Chi-Square Hypothesis Testing

\begin{tabular}{|c|c|c|}
\hline $\boldsymbol{p}$ value & Reject Null Hypothesis & Meaning \\
\hline Less than 0.05 & Yes & Disproves that there is no relationship \\
\hline Greater than 0.05 & No & There is no relationship \\
\hline
\end{tabular}

The data represents a small portion of the contract files administered and executed at Army MICC centers and DOCs, a research limitation we discussed in Chapter I. As we stated in Chapter IV, the sample size we used for this research included 154 contracts. McFall and La (2011), in their pilot project, evaluated 40 contracts, and in this study we collected data on 114 additional contracts. Although the sample size is small compared to the entire pool of contracts at the installations, we can analyze the information we collected to recommend improvements and to guide future research.

\section{B. SERVICE TYPE AND CONTRACT CHARACTERISTICS}

The focus of our first research question was to determine whether a relationship exists between contract characteristics and service type, as illustrated in Figure 14. We collected and evaluated information concerning six specific contract characteristics. The six contract characteristics we examined were (1) level of competition used, (2) contract type, (3) award/incentive fee, (4) contract cost in dollar value, (5) number of modifications, and (6) award basis. 


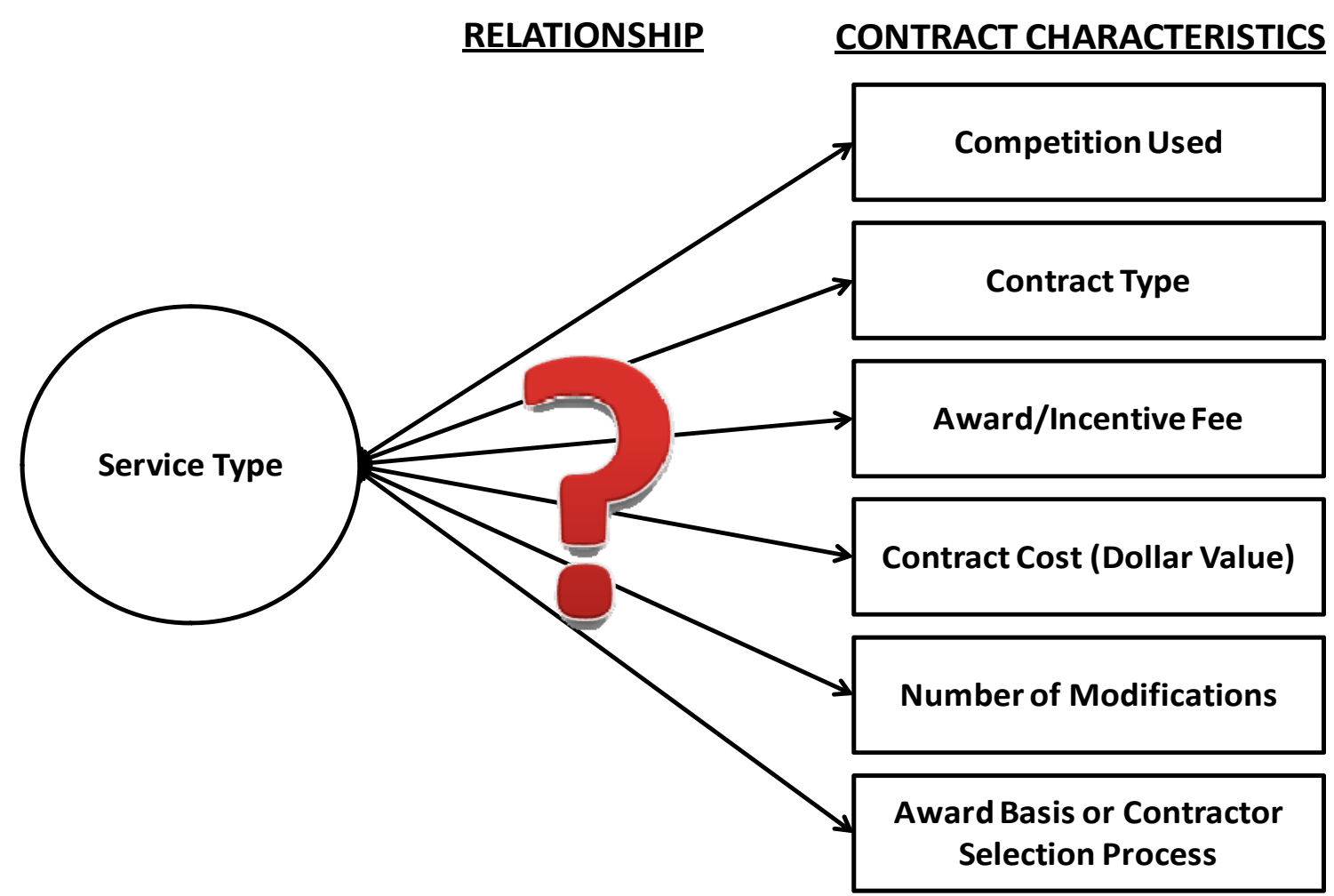

Figure 14. Assessment of Relationship Between Service Type and Contract Characteristics

In this section, we define the categories for award basis or contractor selection process as full and open competition (lowest price technically acceptable [LPTA] and bestvalue tradeoff) and as sole source (e.g., AbilityOne, direct-award-to-small-business setasides, only one provider, and unusual and compelling urgency). According to the Federal Acquisition Regulation (FAR), full and open competition, "when used with respect to a contract action, means that all responsible sources are permitted to compete" for contract award (FAR, 2011, subpart 2.101). The LPTA selection process is appropriate when bestvalue is expected to result from the selection of the technically acceptable proposal with the lowest evaluated price (FAR, 2011, subpart 15.101-2). A best-value tradeoff process is appropriate when it is in the best interest of the government to consider award to other than the lowest priced offeror or other than the highest technically rated offeror (FAR, 2011, subpart 15.101-1). Additionally, a sole-source acquisition means a contract for the purchase of supplies or services that an agency enters into or proposes to enter into after soliciting and negotiating with only one source (FAR, 2011, subpart 2.101). The types of sole-source acquisitions that we evaluate in this research are AbilityOne, direct-award-to-small-business 
set-asides, only one provider, and unusual and compelling urgency. AbilityOne, as stated in the FAR (2011, subpart 8.7), is a mandatory source of services that requires ordering offices to purchase services from nonprofit agencies participating in AbilityOne, unless the agency cannot perform the service.

When an acquisition exceeds the competitive threshold, the Small Business Administration (SBA) is allowed to use direct-awards-to-small-business-set-asides if there is not a reasonable expectation that at least two eligible and responsible 8(a) firms (a specific type of set-aside) will submit offers at a fair market price; or the SBA can accept a new requirement on behalf of a concern owned by an Indian tribe or Alaska Native Corporation (FAR, 2011, subpart 19.805-1). Only one provider means that the supplies or services the agency requires are available from only one responsible source, and no other type of supplies or services will satisfy agency requirements (FAR, 2011, subpart 6.302-1). According to the FAR, "services is of such an unusual and compelling urgency that the government would be seriously injured unless the agency is permitted to limit the number of sources from which it solicits bids or proposals, full and open competition need not be provided for" (FAR, 2011, subpart 6.302-2).

In the following evaluation of service types, we use the terms we defined previously. Service types $\mathrm{J}$ and $\mathrm{S}$, which can be categorized as simple non-recurring services, used an LPTA award basis more often. Service types R \& D, which are typically categorized as more complex, used best value tradeoff procedures as an award basis more frequently.

Service type S displayed the use of AbilityOne contractors as an award basis more frequently than any other service type. Additionally, we observed that service type $\mathrm{S}$ had a higher dollar value and required a high number of modifications, most likely due to the fact that service type $\mathrm{S}$ is a recurring service. However, the data disproved that there was not a relationship overall between service type and award basis.

Analysis results also revealed areas where all four service types shared the same contract characteristics. All of the contracts were firm-fixed-price (FFP) with only one utilizing incentive or award fee. This observation is not unusual given these types of services are highly commercialized and well-defined. Table 3 summarizes the chi-squared test results 
between service type (factor 1) and contract characteristics (factor 2). From the table, we can ascertain whether the data suggests a relationship between factor 1 and factor 2 .

Table 3. Chi-Square Hypothesis Testing Results Between Service Type and Contract Characteristics

\begin{tabular}{|c|c|c|c|c|}
\hline Factor 1 & Factor 2 & P-value & Significance & $\begin{array}{l}\text { Reject Null } \\
\text { Hypothesis }\end{array}$ \\
\hline Service Type & $\begin{array}{c}\text { Level of Competition } \\
\text { Used }\end{array}$ & 0.8958 & $>0.05$ & No \\
\hline Service Type & Contract Type & $\begin{array}{c}\text { Not } \\
\text { Applicable }\end{array}$ & $\begin{array}{c}\text { Not } \\
\text { Applicable }\end{array}$ & No \\
\hline Service Type & Award/Incentive Fee & $\begin{array}{c}\text { Not } \\
\text { Applicable }\end{array}$ & $\begin{array}{c}\text { Not } \\
\text { Applicable }\end{array}$ & No \\
\hline Service Type & $\begin{array}{c}\text { Contract Cost (Dollar } \\
\text { Value) }\end{array}$ & 0.0022 & $<0.05$ & Yes \\
\hline Service Type & $\begin{array}{l}\text { Number of } \\
\text { Modifications }\end{array}$ & 0.0442 & $<0.05$ & Yes \\
\hline Service Type & $\begin{array}{c}\text { Award Basis or } \\
\text { Contractor Selection } \\
\text { process }\end{array}$ & 0.0268 & $<0.05$ & Yes \\
\hline
\end{tabular}

We evaluate each contract characteristic compared to service type in further detail in Subsections 1-5.

\section{Level of Competition Used}

Level of competition used refers to whether or not the contracts were solicited by the MICC offices using full and open competition or sole-source methods. Figure 15 depicts the use of competition by service type for the data we observed in this study. As Table 3 shows, the $p$ value is greater than 0.05 ; therefore, we cannot reject the null hypothesis. Based on this information and the information in Figure 15, we can determine that there is no relationship between service types and whether or not the requirement was solicited using full and open competition or sole-source methods. Figure 15 shows that $56 \%$ of the requirements for all four service types were solicited using full and open competition and $44 \%$ were sole sourced. 
Based on the data presented, we recommend that the MICC offices further analyze its methods to increase competition and steer away from the use of sole-source methods, unless regulation or law dictates otherwise. Competition needs to be increased in an effort to answer USD(AT\&L) Carter's call for the DoD to focus on promoting real competition and to "DO MORE WITHOUT MORE” (USD[AT\&L], 2010, p. 1).

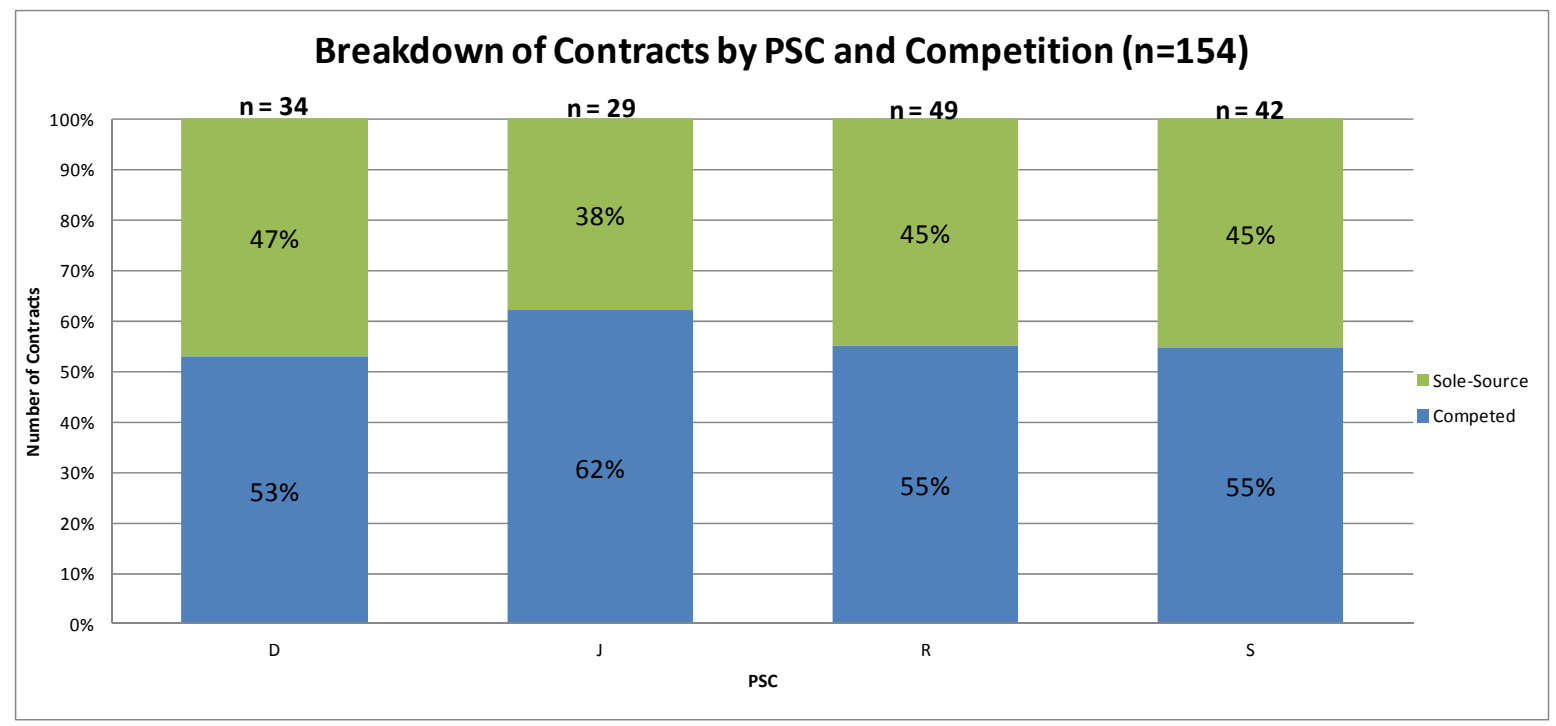

Figure 15. Analysis of Level of Competition Used by Service Types

To promote a better understanding of the large percentage of sole-sourced contracts, as displayed in Figure 16, we discuss the various justifications used for those requirements. Out of the 154 contracts in the sample that we evaluated, $44 \%$ of the contracts were not used in competition. Figure 16 shows that out of the 68 sole-sourced contracts, $38 \%$ of the justifications were classified as claiming that there was only one responsible provider that could satisfy agency requirements. In addition, $16 \%$ of justifications were of an unusual and compelling urgency, which is a high percentage considering the contracts being awarded were not for a contingency. Justifications should be scrutinized further to increase competition in service contracts at all Army MICCs.

However, $46 \%$ of the sole-source justifications were for direct award to small business set-asides, utilities, and AbilityOne agencies. Set-aside programs, such as small businesses, accounted for $28 \%$ of the sole-source justifications. Another $9 \%$ was composed of AbilityOne contractors, such as National Industries for the Blind (NIB) and National Industries for the Severely Handicapped (NISH). Utilities, usually regulated by states or 
counties, accounted for $9 \%$ of the justifications. The use of both AbilityOne contractors and specific utility companies is a result of mandatory laws and regulations limiting the MICC offices from providing for full and open competition in these instances. Nevertheless, there is still evidence that contracts are not being competed to the fullest extent possible. As Figure 15 shows, all four types of services were solicited for competition about $56 \%$ of the time, which does not conform to the FAR (2011) part 6 (Competition Requirements) and statutory requirements to provide for full and open competition to the maximum extent possible.

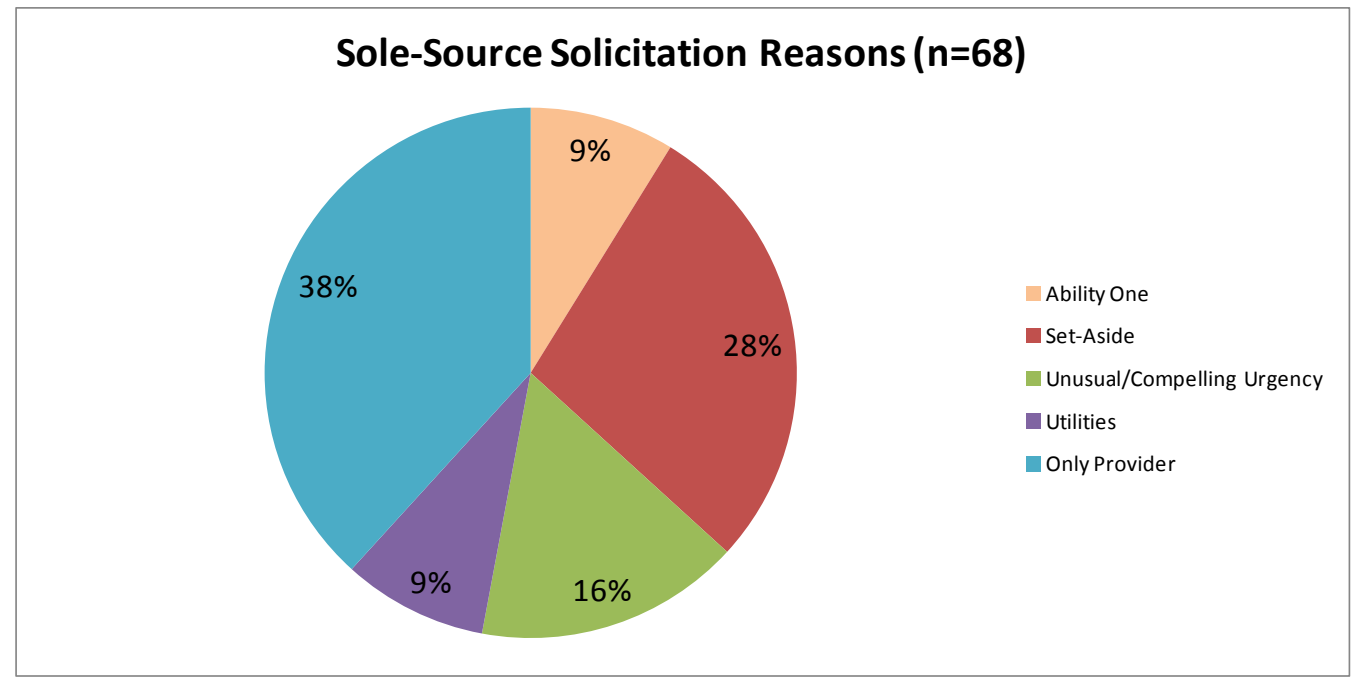

Figure 16. Justification for Sole-Source Solicitation

\section{Contract Type and Incentive or Award Fees}

Contract types are grouped into two broad categories: fixed-price contracts and costreimbursement contracts. According to the FAR part 16,

the specific contract types range from firm-fixed-price (FFP), in which the contractor has full responsibility for the performance costs and resulting profit (or loss), to cost-plus-fixed-fee, in which the contractor has minimal responsibility for the performance costs and the negotiated fee (profit) is fixed. (FAR, 2011, subpart 16.101)

The sample of contracts we reviewed consisted of all FFP contracts, consequently rendering the chi-squared test as invalid, as shown in Table 3. The types of services that we evaluated were all highly commercialized and well-defined. Thus, the FAR (2011) subpart 16.201 states that the contracting officer shall use FFP or fixed-price economic price adjustment 
contracts when acquiring commercial items. As well, FFP contracts should be used when the risk involved is minimal or can be predicted with an acceptable degree of certainty; however, in situations where the risk for the contractor is high and a reasonable basis for firm pricing does not exist, other contract types should be considered (FAR, 2011, subpart 16.103). As expected, FFP is the preferred method for requirements that are well-defined and can be easily measured, such as the four types of services we evaluated in this study, because FFP contracts decrease the risk for the government and increases the risk for contractors. Because our data showed all FFP contracts, the results indicate that there is no relationship between the type of service and contract type presented in this data.

Incentive or award fee refers to whether or not an incentive or award fee was used in the contract to motivate contractors. All the contracts we evaluated did not include incentive or award fees except for one; as a result, the chi-squared test was invalid. The one contract that did include an award term was for a 10-year dining facilities contract, a service type $\mathrm{S}$ contract. The fact that there was only one contract that utilized an award term fee out of 154 contracts we reviewed confirms the null hypothesis that there is no relationship between the types of services used and the use of incentive or award fees in the acquisition process. Incentive or award fees require additional resources and might discourage contracting offices from using them. They also require a higher level of contracting expertise, and many offices may not have enough qualified personnel to administer them. Additionally, there is little risk and uncertainty in these four types of commercial services. They do not require extra consideration to incentivize suppliers compared to a research-and-development type service, where a cost-reimbursable contract with an award or incentive fee to take on high risk and uncertain types of work may be considered. Contractors have no incentive to innovate without incentive or award fees. They should be used only when there are possibilities for the contractor to be innovative in satisfying contract requirements.

We recommend that future procurements that involve recurring or non-severable services utilize the exercising of an option as an incentive to motivate contractors. This will steer organizations away from exercising options at end of year just to eliminate the administrative burden of awarding another contract. It may be beneficial to conduct future studies to analyze cost-reimbursable contracts in these four service types and determine 
whether there are any reasons for or benefits to using cost contracts or incentives or award fees for these types of services.

\section{Contract Value}

The average base value of contract by service type, as illustrated in Figure 17, shows that the average base value of service type S contracts (Utilities and Housekeeping Services) are significantly more than the other three types of services. Typically, services for utilities and housekeeping are annual services versus the non-recurring services that may exist for one month in the other three types of services we evaluated. Furthermore, the contract for utilities and housekeeping typically supports the needs of the whole military installation, which results in higher costs. A good portion of service type $\mathrm{S}$ contracts are not competed because of the required use of AbilityOne contractors or specific utility providers, which potentially drive up costs. The chi-squared test resulted in a $p$ value less than 0.05 ; therefore, we rejected the null hypothesis, as illustrated in Table 3, and disproved that there is no relationship between service type and contract value.

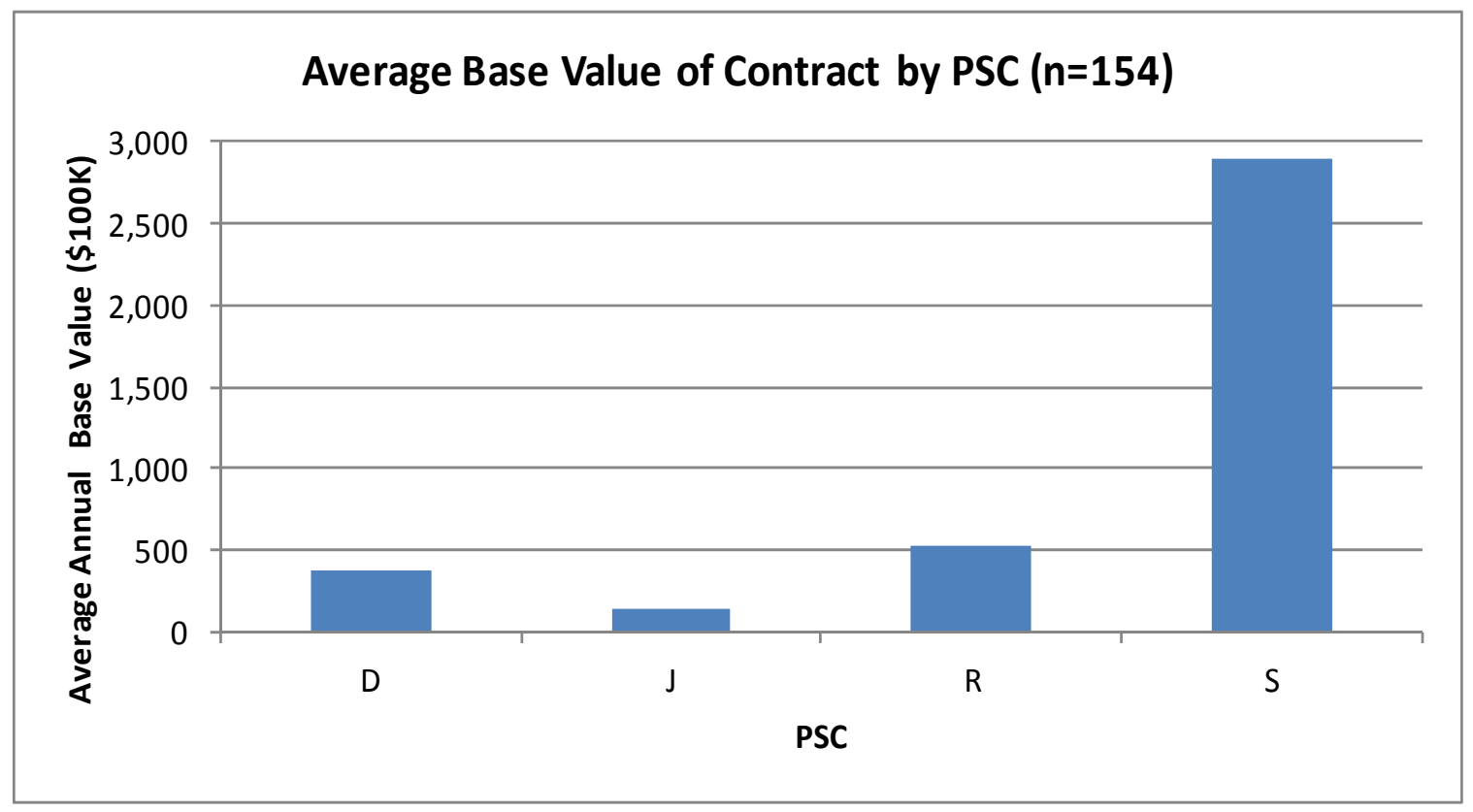

Figure 17. Average Annual Base Value of Contracts by Service Type

\section{Number of Modifications}

In the sample of contracts we evaluated, there were a total of 570 modifications. The types of modifications we observed included supplemental agreements, novation agreements, 
termination of contracts, administrative changes, funding changes, and the exercising of options. Service type R and S contracts had a total of 423 modifications, which is significantly higher than the total number of modifications for service types $\mathrm{D}$ and $\mathrm{J}$, as illustrated in Figure 18. We expected this high number, considering contracts for service types $\mathrm{R}$ and $\mathrm{S}$ are usually services recurring for mutiple years compared to service types $\mathrm{D}$ and $\mathrm{J}$ that are typically severable or non-recurring. However, Figure 18 shows that the percentage of modifications that were made to exercise an option were greater for service types $\mathrm{D}$ and $\mathrm{J}$. This result was not expected considering service types $\mathrm{D}$ and $\mathrm{J}$ are typically severable services. Additionally, Figure 18 reveals that the percentage of administrative changes were significantly high for service types $\mathrm{D}$ and $\mathrm{J}$. The percentage of funding modifications was higher for service type $\mathrm{S}$, which is most likely due to the type of contract used. Based on the number of modifications, we can assume that service type $\mathrm{S}$ contracts have many requirements or use indefinite delivery indefinite quantity (IDIQ) contracts in which funding is added whenever a task order is executed off the basic contract.

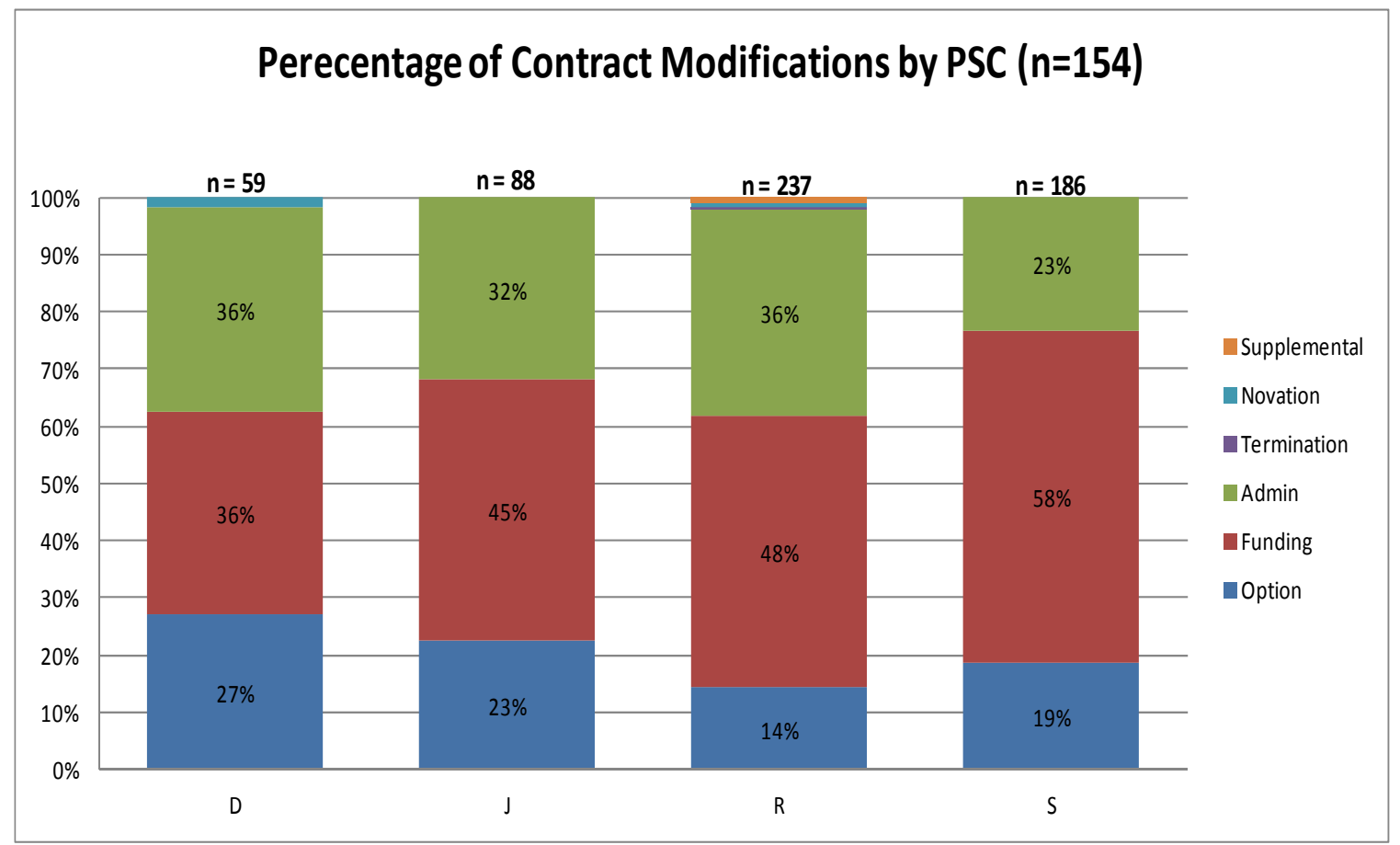

Figure 18. Percentage of Modifications for Contracts by Service Type

The $p$ value, shown in Table 3, is less than 0.05 ; therefore, we reject the null hypothesis. Accordingly, the data suggests that there is a relationship between service type and the number of and reasons for modifications. However, there is a limitation in the data 
analysis for this particular chi-squared test because there were fewer than five observations in a few cells of the contingency table. An accepted validation for a chi-squared statistic derived from a contingency table is that the "expected cell frequencies should satisfy the rule of five" (Keller, 2009 p. 591). While this particular calculation did not satisfy this rule, we determinined that this particular category warranted further analysis. As a result, there could be numerous reasons for this observation; however, there is no way to show causation with the data collected.

We recommend that MICC offices further evaluate this statistic to determine whether there is any potential for reducing the number of modifcations for service type $\mathrm{R}$ and $\mathrm{S}$ contracts to ease unecessary burdens on contracting personnel. The restructuring and management practices of the MICC centers normally drive administrative changes, and if not managed correctly these changes increase the workload for contracting personnel, which are valuable resources. In order to avoid numerous modifications that could drive up costs, requirements should be defined as early and as clearly as possible during the acquisiton planning phase. Although the data suggests a relationship between service type and the number of modifications, other factors not related to service type might share a relationship with the number of contract modifications.

\section{Award Basis or Contractor Selection Process}

Award basis refers to the strategy used to select which contractor receives the contract award. The categories for the award basis or contractor selection process include full and open competition (LPTA and best value tradeoff) and sole source (e.g., AbilityOne, direct award to small business set-asides, only one provider, and unusual and compelling urgency). The chi-squared test revealed a $p$ value less than 0.05 ; therefore, we reject the null hypothesis suggesting that there is a relationship between service type and award basis. Figure 19 summarizes the percentage of award basis type used for the observed service type contracts. An LPTA contract was used more frequently for all service types; however, the data in Figure 19 shows that an LPTA was used at least $50 \%$ of the time for service types D and J. Additionally, Figure 19 illustrates that direct awards to small business set-asides exist regardless of the service type, and that there is a relationship between AbilityOne programs and service type S. The figure also shows that a best value tradeoff determination that 
includes evaluation of price and non-price factors for award was used more for service types $\mathrm{D}$ and $\mathrm{R}$.

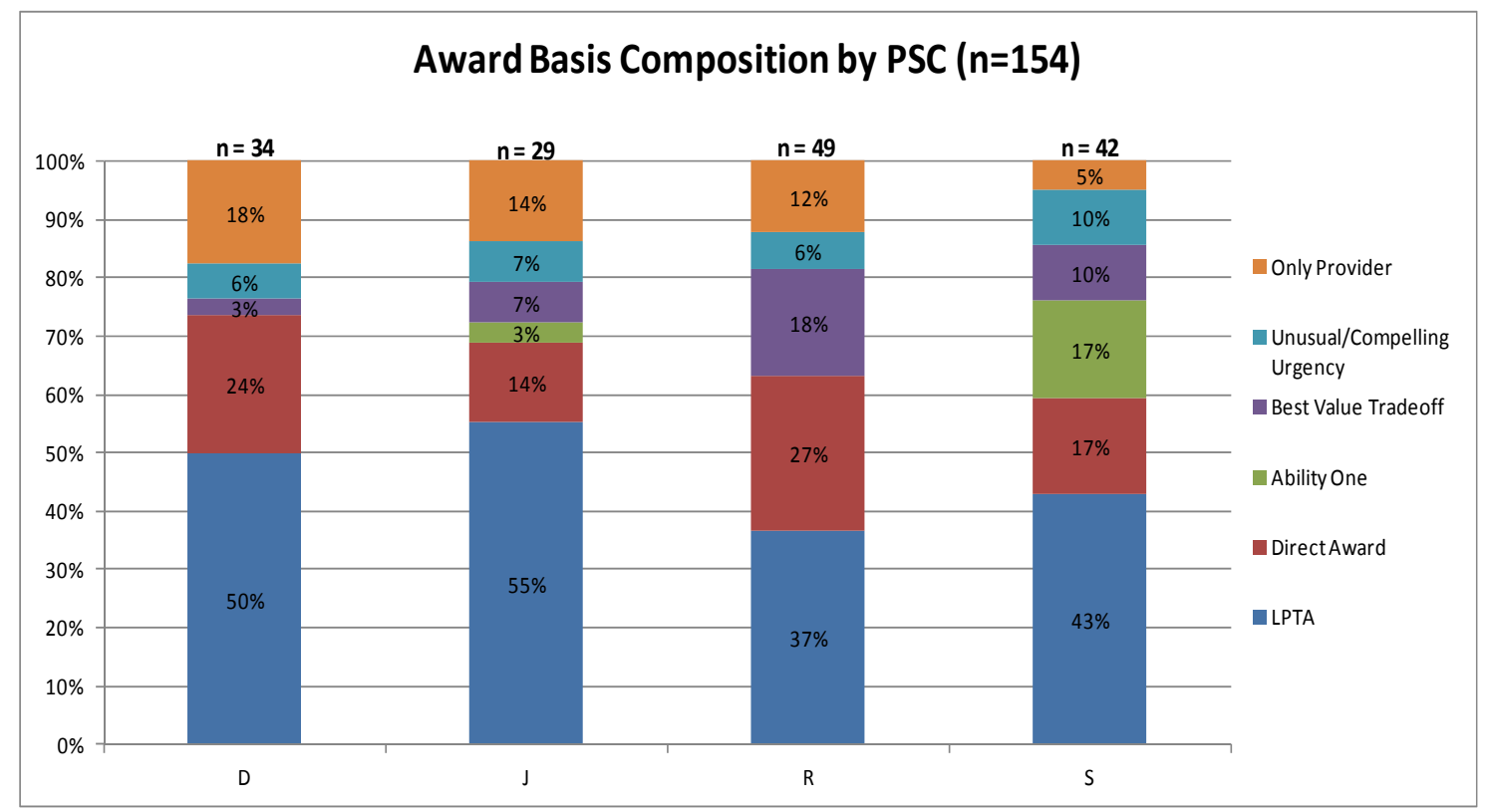

Figure 19. Composition of Award Basis by Service Type

All the contracts we observed that were solicited through full and open competition were awarded based off of an LPTA or best value tradeoff. Nevertheless, an LPTA was the preferred method over best value tradeoff because the majority of the requirements were well-defined, and the best value was expected to result from the selection of the technically acceptable proposal with the lowest evaluated price.

Due to the large amount of sole-source procurements we observed in this sample, we took a deeper look to see if contract files included documentation of price fair and reasonableness as required by both law and the FAR. Types of sole-source acquisition justifications that we observed in this research were AbilityOne, direct award to small business set-asides, only one provider, and unusual and compelling urgency. In order to determine whether fair and reasonable pricing was considered for all sole-source requirements, we reviewed the contract file to see whether an independent government estimate (IGE) or a pricing analysis was documented in the file. Figure 20 reveals that 50\% of the requirements that were considered sole source had no determination of price fair and reasonableness located in the contract file. The MICC offices should further investigate this practice, because determining fair and reasonable pricing is required regardless of the sole- 
source justification. This statistic shows that this practice may be resulting in increased costs for these types of services.

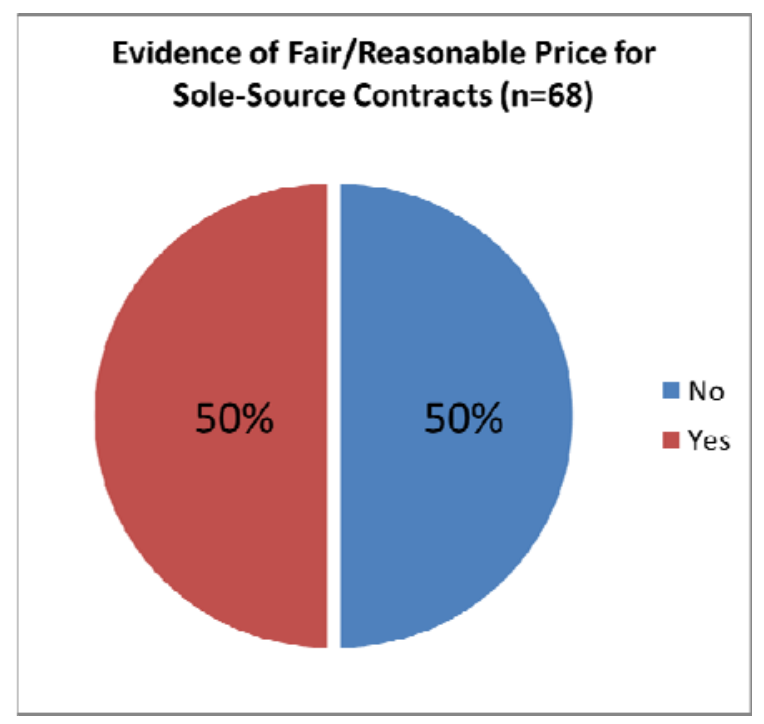

Figure 20. Evidence of Price Fair and Reasonableness of All Sole-Source Contracts

As we discussed previously in Section B, Subsection 1, sole-source justifications should be reduced significantly to align installation level goals, such as promoting real competition, with that of the USD(AT\&L). Even though circumstances permit other than full and open competition (i.e., sole source), the MICC offices should compete all requirements to the maximum extent practicable, which may result in cost savings.

\section{SERVICE TYPE AND MANAGEMENT PRACTICES}

For our second research question, we focus on whether a relationship exists between service type and management practices, as illustrated in Figure 21. 


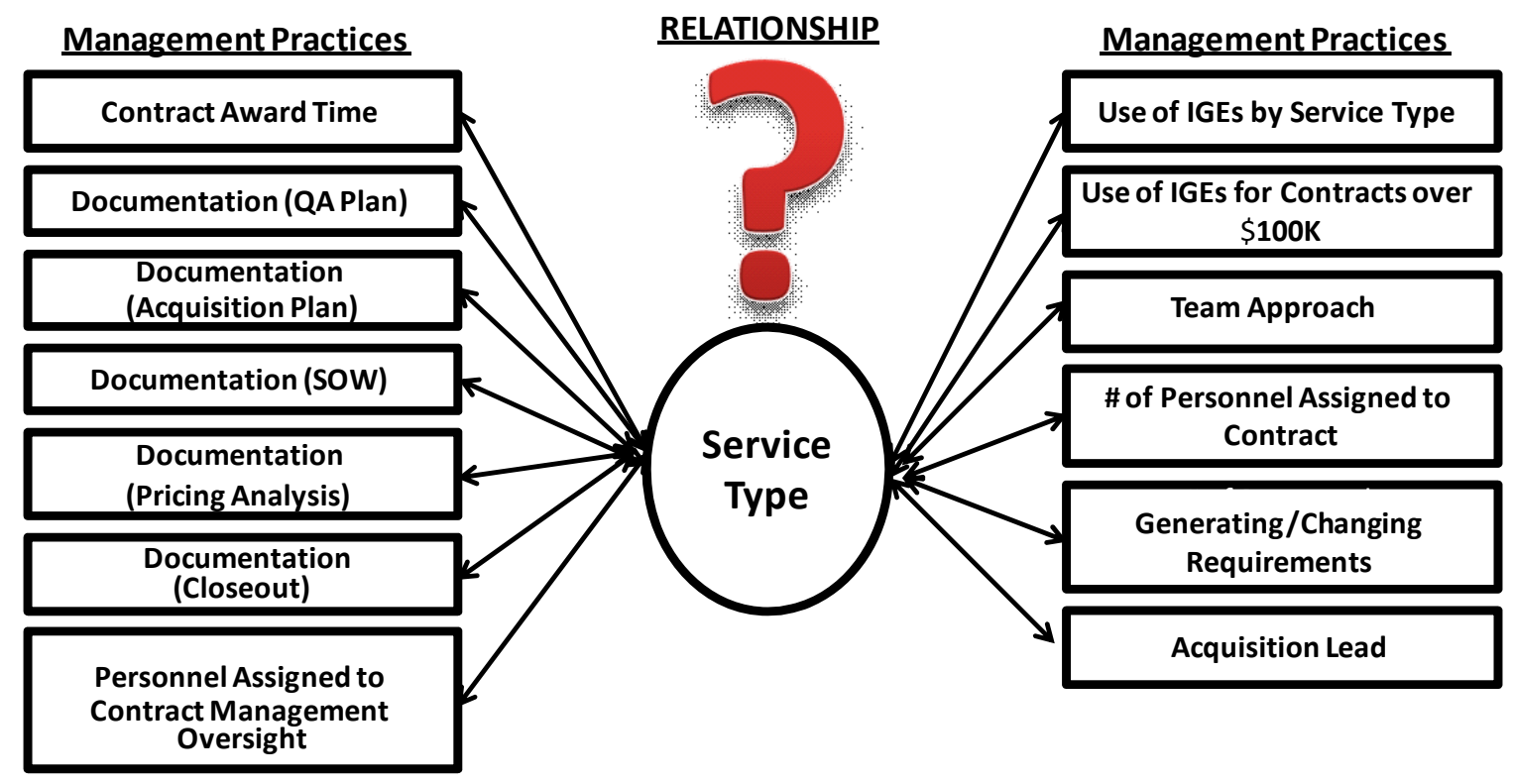

Figure 21. Assessment of Relationship Between Service Type and Management Practices

The majority of management practices we evaluated show no evidence of a relationship between the two factors. Specifically, the data disproves that there is no relationship between service type and the following management practices: the use of IGEs, the use of IGEs provided for contracts based on contract value, the number of personnel assigned to a contract, the contracting lead for the requirement, and the use of a quality assurance surveillance plan (QASP). A summary of the chi-squared test results between service types and management practices are presented in Table 4 . 


\section{Table 4. Chi-Square Hypothesis Testing Results Between Service Type and Management Practices}

\begin{tabular}{|c|c|c|c|c|}
\hline Factor 1 & Factor 2 & P-value & Significance & $\begin{array}{l}\text { Reject Null } \\
\text { Hypothesis }\end{array}$ \\
\hline Service Type & Use of IGEs by Service Type & 0.0068 & $<0.05$ & Yes \\
\hline IGE & Use of IGEs for Contracts over $\$ 100 \mathrm{~K}$ & 0.0002 & $<0.05$ & Yes \\
\hline Service Type & \# of personnel assigned to contract & 0.0449 & $<0.05$ & Yes \\
\hline Service Type & $\begin{array}{l}\text { \# of personnel generating/changing } \\
\text { requirements }\end{array}$ & 0.0822 & $>0.05$ & No \\
\hline Service Type & $\begin{array}{c}\text { \# of Personnel Assigned to Contract } \\
\text { Management Oversight }\end{array}$ & 0.1695 & $>0.05$ & No \\
\hline Service Type & Team Approach & 0.3142 & $>0.05$ & No \\
\hline Service Type & Acquisition Lead & 0.0076 & $<0.05$ & Yes \\
\hline Service Type & Contract Award Time & 0.1127 & $>0.05$ & No \\
\hline Service Type & Documentation (Acquisition Plan) & 0.5665 & $>0.05$ & No \\
\hline Service Type & Documentation (PWS/SOW) & 0.6909 & $>0.05$ & No \\
\hline Service Type & Documentation (Pricing Analysis) & 0.5391 & $>0.05$ & No \\
\hline Service Type & Documentation (PNM) & 0.0871 & $>0.05$ & No \\
\hline Service Type & Documentation (QASP Plan) & 0.0115 & $<0.05$ & Yes \\
\hline Service Type & Documentation (Closeout Letter) & 0.4676 & $>0.05$ & No \\
\hline
\end{tabular}

\section{Use of Independent Government Estimates by Service Type and Use of Independent Government Estimates for Contracts Over \$100,000}

The data indicate that the use of IGEs was low for all four types of services, as illustrated in Figure 22. The $p$ value presented in Table 4 is less than 0.05 ; therefore, we rejected the null hypothesis and disproved that there is no relationship between service type and whether or not an IGE was provided. As illustrated in Figure 22, about 50\% of contracts for all service types did not have an IGE, which is troubling, considering that 68 out of 154 contracts were sole-sourced, as discussed previously in Section B, Subsection 1.

Through further analysis of this data, we show that there is a relationship between the use of IGEs and the dollar value of the contracts, as shown in Figure 23. When testing the relationship between an IGE that was provided and the contract value, we determined that the $p$ value was less than 0.05 ; therefore, we rejected the null hypothesis. This $p$ value suggests a relationship between the use of IGEs and contract value. Furthermore, based on our analysis 
in Section B, Subsection 3, we suggest that there is a relationship between contract dollar value and service type; therefore, the data also implies that there is an indirect relationship between service type and the use of IGEs. Per Army Regulation (AR) 70-13, an IGE is required for all contracts that exceed the simplified acquisition threshold (SAT; Department of the Army, 2010, p. 7). At the time of McFall and La's (2011) study, the simplified acquisition threshold was $\$ 100,000$ but has since been increased to $\$ 150,000$. In order to maintain data integrity, we used the $\$ 100,000$ threshold. Figure 23 illustrates that $62 \%$ of the contracts over $\$ 100,000$ did have an IGE in the contract file. However, this percentage is low considering the requirement to provide an IGE per AR 70-13. We recommend MICC offices further analyze the causes for the lack of an IGE in contract files, and the impact on acquisition performance.

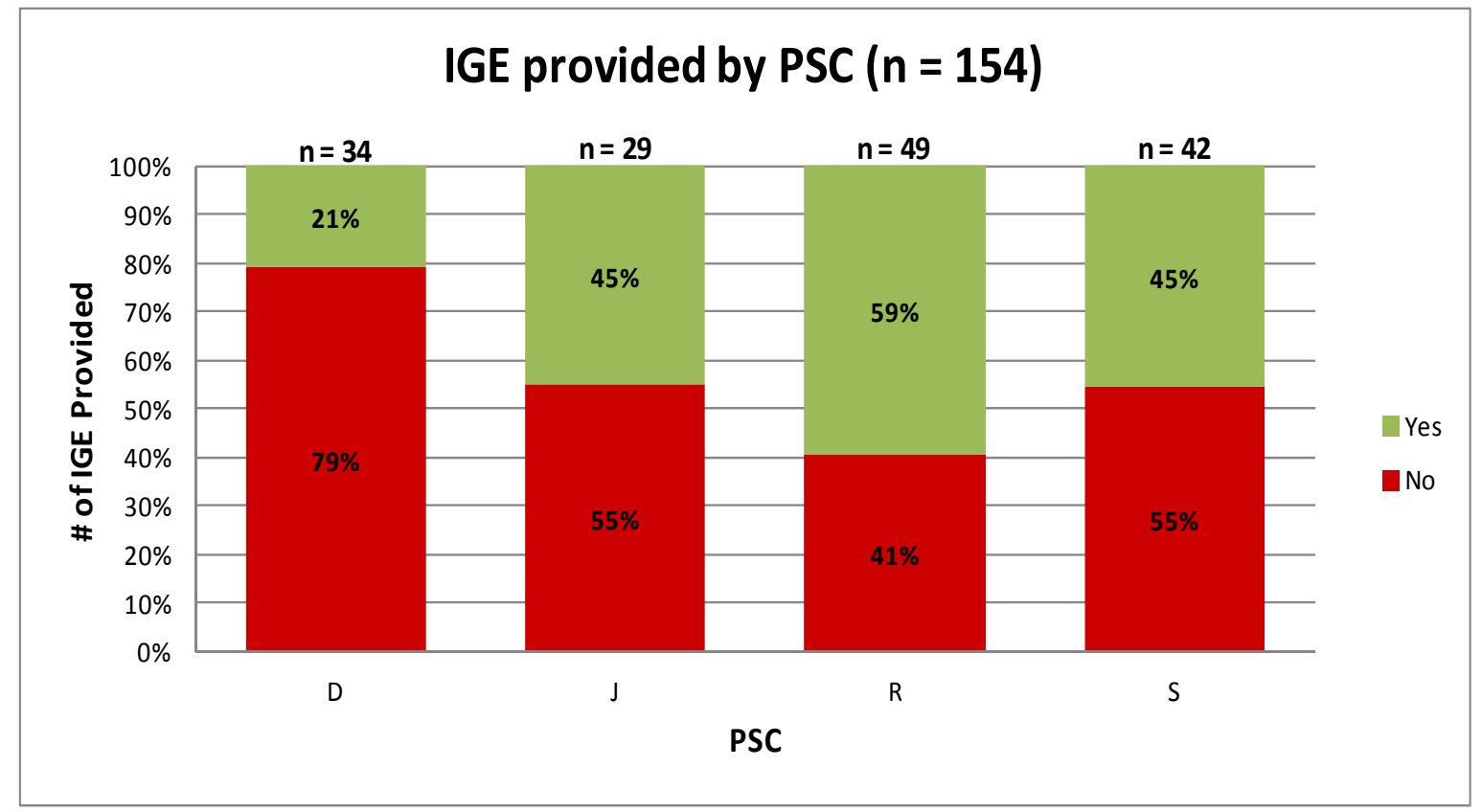

Figure 22. Percentage of IGEs Provided by Service Type 


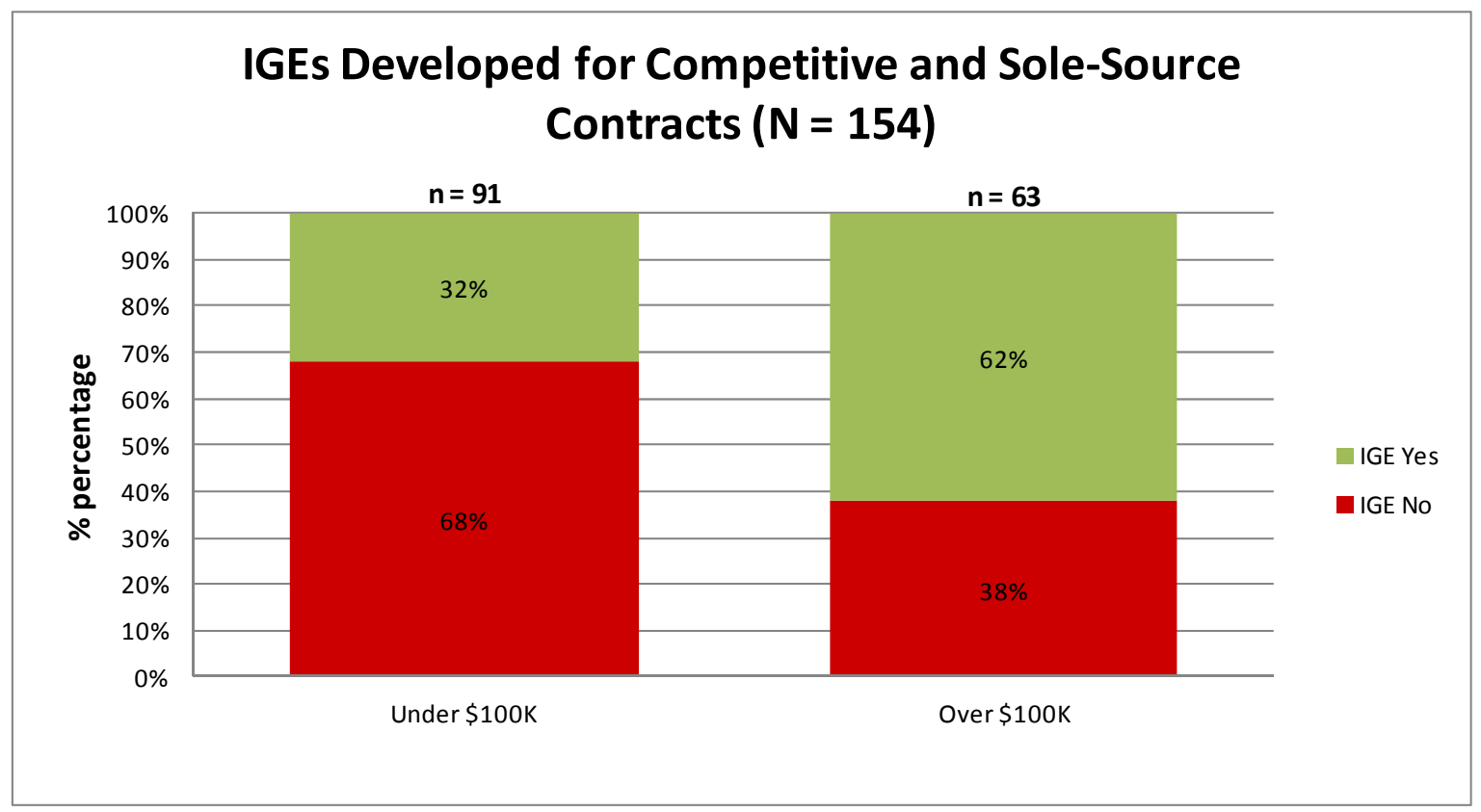

Figure 23. IGEs Provided for Contracts Over or Under \$100,000

\section{The Number of Personnel Assigned to a Contract and the Number of Personnel Generating or Changing Requirements}

We evaluated contract files to determine how many personnel were assigned to contracts, their respective positions, and which personnel generated requirements or changes to those requirements. Personnel included in our review were contracting officers, contracting specialists, customers, contracting officer representatives (COR), and quality assurance evaluators (QAE). During our research, we observed that program managers were non-existent at all the MICC offices. A 2011 GAO report emphasized the need for the involvement of a program manager to initiate services acquisitions (GAO, 2011). The lack of program managers highlights potential problems, especially for large complicated services acquisitions, that may develop into major issues in the future as the need for services in the DoD continues to grow. It is also important to note that we found it difficult to discover exactly which personnel assigned to a contract evaluated the performance of the contractor because each installation managed the filing and storing of contract documentation in different ways. For example, one office stored files electronically, while other offices that maintained hard-copy documentation did not organize and file documents in the same manner. Based on our data, we suggest that the contents of many contract files did not meet 
guidelines found in the FAR (2011) part 4 (Administrative Matters), hindering our ability to objectively evaluate each file.

Based on the results of the chi-squared test for this section, we reject the null hypothesis, which indicates that there is a relationship between service type and the number of personnel assigned to a contract. The average number of personnel assigned to contracts was high for service types R and S, which may have contributed to the fact that these services typically have longer durations and usually involve a much larger scope, such as for an entire installation. However, the number of personnel assigned to a contract appeared to be driven more by the standard practices of the MICC centers we observed. Typically, most centers followed a standard practice of assigning a contracting officer and contracting specialist to a requirement for pre-award activities, and a contracting officer, contracting specialist, and COR or customer for the post-award activities. Therefore, we argue that service type does not have a relationship with the number of personnel assigned as much as the standard practices of a particular contracting office.

Additionally, we performed a chi-squared test to determine whether a relationship existed between service types and the number of personnel generating or changing requirements. The resulting $p$ value was greater than 0.05 ; therefore, we could not reject the null hypothesis, suggesting there is no relationship between the two factors. However, McFall and La (2011) found that there is a relationship between service types and the number of modifications, as we discussed in Section B of this chapter. McFall and La (2011) suggested that the customer or the contracting office may be generating and changing a requirement, which drives whoever develops initial or new requirements. Therefore, agreeing with McFall and La, we suggest an indirect relationship between service type and the number of personnel generating or changing requirements because service type may drive the number of modifications.

\section{The Number of Personnel Assigned to Contract Management Oversight}

Contract management oversight is defined as the duties and responsibilities assigned to personnel for post-award functions in an effort to monitor contactor performance and provide oversight of the contractor. The chi-squared test in Table 4 indicates that there is no relationship between the number of personnel assigned to contract management oversight 
and service type. This observation differs from McFall and La's (2011) calculations and could be the result of a larger sample. Their sample included only 40 contracts, and in our study we combined their 40 contracts with the 114 that we evaluated. This result is not surprising because we expect characteristics such as dollar value, complexity, and scope of the contract to determine the number of personnel assigned to contract management oversight.

\section{Team Approach}

We reviewed contract files to analyze whether a team approach was used in services acquisitions. We considered factors, such as memorandums for record, signature blocks on documents, and documented email correspondence, to determine whether multiple parties were involved during pre-award and post-award activities and these parties had an understanding of roles and responsibilities. The team approach concept includes personnel from contracting, finance, legal, industry and the requiring activity. As a best practice, ideally, a team approach should be used, regardless of service type (Rendon \& Snider, 2008). Based on the calculation shown in Table 4, which used the chi-squared test, we do not reject the null hypothesis; therefore, we suggest that there is no relationship between service type and whether a team approach was used. The data we observed shows that only 93 out of the 154 contracts we evaluated had evidence of a team approach in the contract files, even though the use of a team approach is required per AR 70-13 (Department of the Army, 2010, p. 1). Thus, there is cause for concern, considering only $60 \%$ of the contract files were compliant.

\section{Acquisition Lead}

As previously discussed in section $\mathrm{C} 2$, a program manager was not identified in any of the reviewed contracts. At the operational level, the contracting officer is typically assigned or assumed to act as the acquisition lead because there is no one else available. Out of the 154 contracts we evaluated, we clearly identified the contracting officer as the acquisition lead for 146 of the contracts, with the contracting specialist as the acquisition lead for the remaining eight. We rejected the null hypothesis for this comparison, which demonstrated a relationship between service type and the individual designated as the 
acquisition lead. Because there are very few, if any, program managers at the operational level, we expected this finding. However, if reliance on services continues to grow and the DoD continues to seek ways to improve efficiency for services, including program managers at the installation level may be an area of further research to determine the impact the position would have on the acquisition process.

\section{Contract Award Time}

The time it takes for a contracting office to award a contract after receipt of the purchase request is called the standard procurement administrative lead-time (PALT). The PALT for this study is defined as awarding contracts within 60 days. Chi-squared testing (see Table 4) revealed no relationship between contract type and the PALT for requirements evaluated. Figure 24 shows that service type D met PALT $68 \%$ of the time, service type S met PALT $40 \%$ of the time, and service types $\mathrm{J}$ and R met PALT roughly $50 \%$ of the time. The lack of evidence to support a relationship between service type and PALT may be a result of manning issues, customer relationships, or receiving timely inputs from customers. Other factors may exist that potentially affect the award time for contracts that are not related to service type. For example, award times may be driven by such factors as the workforce workload and availability of funds, which are not related to service type. 


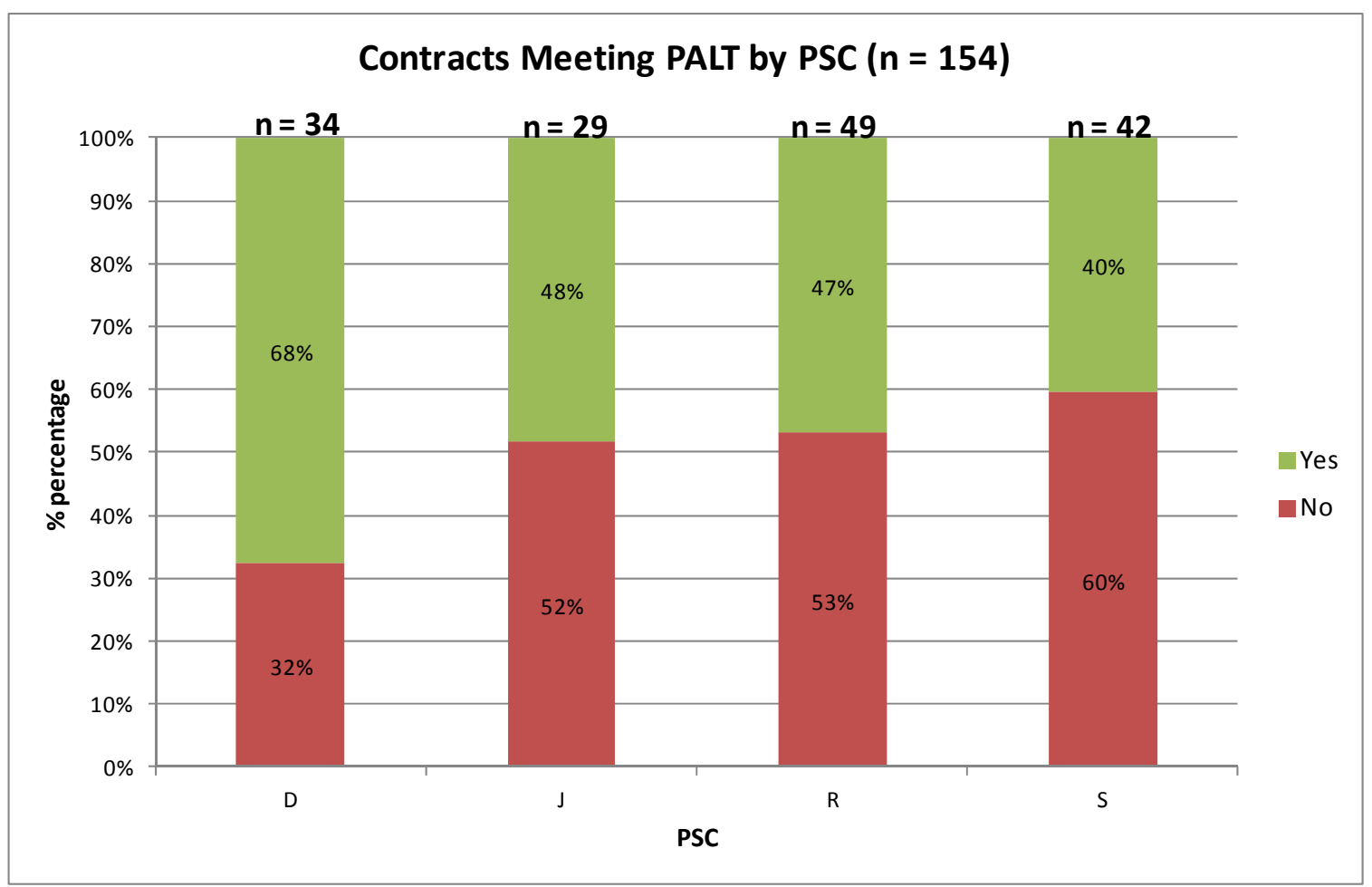

Figure 24. Contracts Meeting PALT by Service Type

\section{Documentation}

During the data collection process, we determined whether the following contract documents were filed: acquisition plan, performance work statement (PWS) or statement of work (SOW), pricing analysis, price negotiation memorandum (PNM), quality assurance surveillance plan (QASP), and contract closeout letter. We performed a chi-squared test for each document type, and the only document rejecting the null hypothesis and appearing to have a relationship with service type was the QASP. However, there was no indication of a relationship between the other documentation and service types. Figure 25 reveals that the majority of contract files we reviewed lacked the specific documentation noted above. For instance, out of 154 contracts, $73 \%$ included a PWS or SOW, and only $40 \%$ had an acquisition plan. Additionally, only $11 \%$ of the contracts that were closed out included a closeout letter. Due to time constraints and workload, the filing of a closeout letter was not a priority across the board. We suppose from these findings that important contract documentation, which are standard requirements for contract files and are used to protect the government's interests, especially a service contract, was either missing or not completed. 
Other factors may impact contract file documentation as well. For example, even though required, the QASPs may not be included in the contracting office's files, but they may be maintained with the COR's or QAE's files. Therefore, MICC offices must emphasize pre-award and post-award documentation to satisfy all requirements, not just the procurement of the service in order to protect the government's interests. This is an area of concern, and management should conduct further analysis to determine whether documentation is missing or incomplete and to ascertain its impact on the acquisition process.

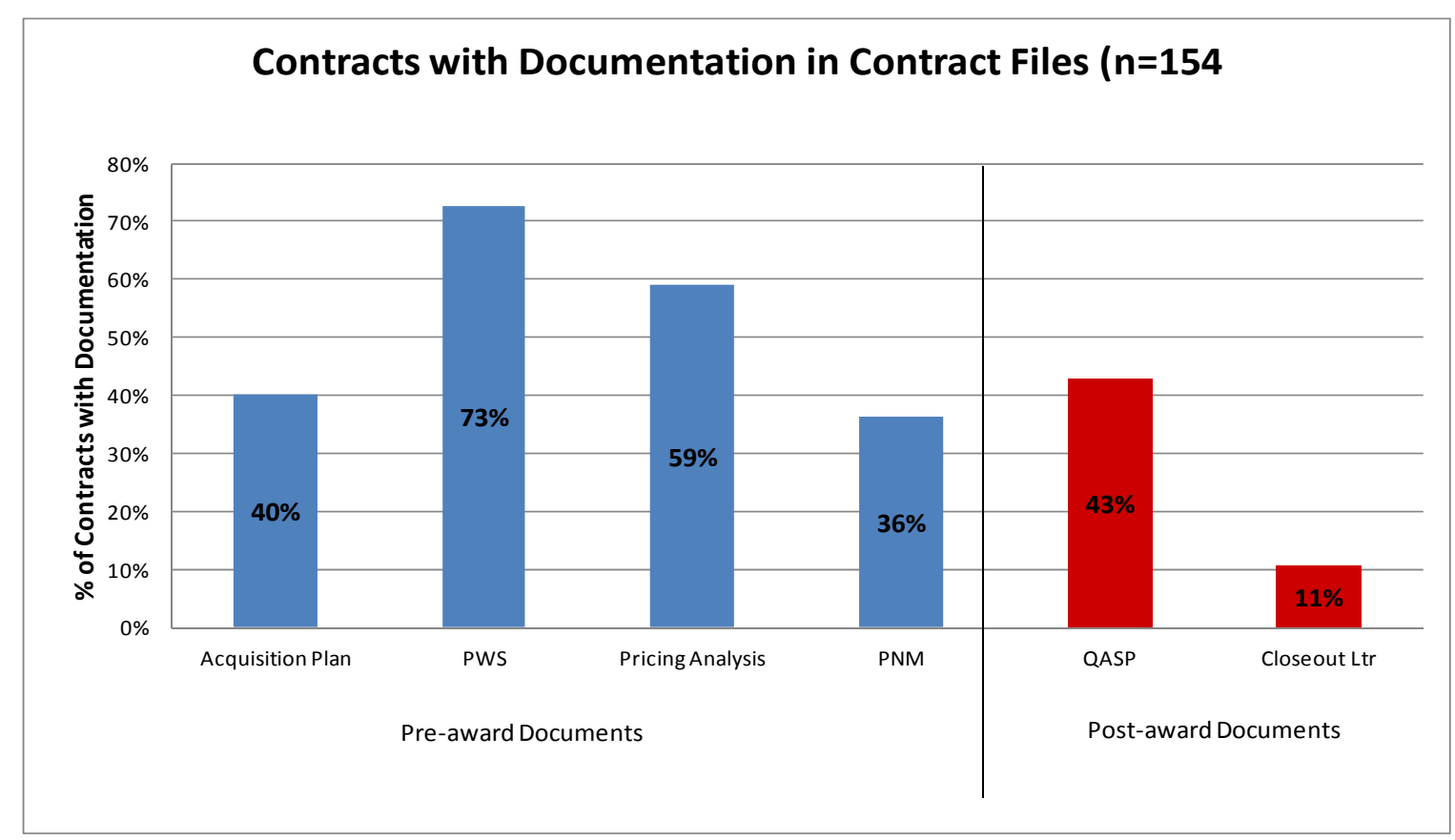

Figure 25. Percentage of Contract File Documentation Found in Contract Files

\section{CAPACITY AND MANAGEMENT PRACTICES}

In our third and final research question, we focused on whether the capacity for carrying out acquisition-related work affects the management practices the MICC offices employ. To have effective capacity, an organization needs an appropriate amount of billets that are filled with personnel that are properly trained. It is beneficial for organizations to ensure that personnel filling billets are well-trained, rather than simply to ensure that all billets are filled. Effective capacity is not realized if billets are filled with personnel that are not properly trained. Without effective capacity, an organization is not assured of getting the best value in its contracts and achieve adequate protection of government's interests. 
In order to determine whether a relationship exists between capacity and management practices, we used Part II of the data collection form developed by McFall and La (2011), found in Appendix A, to collect administrative data from each office. The data we present in this section includes the data collected by McFall and La and data from five of the six offices visited for this study, for a total sample size of seven offices. One office, MICC Office B, was unable to provide the data requested for this section. Because of the small sample size, we used descriptive statistics to evaluate the relationship between capacity and management practices. The capacity categories examined were as follows:

- $\quad$ dollar value by service type;

- number of billets for contracting officers, contracting specialists, program managers, and COR/QAE-authorized and number filled-billets;

- Defense Acquisition Workforce Improvement Act (DAWIA) certification levels for acquisition workforce;

- number of years of experience of the acquisition workforce; and

- $\quad$ average number of contracts the acquisition workforce managed.

A total of $\$ 1.795$ billion was obligated in FY 2010 by these seven offices for the four service contract types observed in this study, a significant dollar amount for seven out of 36 MICC offices and DOCs across the country. Service type R (Professional, Administrative, and Management Support Services) and service type S (Utilities and Housekeeping Services) accounted for $87.4 \%$ of the total contracts. As we discussed in Chapter II, the four PSCs selected for this study accounted for over $60 \%$ of the service contracts utilized across Army installations (McFall \& La, 2011). The high percentage for service types $\mathrm{R}$ and $\mathrm{S}$ indicates a significant reliance on these two particular service types. This high percentage also implies that the majority of resources the acquisition workforce spent revolved around $\mathrm{R}$ and $\mathrm{S}$ type service contracts, which we view as vital components to daily operations across Army installations. For the four service types observed in this study, the total dollar value, the total number of contracts awarded, and the average service contract dollar value for each MICC office are shown in Table 5 . 
Table 5. FY 2010 Service Contracts Awarded

\begin{tabular}{|c|c|c|c|c|c|c|c|}
\hline & $\begin{array}{c}\text { MICC } \\
\text { Office A } \\
\end{array}$ & $\begin{array}{c}\text { MICC } \\
\text { Office C } \\
\end{array}$ & $\begin{array}{c}\text { MICC } \\
\text { Office D } \\
\end{array}$ & $\begin{array}{c}\text { MICC } \\
\text { Office E } \\
\end{array}$ & $\begin{array}{c}\text { MICC } \\
\text { Office F }\end{array}$ & $\begin{array}{c}\text { MICC } \\
\text { Office G }\end{array}$ & $\begin{array}{c}\text { MICC } \\
\text { Office H }\end{array}$ \\
\hline $\begin{array}{l}\text { Total Dollar Value of } \\
\text { Service Contracts } \\
\text { Awarded (R, D, S, \& J) }\end{array}$ & $\$ 17,435,363$ & $\$ 38,361,394$ & $\$ 931,231,325$ & $\$ 316,000,000$ & \multirow{3}{*}{$\begin{array}{l}\text { Data Not } \\
\text { Available }\end{array}$} & $\$ 293,000,000$ & $\$ 301,000,000$ \\
\hline $\begin{array}{l}\text { Total Number of } \\
\text { Service Contracts } \\
\text { Awarded (R, D, S, \& J) }\end{array}$ & 76 & 766 & 542 & 226 & & 350 & 804 \\
\hline $\begin{array}{l}\text { Average Dollar Value } \\
\text { per Service Contract }\end{array}$ & $\$ 229,413$ & $\$ 50,080$ & $\$ 1,718,138$ & $\$ 1,398,230$ & & $\$ 838,000$ & $\$ 374,000$ \\
\hline
\end{tabular}

Based on our data, with the amount of dollars obligated by these offices, the majority of offices do not appear to have the necessary number of contracting officers and contracting specialists authorized to handle this sizable workload. The billets for warranted contracting officers and contracting specialists averaged an $89 \%$ fill rate, with a range of $57 \%$ to $100 \%$. For contracting specialists, the average fill rate was $81 \%$, with a range of $47 \%$ to $117 \%$. While some MICC offices have the authorized number of personnel filling these acquisition roles, the majority does not. Based on the number of filled billets and the number of contracts obligated, acquisition personnel are individually managing 7.8 service contracts, on average. If authorized billets were maintained at a 100\% fill rate, individual acquisition personnel would manage approximately 6.5 service contracts, on average. In this study, we focused on four specific service types and did not account for all procurement requirements the MICC offices handled. Therefore, this fill rate indicates that the MICCs are managing substantial workloads with limited personnel.

In addition, we looked at the number of acquisition personnel filling billets that required DAWIA Level I, II, or III certification, and whether or not certification was obtained. Out of the seven offices surveyed, only $31 \%$ of acquisition personnel holding a billet requiring DAWIA Level I certification were certified at that level. Acquisition personnel holding a billet requiring DAWIA Level II and Level III certification maintained a $70 \%$ and $72 \%$ certification rate, respectively. The data suggests that the acquisition personnel in these MICC offices do not have the proper education, training, or experience for the positions they hold. Based on the workload observed for just four service types and the shortage of personnel, we infer that certification may not have been achieved due to the time constraints placed on the current workforce, the vital nature of mission execution, and funding constraints. Also, the increase in the number of entrants to the DoD acquisition 
workforce and the amount of training required to reach Level I certification may also explain the low percentage of certified personnel.

Next, we observed the experience level of the contracting officers and contracting specialists in these MICC offices. In our questionnaire, we asked for the level of experience of these personnel based on the number of months worked in an acquisition position. The majority of offices have a higher percentage of personnel with at least three years of experience; however, the percentages are relatively low. Table 6 displays the results of the data collected in regards to occupation of billets, certification levels, and experience levels of the acquisition workforce.

Table 6. Office Capacity of MICC Offices Observed

\begin{tabular}{|c|c|c|c|c|c|c|c|c|}
\hline $\begin{array}{c}\text { Capacity } \\
\text { Category }\end{array}$ & $\begin{array}{c}\text { Capacity } \\
\text { Subcategories }\end{array}$ & $\begin{array}{c}\text { MICC } \\
\text { Office A }\end{array}$ & $\begin{array}{c}\text { MICC } \\
\text { Office C }\end{array}$ & $\begin{array}{c}\text { MICC } \\
\text { Office D }\end{array}$ & $\begin{array}{c}\text { MICC } \\
\text { Office E }\end{array}$ & $\begin{array}{c}\text { MICC } \\
\text { Office F }\end{array}$ & $\begin{array}{c}\text { MICC } \\
\text { Office G }\end{array}$ & $\begin{array}{c}\text { MICC } \\
\text { Office H }\end{array}$ \\
\hline \multirow{3}{*}{ Billets } & Warranted & $100 \%$ & $88 \%$ & $83 \%$ & $58 \%$ & $100 \%$ & $100 \%$ & $100 \%$ \\
\cline { 2 - 9 } & Non-warranted & $0 \%$ & $84 \%$ & $106 \%$ & $47 \%$ & $117 \%$ & $86 \%$ & $86 \%$ \\
\hline \multirow{3}{*}{ Certification } & DAWIA I & $23 \%$ & $13 \%$ & $23 \%$ & $8 \%$ & $0 \%$ & $2 \%$ & $0 \%$ \\
\cline { 2 - 9 } & DAWIA II & $162 \%$ & $24 \%$ & $16 \%$ & $54 \%$ & $66 \%$ & $66 \%$ & $68 \%$ \\
\cline { 2 - 9 } & DAWIA III & $100 \%$ & $27 \%$ & $33 \%$ & $118 \%$ & $0 \%$ & $32 \%$ & $32 \%$ \\
\hline \multirow{3}{*}{ Experience } & $<1$ year & $18 \%$ & $14 \%$ & $7 \%$ & $0 \%$ & $14 \%$ & $10 \%$ & $4 \%$ \\
\cline { 2 - 9 } & $1-2$ years & $18 \%$ & $43 \%$ & $12 \%$ & $1 \%$ & $23 \%$ & $3 \%$ & $2 \%$ \\
\cline { 2 - 9 } & $2-3$ years & $10 \%$ & $16 \%$ & $7 \%$ & $9 \%$ & $34 \%$ & $19 \%$ & $21 \%$ \\
\cline { 2 - 9 } & $>3$ years & $55 \%$ & $17 \%$ & $74 \%$ & $90 \%$ & $29 \%$ & $68 \%$ & $73 \%$ \\
\hline
\end{tabular}

Although approximately $60 \%$ of the personnel have more than 36 months of acquisition experience, over $40 \%$ do not. This finding suggests that the workforce, from the Army installation perspective, does not have the level of experience necessary to properly manage the considerable workload imposed on these offices. However, as displayed in Table 6 , there are instances in some MICC offices where billet and certification percentages are greater than $100 \%$, indicating excess personnel in that specific area.

Another area we looked at was the number of certified CORs and QAEs these offices managed; however, only two offices tracked this information. According to ACC Pamphlet 70-1 (2010), contracting officers are responsible for appointing properly trained CORs prior to awarding a contract. Additionally, they are required to track and evaluate the performance 
of CORs. The key role of the COR and QAE is to observe, document, inspect, and communicate contractor performance to both the contracting officer and contractor. The COR and the QAE are technical experts whose role is to ensure that the contractor meets all performance specifications. For example, the COR for an installation dining facility contract is typically an experienced food service technician who confirms whether the contractor is in compliance with dining facility operation regulations and guidelines. If a contract does not employ a COR with the proper technical background to manage the contract, then the government is not able to ensure that the contractor is in compliance with the terms and conditions of the contract, and thus the government's interests are not protected. The COR and QAE are vital to successful contract administration and serve as the eyes and ears of the contracting officer, and it is concerning that these pivotal personnel are not consistently tracked.

\section{E. SUMMARY}

In this chapter, we presented the data we collected from research and the associated findings from the analysis to answer the three research questions we proposed in this study. First, we suggested that some contract characteristics share a relationship with the type of service being procured. Second, we indicated that the type of service being acquired potentially influenced the management practices employed. Third, using administrative data collected from these seven offices, albeit a small sample out of the total population, we suggested that the capacity for carrying out acquisition-related work affected management practices within an office. 


\section{SUMMARY, CONCLUSION, AND AREAS FOR FURTHER RESEARCH}

\section{A. SUMMARY}

This research project was a continuation of McFall and La's 2011 pilot study, and we designed our study to conduct further research in services acquisitions. Our goal was to answer the three research questions related to acquisition in order to gain a better understanding of the drivers that affect management practices in services acquisitions. Ultimately, in this study we emphasize the need for determining new ways to improve performance in service contracting as services for the DoD continue to grow in scope, dollar amount and complexity. In this study, we intended to increase the sample size by collecting data from eight MICC offices, and we hope our research will serve as a template for future research.

In their pilot study, McFall and La (2011) laid the foundation for our research by establishing a model for assessing the acquisition of services of four prevalent PSCs, which were responsible for $60 \%$ of service contracts across Army installations. In the first three chapters of our research, we focused on providing background information to establish the need for this research. In our literature review, we discussed research published with regard to the DoD's acquisition management process and reform initiatives in order to discuss current and relevant sources that contribute to the basis of this research. We presented the historical and current organizational structure of Army contracting, as well as the impact of the Gansler Commission's findings on the establishment of the ACC.

Next, we presented our methodology for data collection and evaluation. We examined contracts at six MICC offices and collected information identified on the data collection form (Appendix A). We compiled our results with those of McFall and La (2011) and presented an analysis on whether a relationship existed between service type and certain contract characteristics and management practices. Additionally, we collected administrative data to observe whether the capacity for conducting acquisition-related work affects management practices. 


\section{B. CONCLUSION}

\section{Research Findings}

The three research questions are restated here:

- $\quad$ Do the contract characteristics differ for different types of services?

- $\quad$ Do the types of services being acquired affect the management practices being used?

- Does the capacity for carrying out acquisition-related work affect the management practices being used?

Our data suggests a relationship between service type and three contract characteristics and between service type and five management practices, as shown in Figure 26. We discuss the specific findings for each relationship in this section.

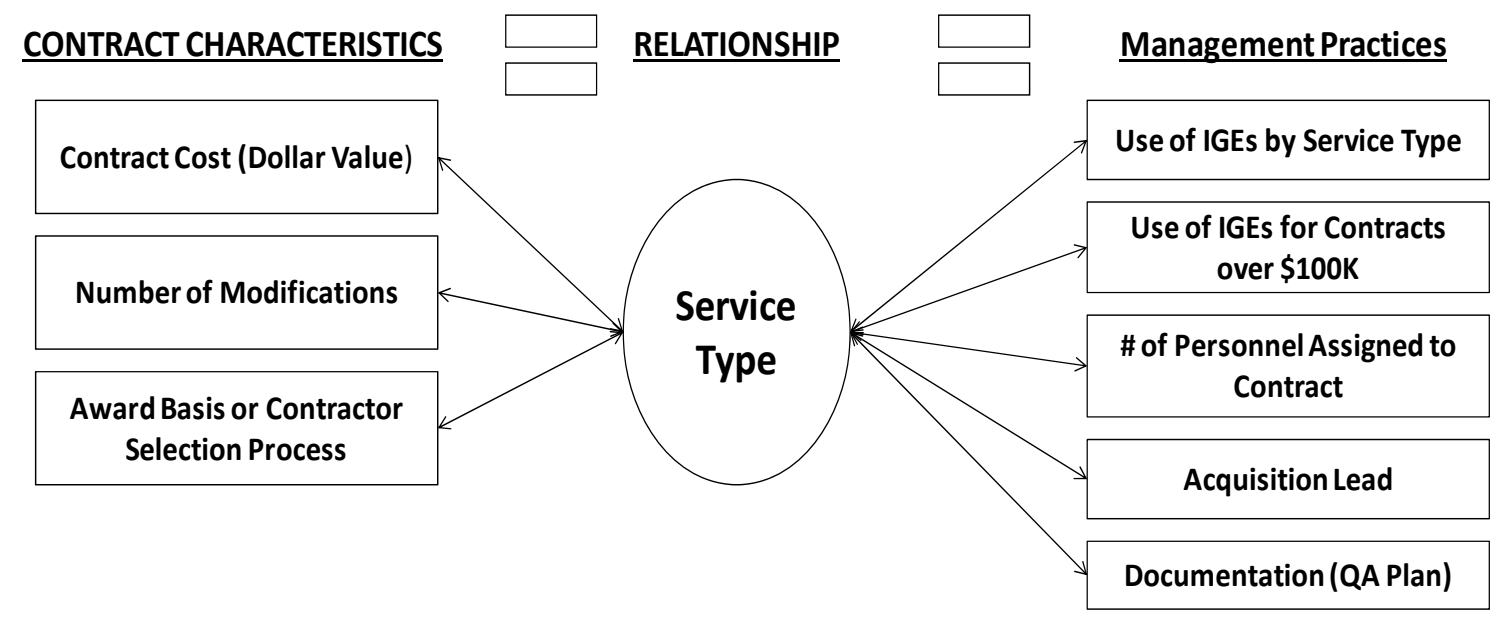

Figure 26. Diagram of Findings From Data Analysis

With regard to the first research question, out of the six characteristics we evaluated, the findings revealed a relationship between service type and three of the contract characteristics. The average annual contract cost for service type $\mathrm{S}$ was significantly higher than the other three service types evaluated. Additionally, the data revealed that the number of modifications applied to service types $\mathrm{R}$ and $\mathrm{S}$ were considerably larger than for service types $\mathrm{D}$ and J. The data also suggested a relationship between service type and the award basis or contractor selection. Service types D and J used LPTA selection approximately 50\% 
of the time, while service types $\mathrm{R}$ and $\mathrm{S}$ awarded contracts more frequently based on a best value tradeoff.

Overwhelming evidence did not exist to support the hypothesis that the six contract characteristics shared a relationship with service type; however, all the contracts we examined did share similar characteristics. We observed that every contract was awarded as FFP, only one contract utilized an incentive or award fee, and the use of competition in the solicitation process was not reliant on service type.

With regard to the second research question, our findings suggested a relationship between service type and five of the 14 management practices evaluated, as shown in Figure 26. The findings indicate a relationship between service types and the following management practices: the use of IGEs, the number of personnel assigned to a contract, the acquisition lead, whether or not a QASP was used, and whether or not an IGE was provided for contracts over the simplified acquisition threshold.

However, some management practices did not show a relationship to service types. Those management practices included the use of a team approach, the number of personnel generating or changing requirements, the number of personnel conducting contract management oversight, contract award time, and contract documentation. Accordingly, it appears that factors other than service type may share a stronger relationship with the management practices that we evaluated in this research.

Standard practices for awarding service contracts were common at all the MICC offices; however, most offices did not incorporate a standard contract filing system. For instance, most offices continue to maintain hard-copy files, while only one office maintained digital files. Regardless of storage method, documentation was either incomplete or missing from files at all locations, making data collection difficult.

Although each center employed different management practices, both centers followed standard practices for awarding service contracts. Even so, we must give consideration to the uniqueness of each center and its physical location, which influences the different management practices employed at each office.

Lastly, with regard to the third research question, we focused on the effect of capacity 
on management practices. The administrative data suggests that a relationship exists between capacity and management practices. For example, offices lacked the requisite number of authorized personnel to perform acquisition functions, and a majority of the personnel on hand lacked proper training certifications. On average, these offices handled a significant amount of service contracts, and, not factoring in other procurement requirements, the MICC acquisition workforce is managing substantial workloads with minimal personnel.

\section{Recommendations}

Based on our findings, we offer recommendations for the awarding of service contracts. With regard to contract characteristics, we have several recommendations based on the data presented. We suggest that MICC offices take a closer look at the justification for awarding sole-source service contracts. Although there are instances in which contracting offices are required by law or regulation to use particular sources, it is imperative to ensure that fair and reasonable prices are obtained. MICC offices need to further scrutinize their justifications to increase the use of competition in service contracts at all MICC offices. Additionally, the use of IGEs was lacking, although IGEs serve as a valuable tool for ensuring fair and reasonable pricing and thus protecting the government's interests.

We also recommend that future procurements that involve recurring or non-severable services utilize options or award terms, such as an incentive, to motivate contractors, instead of exercising options only to save time from awarding another contract.

Next, we recommend further evaluation of the number of modifications per contract to determine whether there is any possibility of reducing the number of modifcations for service types $\mathrm{R}$ and $\mathrm{S}$ in order to ease unecessary burdens on contracting personnel. The restructuring and management practices of the MICC centers normally drive administrative changes, and if not managed correctly, these practices, which are valuable resources, increase the workload for contracting personnel. In order to avoid numerous modifications that could potentially drive up costs, requirements should be defined as early and as clearly as possible during the acquisiton planning phase. Although the data suggests a relationship between the two factors other non-service types, related factors might share a relationship with the number of contract modifications. 
For the relationships proven between service type and management practices, we have several recommendations as well. We recommend that MICC offices further analyze the causes for the lack of an IGE in contract files and the associated impact on acquisition performance.

We also emphatically recommend proper contract documentation and filing. Maintaining accurate records aids in the administration of contracts, as well as in providing proper historical documentation in the event of a protest. With the workload placed on the acquisition workforce today, it is important that files be organized and complete to enable contracting personnel to research contracts and find information quickly for historical information or clarification of issues.

Our overall recommendation is for MICC offices to use the findings of this study to take a deeper look into the administration and management of service contracts. Contracted services are vital to installation operations and impact the mission and training of resident units and soldiers. Additionally, it is important for MICC offices to fulfill their role as public policy enforcers and stewards of taxpayer dollars. Buying services is essential, and personnel at MICC offices must ensure that customers receive the best value to meet mission needs.

\section{AREAS FOR FURTHER RESEARCH}

Although we have indicated common shortfalls in the acquisition process at the MICC level, we recommend further analysis of additional MICC offices and of the four specific service type contracts that we presented in this research. By increasing the sample size and providing a more rigorous statistical analysis, possibly by utilizing a form of regression, future studies may achieve more definitive results. While regulations and guidance exist for standard contracting administrative practices, the practices we observed in this study were not uniform. Because of this lack of uniformity, a study is needed to highlight these trends on a larger scale that includes all DOCs and MICC offices across the Army.

We also recommend further research into the effect of incorporating program managers at the installation level, specifically for service contracts. The expertise and 
knowledge that program managers gain at the system level would prove useful at the installation level, especially for high-value recurring contracts. Applying the perspective of a program manager to the acquisition of an installation-wide service contract could prove beneficial in terms of cost savings and overall better support to the customer, as well as protecting the government's interests. 


\section{LIST OF REFERENCES}

Apte, A. U., Apte, U. M., \& Rendon, R. G. (2008, October). Managing the services supply chain in the Department of Defense: An empirical study of current management practices (NPS-AM-08-137). Retrieved from Naval Postgraduate School, Acquisition Research Program website: http://www.acquisitionresearch.net/_files/FY2008/NPSAM-08-137.pdf

Apte, A. U., Apte, U. M., \& Rendon, R. G. (2009, September). Managing the services supply chain in the Department of Defense: Empirical study of the current management practices in the Army (NPS-CM-09-136). Retrieved from Naval Postgraduate School, Acquisition Research Program website: http://www.acquisitionresearch.net/ beta/files/FY2009/NPS-CM-09-136.pdf

Apte, A. U., Apte, U. M., \& Rendon, R. G. (2010a, April). Services supply chain in the Department of Defense: Comparison and analysis of acquisition management in the Army, Navy, and Air Force (NPS-AM-10-051). Retrieved from Naval Postgraduate School, Acquisition Research Program website: http://www.acquisitionresearch.net/ beta/files/FY2010/NPS-AM-10-051.pdf

Apte, A. U., Apte, U. M., \& Rendon, R. G. (2010b). Services supply chain in the Department of Defense: Drivers of acquisition management practices in the Army (Service VI). Monterey, CA: Naval Postgraduate School, Acquisition Research Program.

Apte, U. M., Ferrer, G., Lewis, I. A., \& Rendon, R. G. (2006, April). Managing the services supply chain in the Department of Defense: Opportunities and challenges (NPS-AM06-085). Retrieved from Naval Postgraduate School, Acquisition Research Program website: http://acquisitionresearch.net/ files/FY2006/NPS-AM-06-085.pdf

Apte, U. M., \& Rendon, R. G. (2007, November). Managing the service supply chain in the Department of Defense: Implications for the program management infrastructure (NPS-PM-07-126). Retrieved from Naval Postgraduate School, Acquisition Research Program website: http://www.acquisitionresearch.net/_beta/files/FY2007/NPS-PM07-126.pdf

Army Contracting Command (ACC). (2010, March). Interim Army Contracting Command: Contracting Officer's representative policy guide (Pamphlet 70-1). Retrieved from https://acc.dau.mil/adl/en-US/389650/file/52603/ACC\%20Pamphlet\%20701 Signed.pdf

Army Contracting Command (ACC). (2011a). About ACC. Retrieved from http://www.acc.army.mil/about/

Army Contracting Command (ACC). (2011b). ACC fact sheet. Retrieved from http://www.acc.army.mil/files/ACC_Fact_Sheet_March_24_2011.pdf 
Center for Strategic and International Studies (CSIS). (2011, May). Defense contract trends: U.S. Department of Defense contract spending and the supporting industrial base [Annotated brief]. Retrieved from http://csis.org/files/publication/110506 CSIS Defense_Contract Trends-sm2.pdf

Defense Acquisition Workforce (DAW). (2010, April). Appendix 9: Army defense acquisition strategic workforce plan. Retrieved from https://acc.dau.mil/acquisitionworkforce

Defense Science Board (DSB). (2011, March). Improvements to service contracting. Retrieved from http://www.acq.osd.mil/dsb/reports/2011-05-Services.pdf

Department of the Army. (2010, July). Management and oversight of service acquisitions (Army Regulation 70-13). Retrieved from http://www.apd.army.mil/pdffiles/r70 $\underline{13 . p d f}$

Department of Defense (DoD). (1999, February 1). Department of Defense budget for FY2000 [Press release]. Retrieved from http://www.defense.gov/releases/release .aspx? releaseid $=1967$

Department of Defense (DoD). (2010, February). Quadrennial defense review report. Retrieved from http://www.defense.gov/qdr/images/QDR_as_of_12Feb10_1000.pdf

Department of Defense Inspector General (DoDIG). (2000, February). DoD acquisition workforce reduction trends and impacts (Report No. D-2000-088). Retrieved from http://www.dodig.mil/audit/reports/fy00/00-088.pdf

Department of the Treasury. (2011, July). Debt limit. Retrieved from http://www.treasury.gov/initiatives/Pages/debtlimit.aspx

Edwards, V. (2010, December). Contracting for services: Challenges for the next generation. Nash \& Cibinic Report, 24(12), 59. Retrieved from http://www.westlaw.com

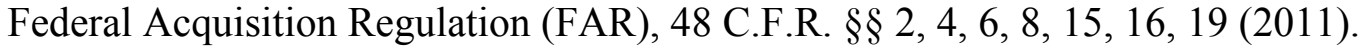

Gansler, J. S., Berteau, D. J., Maddox, D. M., Oliver, D. R., Salomon, L. E., \& Singley, G. T. (2007, October). Urgent reform required: Army expeditionary contracting: Report of the Commission on Army Acquisition and Program Management in Expeditionary Operations. Retrieved from http://www.army.mil/docs/Gansler Commission_Report_Final_071031.pdf

Gates, R. M. (2011, January 11). Statement on department budget and efficiencies. Briefing presented at the Pentagon, Washington, DC. Retrieved from http://www.defense.gov/Speeches/Speech.aspx?SpeechID=1527 
General Accounting Office (GAO). (2002, January). Taking a strategic approach could improve DoD's acquisition of services (GAO-02-230). Retrieved from http://www.ogc.doc.gov.ogc.contracts/cld/papers/d02230.pdf

Government Accountability Office (GAO). (2007, May). Improved management and oversight needed to better control DoD's acquisition of services (GAO-07-832T). Retrieved from http://www.gao.gov/new.items/d07832t.pdf

Government Accountability Office (GAO). (2008, January). Defense acquisitions: DoD's increased reliance on service contractors exacerbates long-standing challenges (GAO-08-621T). Retrieved from http://www.gao.gov/new.items/d08621t.pdf

Government Accountability Office (GAO). (2009, April). Defense acquisition: Actions needed to ensure value for service contracts (GAO-09-643T). Retrieved from http://www.gao.gov/new.items/d09643t.pdf

Government Accountability Office (GAO). (2011, September). Defense acquisition: Better identification, development, and oversight needed for personnel in acquiring services. (GAO-11-892). Retrieved from http://www.gao.gov/new.items/d11892.pdf

Greve, C. (2008). Contracting for public services. New York, NY: Routledge.

Jones, P., Klaft, D., \& Pettygrue, V. (2010, December). Joint applied project: An analysis of the training and development of the contract specialist 1102 interns (Master's thesis, Naval Postgraduate School). Retrieved from http://edocs.nps.edu/npspubs/scholarly/JAP/2010/Dec/10Dec_Jones_JAP.pdf

Keller, G. (2009). Statistics for management and economics (8th ed.). Mason, OH: SouthWestern Cengage Learning.

McFall, T. G., \& La, D. (2011, June). Mission and installation contracting command services acquisition: Empirical analysis of Army service contract management practices (Master's thesis, Naval Postgraduate School). Retrieved from http://edocs.nps.edu/npspubs/scholarly/MBAPR/2011/June/11Jun_McFall_MBA.pdf

Mission \& Installation Contracting Command (MICC). (2011). MICC mission, vision, and goals. Retrieved from http://www.acc.army.mil/micc/mission-vision.html

Office of Management and Budget (OMB). (n.d.). The president's budget for fiscal year 2012. Retrieved from http://www.whitehouse.gov/omb/budget

Office of the President of the United States (POTUS). (2010, May). National security strategy. Retrieved from http://www.whitehouse.gov/sites/default/files/rss viewer/national_security_strategy.pdf

Office of the Under Secretary of Defense, Comptroller (OUSD[C]). (2010, February). United 
States Department of Defense: Fiscal year 2011 budget request overview. Retrieved from http://comptroller.defense.gov/defbudget/fy2011/FY2011

Budget_Request_Overview_Book.pdf

Rendon, R. G., \& Snider, K. F. (2008). Management of defense acquisition projects. Reston, VA: American Institute of Aeronautics and Astronautics.

Rosenzweig, R., \& Thelen, D. (1998). The presence of the past: Popular uses of history in American life. Retrieved from http://chnm.gmu.edu/survey/sig.html

Snider, K. F., \& Rendon, R. G. (2008). Public procurement policy: Implications for theory and practice. Journal of Public Procurement, 8(3), 285-308. Retrieved from http://www.ippa.ws/IPPC3/JoPP\%208(3)/IPPC_Ar1_Snider_Rendon.pdf

Spisak, C. A. (2011, October-December). Why section 852? Army AL\&T, 126-127. Retrieved from http://armyalt.va.newsmemory.com/

Spruill, N. L. (2011, May 11). Today's acquisition challenges [Presentation slides]. Retrieved from http://www.acquisitionresearch.net

Under Secretary of Defense for Acquisition, Technology, \& Logistics (USD[AT\&L]). (2010, September). Better buying power: Guidance for obtaining greater efficiency and productivity in defense spending [Memorandum]. Retrieved from http://www.acq.osd.mil/dpap/cpf/docs/USD_ATL_Guidance_Memo_September 14 2010 FINAL.PDF 


\section{APPENDIX A. SAMPLE DATA COLLECTION FORMS}

\section{Army Mission and Installation Contracting Command Services Acquisition Data Collection Form (Part I)}

1. Office

2. Contract number and title

3. What type of service is this contract (mark all that apply)?

Professional, Administrative, and Management Support (R)

Data Processing and Telecommunications (D)

Maintenance and Repair of Equipment (J)

Utilities and Housekeeping (S)

4. What approach was the contract solicited through?

Competitively Bid (Full and Open)

Sole Source

Other (please specify):

5. What was the type of contract awarded for this service?

Fixed-price

Cost-reimbursable

Other (please specify):

6. What incentive/award type does this contract include?

Incentive Fee

Award Fee

Award Term

Other (please specify):

7. What is the current contract value (breakdown by base award and individual modifications)?

8. How many modifications were there and what were the reasons for each one?

9. Was an independent government estimate (IGE) included and what was the value?

IGE - Yes/No

Value

10. What was the award basis for this contract?

Lowest-Price Technically-Acceptable (LPTA)

Best-Value (e.g. use of trade-off analysis) 
Other (please specify):

11. Was a Project Team Approach used in the acquisition of this service contract? Yes

No

12. How many people in the following positions are assigned to this service contract? Contracting Officer (PCO, ACO, CO)

Contract Specialist

Project Manager

Contracting Officer Representative (COR)

Quality-assurance Evaluator (QAE)

Customer (unit which requested requirement)

Other (please explain)

13. Who leads the acquisition of this service contract?

Contracting Officer (PCO, ACO, CO)

Contract Specialist

Project Manager

Contracting Officer Representative (COR)

Quality-assurance Evaluator (QAE)

Customer (unit which requested requirement)

Other (please explain)

14. Who generates and decides changes to the service requirements?

Contracting Officer (PCO, ACO, CO)

Contract Specialist

Project Manager

Contracting Officer Representative (COR)

Quality-assurance Evaluator (QAE)

Customer (unit which requested requirement)

Other (please explain)

15. Who performs the surveillance of this service contract?

Contracting Officer (PCO, ACO, CO)

Contract Specialist

Project Manager

Contracting Officer Representative (COR)

Quality-assurance Evaluator (QAE)

Customer (unit which requested requirement)

Other (please explain)

16. What were the dates $(\mathrm{mm} / \mathrm{dd} / \mathrm{yyyy})$ for the following events?

Purchase Request

Solicitation

Award 
Completion

Closeout

17. Were the following items documented in the contract file?

Acquisition plan - Yes/No

Statement of work (SOW) / Performance Work Statement (PWS) - Yes/No

Pricing analysis - Yes/No

Price negotiation memorandum (PNM) - Yes/No

Quality Assurance Plan (QASP) - Yes/No

Closeout letter - Yes/No

18. Other comments not covered by questions above? 


\section{Army Mission and Installation Contracting Command Services Acquisition Data Collection Form (Part II)}

When answering below questions, only consider the service contracts element of the command.

1. Office

2. How many service contracts were awarded for FY10 in the following services?

Professional, Administrative, and Management Support (R)

Data Processing and Telecommunications (D)

Maintenance and Repair of Equipment $(\mathrm{J})$

Utilities and Housekeeping (S)

3. What was the total dollar value awarded in FY10 for the following services?

Professional, Administrative, and Management Support (R)

Data Processing and Telecommunications (D)

Maintenance and Repair of Equipment $(\mathrm{J})$

Utilities and Housekeeping (S)

4. What was the annual budget for the government service contracts staff in FY10?

5. How many billets are authorized for the following positions?

Contracting Officers/Contract Specialists (Warranted)

Contracting Officers/Contract Specialists (Unwarranted)

Project managers

QAE

6. How many authorized billets are filled for the following positions?

Contracting Officers/Contract Specialists (Warranted)

Contracting Officers/Contract Specialists (Unwarranted)

Project managers

QAE

7. What are the number of contracting personnel Defense Acquisition Workforce Improvement Act (DAWIA) certified in the following levels?

DAWIA Level I (authorized

DAWIA Level II (authorized , filled

DAWIA Level III (authorized , filled , trained , trained , filled trained

8. How many Contracting Officer Representatives (COR) / Quality Assurance Evaluators (QAE) are COR/QAE certified?

COR

QAE

9. How many contracting officers / contract specialists have the following time of 
experience?

0-6 months

6-12 months

12-24 months

24-36 months

Beyond 36 months

10. How many project managers have the following time of experience?

0-6 months

6-12 months

12-24 months

24-36 months

Beyond 36 months

11. How many CORs have the following time of experience?

0-6 months

6-12 months

12-24 months

24-36 months

Beyond 36 months

12. How many QAEs have the following time of experience?

0-6 months

6-12 months

12-24 months

24-36 months

Beyond 36 months

13. What is the average number of service contracts that a person in each of the following positions manages?

Contracting officers

Contract specialists (1102)

Project managers (1101)

QAE

14. We appreciate any comments or feedback you can provide on the topic of services acquisition. 
THIS PAGE INTENTIONALLY LEFT BLANK 


\section{APPENDIX B. CHI-SQUARED CALCULATIONS}

1. Service Type and Contract Characteristics

\begin{tabular}{|c|c|c|c|}
\hline \multicolumn{4}{|l|}{ Contingency Table } \\
\hline & \multicolumn{2}{|c|}{ Level of Competition Used } & \\
\hline & Full/Open Competition & Sole-Source & TOTAL \\
\hline$D$ & 18 & 16 & 34 \\
\hline$J$ & 18 & 11 & 29 \\
\hline$R$ & 27 & 22 & 49 \\
\hline$S$ & 23 & 19 & 42 \\
\hline TOTAL & 86 & 68 & 154 \\
\hline chi-squared Stat & & & 0.6028 \\
\hline df & & & 3 \\
\hline p-value & & & 0.8958 \\
\hline chi-squared Critical & & & 7.8147 \\
\hline
\end{tabular}

\begin{tabular}{|l|c|c|c|}
\hline Contingency Table & \multicolumn{3}{|c|}{ Award Cost-Structure } \\
\hline & Firm-Fixed Price & Cost Reimbursable & TOTAL \\
\hline$D$ & 34 & 0 & 34 \\
\hline$J$ & 29 & 0 & 29 \\
\hline$R$ & 49 & 0 & 49 \\
\hline$S$ & 42 & 0 & 42 \\
\hline TOTAL & 154 & 0 & 154 \\
\hline & & & 0 \\
\hline chi-squared Stat & & & 0 \\
\hline df & & & error \\
p-value & & & error \\
\hline chi-squared Critical & & & \\
\hline
\end{tabular}




\begin{tabular}{|c|c|c|c|}
\hline \multicolumn{4}{|l|}{ Contingency Table } \\
\hline & \multicolumn{2}{|c|}{ Incentives/Award Fees } & \\
\hline & Yes & No & TOTAL \\
\hline$D$ & $\mathrm{O}$ & 34 & 34 \\
\hline$J$ & $\mathrm{O}$ & 29 & 29 \\
\hline$R$ & O & 49 & 49 \\
\hline$S$ & 1 & 41 & 42 \\
\hline TOTAL & 1 & 153 & 154 \\
\hline chi-squared Stat & & & 0 \\
\hline df & & & $\mathrm{O}$ \\
\hline p-value & & & error \\
\hline chi-squared Critical & & & error \\
\hline
\end{tabular}

\begin{tabular}{|l|c|c|c|}
\hline Contingency Tab le & \multicolumn{3}{|c|}{} \\
\hline & Contract Cost (DollarValue) & \\
\hline$D$ & $N o$ & Yes & TO TA L \\
\hline$J$ & 12 & 22 & 34 \\
\hline$R$ & 6 & 23 & 29 \\
\hline$S$ & 23 & 26 & 49 \\
\hline TOTAL & 27 & 15 & 42 \\
\hline & 68 & 86 & 154 \\
\hline chi-squared Stat & & & 14.6147 \\
df & & & 3 \\
p-value & & & 0.0022 \\
chi-squared Critical & & & 7.8147 \\
\hline
\end{tabular}

\begin{tabular}{|c|c|c|c|c|c|c|c|}
\hline \multicolumn{8}{|l|}{ Contingency Table } \\
\hline & \multicolumn{6}{|c|}{ Number of Mbdifications } & \multirow[b]{2}{*}{ TOTAL } \\
\hline & Option & Funding & Admin & Termination & Novation & Supplemental & \\
\hline$D$ & 16 & 21 & 19 & 0 & 1 & 0 & 57 \\
\hline J & 20 & 40 & 21 & 0 & 0 & 0 & 81 \\
\hline$R$ & 30 & 113 & 70 & 1 & 2 & 2 & 218 \\
\hline$S$ & 27 & 108 & 39 & 0 & 0 & 0 & 174 \\
\hline TOTAL & 9 & 282 & 149 & 1 & 3 & 2 & 530 \\
\hline chi-squared Stat & & & & & & & 25.4534 \\
\hline df & & & & & & & 15 \\
\hline$p$-value & & & & & & & 0.0442 \\
\hline chi-squared Critical & & & & & & & 24.9958 \\
\hline
\end{tabular}




\begin{tabular}{|c|c|c|c|c|c|c|c|}
\hline \multicolumn{8}{|l|}{ Contingency Table } \\
\hline & \multicolumn{6}{|c|}{ Award Basis or Contractor Selection Process } & \multirow[b]{2}{*}{ TOTAL } \\
\hline & LPTA & Direct Award & AbilityOne & Best Value & Urgent/Compelling & Only Provider & \\
\hline$D$ & 17 & 8 & 0 & 1 & 2 & 6 & 34 \\
\hline J & 16 & 4 & 1 & 2 & 2 & 4 & 29 \\
\hline$R$ & 18 & 13 & 0 & 9 & 3 & 6 & 49 \\
\hline$S$ & 18 & 7 & 7 & 4 & 4 & 2 & 42 \\
\hline TOTAL & 69 & 32 & 8 & 16 & 11 & 18 & 154 \\
\hline dhi-squaredStat & & & & & & & 27.2478 \\
\hline df & & & & & & & 15 \\
\hline$p$-value & & & & & & & 0.0268 \\
\hline dhi-squared Critical & & & & & & & 24.9958 \\
\hline
\end{tabular}

\section{Service Type and Management Practices}

\begin{tabular}{|l|r|r|r|}
\hline Contingency Table & \multicolumn{3}{|c|}{} \\
\hline & Use of IGEs by Service Type & \\
\hline$D$ & $N o$ & $Y e s$ & TO TA L \\
\hline$J$ & 27 & 7 & 34 \\
\hline$R$ & 16 & 13 & 29 \\
\hline$S$ & 20 & 29 & 49 \\
\hline TOTAL & 23 & 19 & 42 \\
\hline chi-squared Stat & 86 & 68 & 154 \\
\hline df & & & 12.1715 \\
p-value & & & 3 \\
chi-squared Critical & & & 0.0068 \\
\hline
\end{tabular}

\begin{tabular}{|l|c|c|c|}
\hline Contingency Table & \multicolumn{3}{|c|}{} \\
\hline & Use of IGEs for Contracts Over \$100K & \\
\hline IGE No & Under \$100K & Over \$100K & TOTAL \\
\hline IGEYes & 62 & 24 & 86 \\
\hline TOTAL & 29 & 39 & 68 \\
\hline chi-squared Stat & 91 & 63 & 154 \\
\hline df & & & 13.6206 \\
p-value & & & 1 \\
chi-squared Critical & & & 0.0002 \\
\hline
\end{tabular}




\begin{tabular}{|c|c|c|c|}
\hline \multicolumn{4}{|l|}{ Contingency Table } \\
\hline & \multicolumn{2}{|c|}{ Te a m Aproach } & \\
\hline & No & Yes & TO TA L \\
\hline$D$ & 18 & 16 & 34 \\
\hline J & 10 & 19 & 29 \\
\hline$R$ & 19 & 30 & 49 \\
\hline$S$ & 14 & 28 & 42 \\
\hline TO T A L & 61 & 93 & 154 \\
\hline$c h i-s q u a r e d s t a t$ & & & 3.5508 \\
\hline$d f$ & & & 3 \\
\hline$p-v a l u e$ & & & 0.3142 \\
\hline chi-squared Critical & & & 7.8147 \\
\hline
\end{tabular}

\begin{tabular}{|c|c|c|c|c|c|c|c|c|}
\hline \multicolumn{9}{|l|}{ Contingency Table } \\
\hline & \multicolumn{7}{|c|}{ \# of Personnel Assigned to Contract } & \\
\hline & 1 & 2 & 3 & 4 & 5 & 6 & 8 & TOTAL \\
\hline$D$ & 2 & 10 & 14 & 2 & 6 & 0 & 0 & 34 \\
\hline J & 2 & 2 & 20 & & 5 & 0 & 0 & 29 \\
\hline$R$ & 0 & 9 & 25 & 8 & 5 & 1 & 1 & 49 \\
\hline$S$ & 0 & 13 & 14 & 4 & 9 & 0 & 2 & 42 \\
\hline TOTAL & 4 & 34 & 73 & 14 & 25 & 1 & 3 & 154 \\
\hline chi-squared Stat & & & & & & & & 29.2978 \\
\hline df & & & & & & & & 18 \\
\hline $\mathrm{p}$-value & & & & & & & & 0.0449 \\
\hline chi-squared Critical & & & & & & & & 28.8693 \\
\hline
\end{tabular}

\begin{tabular}{|c|c|c|c|}
\hline \multicolumn{4}{|l|}{ Contingency Table } \\
\hline & \multicolumn{2}{|c|}{ Acquisition Lead } & \\
\hline & Contract Specialist & Contracting Officer & TOTAL \\
\hline$D$ & 2 & 32 & 34 \\
\hline$J$ & 5 & 24 & 29 \\
\hline$R$ & 0 & 49 & 49 \\
\hline$S$ & 1 & 41 & 42 \\
\hline TOTA L & 8 & 146 & 154 \\
\hline chi-squared Stat & & & 11.938 \\
\hline$d f$ & & & 3 \\
\hline$p$-value & & & 0.0076 \\
\hline chi-squared Critical & & & 7.8147 \\
\hline
\end{tabular}




\begin{tabular}{|l|c|c|c|c|c|}
\hline Contingency Table & \multicolumn{5}{|c|}{} \\
\hline & \# of Personnel & Generating/Changing Requirements & \\
\hline$D$ & 1 & 2 & 3 & 8 & TOTAL \\
\hline$J$ & 7 & 26 & 1 & 0 & 34 \\
\hline$R$ & 6 & 16 & 7 & 0 & 29 \\
\hline$S$ & 4 & 40 & 5 & 0 & 49 \\
\hline TOTAL & 3 & 32 & 6 & 1 & 42 \\
\hline & 20 & 114 & 19 & 1 & 154 \\
\hline chi-squared Stat & & & & & \\
\hline df & & & & & 15.3324 \\
\hline$p$-value & & & & & \\
\hline chi-squared Critical & & & & & 16.919 \\
\hline
\end{tabular}

\begin{tabular}{|l|r|c|c|c|c|c|c|c|c|}
\hline Contingency Table & \multicolumn{10}{|c|}{ Personnel } & Assigned to & Contract & Management & Oversight & \\
\hline & 1 & 2 & 3 & 4 & 5 & 6 & 8 & TOTAL \\
\hline & 3 & 15 & 15 & 1 & 0 & 0 & 0 & 34 \\
\hline$J$ & 4 & 7 & 15 & 3 & 0 & 0 & 0 & 29 \\
\hline$R$ & 0 & 17 & 24 & 8 & 0 & 0 & 0 & 49 \\
\hline$S$ & 1 & 17 & 19 & 2 & 1 & 1 & 1 & 42 \\
\hline TOTAL & 8 & 56 & 73 & 14 & 1 & 1 & 1 & 154 \\
\hline chi-squared Stat & & & & & & & & \\
\hline df & & & & & & & & 23.5729 \\
\hline$p$-value & & & & & & & & 0.1695 \\
\hline chi-squared Critical & & & & & & & & 28.8693 \\
\hline
\end{tabular}

\begin{tabular}{|c|c|c|c|}
\hline \multicolumn{4}{|l|}{ Contingency Table } \\
\hline & \multicolumn{2}{|c|}{ Contract Aw ard Time (Meets PALT) } & \multirow[b]{2}{*}{ TOTA L } \\
\hline & No & Yes & \\
\hline$D$ & 11 & 23 & 34 \\
\hline J & 15 & 14 & 29 \\
\hline$R$ & 26 & 23 & 49 \\
\hline$S$ & 25 & 17 & 42 \\
\hline TO TA L & 77 & 77 & 154 \\
\hline chi-squared Stat & & & 5.9773 \\
\hline$d f$ & & & 3 \\
\hline$p-v a l u e$ & & & 0.1127 \\
\hline chi-squared Critical & & & 7.8147 \\
\hline
\end{tabular}




\begin{tabular}{|c|c|c|c|}
\hline \multicolumn{4}{|l|}{ Contingency Table } \\
\hline & \multicolumn{2}{|c|}{ Documentation (Acq Plan) } & \multirow[b]{2}{*}{ TO TA L } \\
\hline & No & Yes & \\
\hline$D$ & 20 & 14 & 34 \\
\hline J & 20 & 9 & 29 \\
\hline$R$ & 30 & 19 & 49 \\
\hline$S$ & 22 & 20 & 42 \\
\hline TO T A L & 92 & 62 & 154 \\
\hline chi-squared Stat & & & 2.0287 \\
\hline$d f$ & & & 3 \\
\hline$p-v$ alu e & & & 0.5665 \\
\hline chi-squared Critical & & & 7.8147 \\
\hline
\end{tabular}

\begin{tabular}{|l|c|c|c|}
\hline Contingency Tab le & \multicolumn{3}{|c|}{} \\
\hline & Docum e ntation (P W S) & \\
\hline$D$ & $N o$ & Yes & TO TA L \\
\hline$J$ & 12 & 22 & 34 \\
\hline$R$ & 7 & 22 & 29 \\
\hline$S$ & 12 & 37 & 49 \\
\hline TO TA L & 11 & 31 & 42 \\
\hline chi-squared Stat & 42 & 112 & 154 \\
df & & & 1.4627 \\
p-value & & & 0.6909 \\
chi-squared Critical & & & 7.8147 \\
\hline
\end{tabular}

\begin{tabular}{|c|c|c|c|}
\hline \multicolumn{4}{|l|}{ Contingency Table } \\
\hline & \multicolumn{2}{|c|}{ Documentation (Pricing Analysis) } & \\
\hline & No & Yes & TOTAL \\
\hline$D$ & 16 & 18 & 34 \\
\hline J & 13 & 16 & 29 \\
\hline$R$ & 16 & 33 & 49 \\
\hline$S$ & 18 & 24 & 42 \\
\hline TOTA L & 63 & 91 & 154 \\
\hline chi-squared Stat & & & 2.1637 \\
\hline$d f$ & & & 3 \\
\hline$p-v a l u e$ & & & 0.5391 \\
\hline chi-squared Critical & & & 7.8147 \\
\hline
\end{tabular}




\begin{tabular}{|l|c|c|c|}
\hline Contingency Tab le & \multicolumn{3}{|c|}{} \\
\hline & Docum entation (Q A P Ian) & \\
\hline$D$ & $N o$ & $Y e s$ & TO TA L \\
\hline$J$ & 27 & 7 & 34 \\
$R$ & 18 & 11 & 29 \\
S & 22 & 27 & 49 \\
\hline TOTA L & 21 & 21 & 42 \\
\hline chi-squared Stat & 88 & 66 & 154 \\
df & & & 11.0472 \\
p-value & & & 0.0115 \\
chi-squared Critical & & & 7.8147 \\
\hline
\end{tabular}

\begin{tabular}{|l|c|c|c|c|}
\hline Contingency Table & \multicolumn{4}{|c|}{} \\
\hline & Documentation (Close out Lette r) & \\
\hline$D$ & $N o$ & Yes & N/A & TOTAL \\
\hline$J$ & 15 & 3 & 16 & 34 \\
\hline$R$ & 16 & 2 & 11 & 29 \\
\hline$S$ & 20 & 1 & 28 & 49 \\
\hline TOTAL & 17 & 1 & 24 & 42 \\
\hline & 68 & 7 & 79 & 154 \\
\hline chi-squared Stat & & & & \\
df & & & & 5.6156 \\
p-value & & & & 12.5916 \\
\hline chi-squared Critical & & & & \\
\hline
\end{tabular}

\begin{tabular}{|c|c|c|c|c|}
\hline \multicolumn{5}{|l|}{ Contingency Table } \\
\hline & \multicolumn{3}{|c|}{ Documentation (PNM) } & \\
\hline & No & Yes & $N / A$ & TOTAL \\
\hline$D$ & 19 & 8 & 7 & 34 \\
\hline$J$ & 22 & 4 & 3 & 29 \\
\hline$R$ & 26 & 18 & 5 & 49 \\
\hline$S$ & 18 & 14 & 10 & 42 \\
\hline TOTAL & 85 & 44 & 25 & 154 \\
\hline chi-squared Stat & & & & 11.0402 \\
\hline df & & & & 6 \\
\hline$p$-value & & & & 0.0871 \\
\hline chi-squared Critical & & & & 12.5916 \\
\hline
\end{tabular}


THIS PAGE INTENTIONALLY LEFT BLANK

ACQUISITION RESEARCH PROGRAM

GRADUATE SCHOOL OF BUSINESS \& PUBLIC POLICY

$-84-$ NAVAL POSTGRADUATE SCHOOL 


\section{3 - 2011 SPONSORED RESEARCH TOPICS}

\section{Acquisition Management}

- $\quad$ Acquiring Combat Capability via Public-Private Partnerships (PPPs)

- $\quad$ BCA: Contractor vs. Organic Growth

- Defense Industry Consolidation

- $\quad$ EU-US Defense Industrial Relationships

- Knowledge Value Added (KVA) + Real Options (RO) Applied to Shipyard Planning Processes

- Managing the Services Supply Chain

- MOSA Contracting Implications

- Portfolio Optimization via KVA + RO

- Private Military Sector

- Software Requirements for OA

- Spiral Development

- $\quad$ Strategy for Defense Acquisition Research

- $\quad$ The Software, Hardware Asset Reuse Enterprise (SHARE) repository

\section{Contract Management}

- Commodity Sourcing Strategies

- Contracting Government Procurement Functions

- Contractors in $21^{\text {st }}$-century Combat Zone

- Joint Contingency Contracting

- Model for Optimizing Contingency Contracting, Planning and Execution

- Navy Contract Writing Guide

- Past Performance in Source Selection

- $\quad$ Strategic Contingency Contracting

- Transforming DoD Contract Closeout

- USAF Energy Savings Performance Contracts

- $\quad$ USAF IT Commodity Council

- $\quad$ USMC Contingency Contracting 


\section{Financial Management}

- Acquisitions via Leasing: MPS case

- Budget Scoring

- $\quad$ Budgeting for Capabilities-based Planning

- Capital Budgeting for the DoD

- Energy Saving Contracts/DoD Mobile Assets

- $\quad$ Financing DoD Budget via PPPs

- Lessons from Private Sector Capital Budgeting for DoD Acquisition Budgeting Reform

- $\quad$ PPPs and Government Financing

- ROI of Information Warfare Systems

- $\quad$ Special Termination Liability in MDAPs

- $\quad$ Strategic Sourcing

- Transaction Cost Economics (TCE) to Improve Cost Estimates

\section{Human Resources}

- Indefinite Reenlistment

- Individual Augmentation

- $\quad$ Learning Management Systems

- Moral Conduct Waivers and First-term Attrition

- Retention

- The Navy's Selective Reenlistment Bonus (SRB) Management System

- Tuition Assistance

\section{Logistics Management}

- $\quad$ Analysis of LAV Depot Maintenance

- $\quad$ Army LOG MOD

- $\quad$ ASDS Product Support Analysis

- Cold-chain Logistics

- Contractors Supporting Military Operations

- Diffusion/Variability on Vendor Performance Evaluation

- Evolutionary Acquisition

- Lean Six Sigma to Reduce Costs and Improve Readiness

- $\quad$ Naval Aviation Maintenance and Process Improvement (2) 
- $\quad$ Optimizing CIWS Lifecycle Support (LCS)

- $\quad$ Outsourcing the Pearl Harbor MK-48 Intermediate Maintenance Activity

- Pallet Management System

- $\quad$ PBL (4)

- Privatization-NOSL/NAWCI

- RFID (6)

- Risk Analysis for Performance-based Logistics

- R-TOC AEGIS Microwave Power Tubes

- $\quad$ Sense-and-Respond Logistics Network

- $\quad$ Strategic Sourcing

\section{Program Management}

- Building Collaborative Capacity

- $\quad$ Business Process Reengineering (BPR) for LCS Mission Module Acquisition

- $\quad$ Collaborative IT Tools Leveraging Competence

- $\quad$ Contractor vs. Organic Support

- $\quad$ Knowledge, Responsibilities and Decision Rights in MDAPs

- KVA Applied to AEGIS and SSDS

- Managing the Service Supply Chain

- Measuring Uncertainty in Earned Value

- Organizational Modeling and Simulation

- Public-Private Partnership

- Terminating Your Own Program

- Utilizing Collaborative and Three-dimensional Imaging Technology

A complete listing and electronic copies of published research are available on our website: www.acquisitionresearch.net 
THIS PAGE INTENTIONALLY LEFT BLANK 


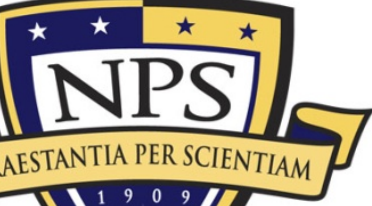

ACQUISITION RESEARCH PROGRAM

GRADUATE SCHOOL OF BUSINESS \& PUBLIC POLICY

NAVAL POSTGRADUATE SCHOOL

555 DYER ROAD, INGERSOLL HALL

MONTEREY, CALIFORNIA 93943

www.acquisitionresearch.net 